\title{
Phase Diagram for Liquid Crystalline Polymer/ Polycarbonate Blends
}

by

Gang Huang

A Thesis submitted to the Faculty of Graduate Studies and Research in partial fulfillment of the requirements of the degree of Master of Engineering

\author{
November 2001 \\ Department of Chemical Engineering \\ McGill University, Montreal \\ (C) Gang Huang (2001)
}


National Librany

of Canada

Acquisitions and

Bibliographic Services

305 Wellingron streel

Olawe ON KIA ONA

Canace
Bibliotheque nationalo

du Canada

Acquisitions ef services bibliographiques

395. nue Wallingtion

Orame ON KIA ONA

rac in vow

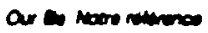

The author has granted a nonexclusive licence allowing the National Library of Canada to reproduce, loan, distribute or sell copies of this thesis in microform, paper or electronic formats.
The author retains ownership of the copyright in this thesis. Neither the thesis nor substantial extracts from it may be printed or otherwise reproduced without the author's permission.
L'auteur a accordé une licence non exchusive permettant à la Bibliothèque nationale du Canada de reproduire, prêter, distribuer ou vendre des copies de cette thèse sous la forme de microfiche/film, de reproduction sur papier ou sur format électronique.

L'auteur conserve la proprété du droit d'auteur qui protège cette thèse. Ni la thèse ni des extraits substantiels de celle-ci ne doivent être imprimés ou autrement reproduits sans son autorisation. 
To my parents 


\begin{abstract}
Blends containing a thermotropic liquid crystalline polymer and an engineering thermoplastic polymer have recently received considerable attention, because liquid crystalline polymers display low melt viscosity, excellent chemical resistance, thermal stability and mechanical performance. A novel mechanism to form binary polymer blends is through phase separation by spinodal decomposition in the unstable region of the phase diagram. The overall objective of this work is to investigate the effects of thermally induced phase separation by spinodal decomposition on the morphology development of liquid crystalline polymer/polycarbonate blends and to obtain a thermodynamic binary phase diagram. The blends were obtained using a twin-screw extruder at various processing melt temperatures. To study miscibility of the blends and the resulting morphology, techniques such as differential scanning calorimetry and scanning electron microscopy were used. The liquid crystalline polymer/polycarbonate blend undergoes phase separation during thermally induced spinodal decomposition exhibiting a miscibility window reminiscent of a lower critical solution temperature. The blend is found to be miscible, when blend $T_{g}$ slightly decreases. On the other hand, the blend is found to be immiscible as blend $T_{g}$ increases. A thermodynamic two-phase transition curve phase diagram was obtained using an innovative practical experimental technique in conjunction with twin screw extrusion and scanning electron microscopy.
\end{abstract}




\section{Résumé}

Les mélanges contenant un polymère cristallin liquide thermotropique et un polymère d'ingénierie thermoplastique ont reçu récemment une attention considérable, parce que les polymères cristallins liquides affichent de basses viscosités de fonte, d'excellentes résistances chimiques, thermique et performances mécaniques. Un nouveau mécanisme pour créer des mélanges binaires de polymères consiste en une séparation spinodal dans la région instable du diagramme de phase. L'objectif global de ce travail est d'investiguer les effets de la décomposition spinodal de phase, induite de façon thermale, sur le développement de la morphologie de mélanges de polymères/poly carbonates liquides cristallins et d'obtenir un diagramme de phase thermodynamique binaire. Les mélanges ont été obtenus en utilisant une extrudeuse double vis co-rotative fonctionnant à différentes températures de fontes. Pour étudier la miscibilité des mélanges et leurs résultantes morphologies, des techniques tel que la calorimétrie différentielle et la microscopie électronique ont été utilisées. Le mélange polymère/poly carbonate cristallin liquide subit une séparation de phase lors de la décomposition spinodal induite de façon thermale exhibe une fenêtre de miscibilité réminiscente à une température de solution critique inférieure. Le mélange apparaît être miscible, quand $T_{g}$ du mélange diminue légèrement. D'un autre coté, le mélange apparaît être non miscible a mesure que $T_{g}$ du mélange augmente. Un diagramme thermodynamique de transition de phases a été obtenu en utilisant une technique expérimentale pratique innovante en conjonction avec l'extrudeuse double vis co-rotative jumeler et la microscopie électronique. 


\section{Acknowledgments}

I would like to express my deepest gratitude towards my supervisors, Dr. Musa R. Kamal and Dr. Philip K. Chan, for giving me the opportunity to work on this research project, for their valuable research guidance and encouragement throughout the course of this thesis.

I would like to thank Dr. Richard Lai-Fook for introducing me to twin screw extrusion and injection molding, and for his suggestions throughout the course of my work.

Thanks to Mr. Christian Lungu for introducing me to DSC and Mr. Yong Cho for introducing me to the Haake mixer.

Thanks to Ms. Helen Campbell and Dr. Florence Paray for their invaluable help with the SEM measurements and image analysis.

Thanks to Mr. Jun Yan for his kind help with the computing and simulating methods.

Special thanks to Mr. Lijun Feng, a Ph.D. student of our research group, for his advice and assistance throughout this project.

I also wish to acknowledge the financial support from the Natural Sciences and Engineering Research Council of Canada (NSERC) and McGill University.

Finally, I would like to thank my parents and my brother for their love, understanding, encouragement and support throughout my studies. 


\section{Table of Contents}

Abstract

Résumé $\quad$ ii

Acknowledgements iii

Table of Contents $\quad$ iv

List of Figures vii

List of Tables $\quad x$

Nomenclature $\quad$ xi

1. Introduction 1

1.1 Introduction to Liquid Crystals 1

1.2 Liquid Crystalline Polymer/Polycarbonate Blends 3

1.3 Thesis Objectives 5

1.4 Thesis Organization 5

2. Technical Background 7

2.1 Introduction 7

2.2 Phase Separation Thermodynamics 9

2.3 Phase Separation Methods 11

2.3.1 Thermally induced Phase Separation (TIPS) 13

2.4 Spinodal Decomposition Theory 15

2.4.1 Cahn-Hilliard Equation 15

$\begin{array}{ll}\text { 2.4.2 The Flory-Huggins Theory and Phase Diagram } & 17\end{array}$

2.5 Thermodynamic Phase Diagram for Binary Polymer Blends Containing

Liquid Crystalline Polymer (LCP) 19

3. Experimental Techniques 23

3.1 Resin Selection 23

3.2 Blend Sample Preparation $\quad 26$

3.2.1 Haake Mixer 26

$\begin{array}{ll}\text { 3.2.1.1 Experimental Procedure } & 27\end{array}$ 
3.2.2 Solvent Casting Techniques 28

3.2.2.1 Phenol and 1,1,2,2-tetrachloroethane Solvent System 28

3.2.2.2 Trifluoroacetic acid - Chloroform Solvent System 30

3.2.3 Twin Screw Extruder (TSE) 30

3.2.3.1 Feeder Calibration 31

3.2.3.2 Blending Process 35

3.2.3.3 Processing Melt Temperature $\left(T_{\mathrm{pm}}\right)$ Measurement 35

3.3 Microstructural Analysis $\quad 36$

3.3.1 Polarized Light Microscopy (PLM) 37

3.3.1.1 Apparatus 38

3.3.1.2 Sample Preparation 39

3.3.1.3 Morphology of LCP/PC blend 39

3.3.2 Scanning Electron Microscopy (SEM) 45

3.3.2.1 Introduction 45

3.3.2.2 Sample Preparation 45

3.3.2.3 Morphology of LCP/PC blend 47

3.3.2.4 Image Analysis $\quad 50$

3.4 Thermal Analysis $\quad 50$

3.4.1 Differential Scanning Calorimetery (DSC) Pyris1 50

3.4.2 Glass Transition Temperature $\left(T_{g}\right)$ Measurement 51

3.4.3 Phase Transition Temperature Calculation 53

3.5 Discussion of Experimental Techniques $\quad 54$

4. Results and Discussion $\quad 57$

4.1 Introduction $\quad 57$

4.2 Thermodynamic Phase Diagram for LCP/PC Blend 58

4.2.1 Determination of Phase Transition Temperatures 58

4.2.2 LCP Volume Fraction Phase Diagram 65

$\begin{array}{lll}\text { 4.2.3 Morphology } & 68\end{array}$

4.2.4 Influence of Shear Rate on Phase Morphology 75

4.2.5 Errors Estimation for the Phase Diagram 80

4.3 Flory-Huggins Theory Phase Diagram for LCP/PC Blend 81 
4.4 Droplet Size Distribution for LCP/PC Blend

5. Conclusions and Recommendations

References

Appendix

96 


\section{List of Figures}

Figures

1-1 Schematic representations of the (A) nematic, (B) cholesteric, (C) smectic-A, and (D) smectic-C liquid crystalline phases

2-1 Schematic diagram of the interrelation between the different types of polymer blends

2-2 Schematic diagram of Gibbs free energy of mixing $\Delta G_{m}$ as a function of the mole fraction $\phi_{1}$ of a binary polymer blend

2-3 Schematic representation of phase separation processes

2-4 TIPS type phase diagram for the (a) Lower Critical Solution Temperature and (b) Upper Critical Solution Temperature .............. 14

2-5 Schematic representation of three regimes for spinodal decomposition ...

2-6 Schematic representation of the relationship for droplet diameter $d_{m}$ and wavelength $\lambda_{m}$

2-7 A cloud point phase diagram of PC/PHB-PET blends obtained at 2 ${ }^{\circ} \mathrm{C} / \mathrm{min}$

3-1 Chemical structure of the polymer (A) polycarbonate and (B) copolyester LCP

3-2 The glass transition temperatures $\left(T_{g}^{\prime}\right.$ s) of (A) PC, (B) LCP were obtained automatically from DSC thermograms

3-3 Feed rate vs. feed speed of TSE, (A) PC master hopper \#1 and (B) LCP minor hopper \#2

3-4 Twin screw extruder feeder calibrations for actual values vs. nominal values

3-5 Processing melt temperatures of $25 \mathrm{wt} \% \mathrm{LCP} / \mathrm{PC}$ blend as a function of time

3-6 OLYMPUS ${ }^{\circledR}$ BX50 Microscopy System

3-7 (A) Definition of the plane that is perpendicular to flow, (B) the different locations investigated inside the twin screw extruded sample 
3-8 Polarized light microscope (PLM) micrographs of the surfaces of $30 \%$ $\mathrm{LCP} / \mathrm{PC}$ blend using Haake mixer at different hot-stage temperature

3-9 Polarized light microscope (PLM) micrographs of the surfaces of $30 \%$ $\mathrm{LCP} / \mathrm{PC}$ blend at ambient temperature after twin screw extrusion at processing temperatures

3-10 Information that can be generated in the SEM by an electron beam striking the sample.....

3-11 SEM micrograph of fractured LCP/PC blend ....................... 48

3-12 SEM micrograph of microtomed LCP/PC blend ..................... 49

3-13 A schematic representation of a power compensating DSC instrument and its operation

4-1 Schematic diagram of the onset glass transition temperature $T_{g}$ obtained by DSC Pyris1

4-2 DSC thermograms of the blend containing $25 \mathrm{wt} \%$ LCP after being mixed for different processing melt temperatures $T_{\mathrm{pm}} \mathrm{s}$ in twin screw extrusion

4-3 Glass transition temperatures $T_{g}$ vs. $T_{\mathrm{pm}}$ for different LCP wt\% $\ldots \ldots \ldots \ldots 6$

4-4 LCP/PC Blend $T_{g}$ values as a function of LCP weight fraction .......... 64

4-5 Phase diagram for LCP/PC blend ................................. 67

4-6 SEM micrographs of the fractured surfaces of $30 \mathrm{wt} \% \mathrm{LCP}$ blend extruded in twin screw extrusion

4-7 PLM micrographs of the $30 \mathrm{wt} \% \mathrm{LCP} / \mathrm{PC}$ blend in $5 \mu \mathrm{m}$ thickness ......... $72-73$

4-8 PLM micrographs of 30wt\% LCP/PC blend in $5 \mu \mathrm{m}$ specimen thickness with $1{ }^{\circ} \mathrm{C} / \mathrm{min}$ heating and cooling rate ................................

4-9 SEM micrograph of fractured surfaces of $30 \mathrm{wt} \% \mathrm{LCP}$ blend extruded at $T_{\mathrm{pm}}=300^{\circ} \mathrm{C}$ with different screw speed

4-10 SEM micrograph of fractured surfaces of $50 \mathrm{wt} \% \mathrm{LCP}$ blend extruded at $T_{\mathrm{pm}}=310^{\circ} \mathrm{C}$ with different screw speed

4-11 Phase diagram for LCP/PC blend prepared by twin screw extrusion, determined by DSC thermal analysis and calculation 
4-12 Curve fitting for experimental $\chi$ values ............................... 84

4-13 Simulated phase diagram derived from Flory-Huggins theory …....... 85

4-14 SEM micrographs of $30 \mathrm{wt} \% \mathrm{LCP}$ blend at different processing melt

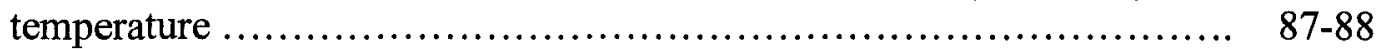

4-15 Droplet size distribution for $30 \mathrm{wt} \% \mathrm{LCP} / \mathrm{PC}$ blend $\ldots \ldots \ldots \ldots \ldots \ldots \ldots \ldots . \quad 90$

A-1 Schematic design of the screw arrangement for twin screw extrusion ...... 96 


\section{List of Tables}

Tables

Page

3-1 Material Properties of the Polymers Used .............................. 24

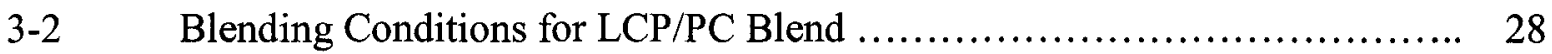

3-3 Summary of Blending Ratio Conditions for LCP/PC Blend ............... 33

3-4 Summary of Processing Conditions for 30\% LCP/PC Blending Samples .... 44

3-5 Summary of LCP/PC Blend Sample Preparation Conditions for SEM ....... 47

4-1 LCP/PC Blend Processing Conditions and Their Corresponding $T_{g}$ Data $\ldots . . \quad 60$

4-2 Summary of Calculated Transition Temperatures for LCP/PC Blend ........ 62

4-3 Summary of LCP Weight Fraction Converting to Volume Fraction ......... 65

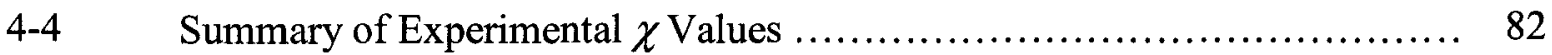

4-5 Summary of Calculated Dimensionless Wavelength for 30\% LCP Blend .... 86

4-6 Summary of Calculated $\left.\langle D\rangle_{n}, \angle D\right\rangle_{w}$ and $P D$ for $30 \%$ LCP Blend .......... 91 


\section{Nomenclature}

\begin{tabular}{|c|c|}
\hline Symbols & \\
\hline$d_{m}$ & droplet diameter \\
\hline$D_{i}$ & droplet diameter of particles $i$ \\
\hline$<D>_{n}$ & number average droplet size \\
\hline$<D>_{w}$ & weight average droplet size \\
\hline$f$ & Flory-Huggins' free energy density of mixing \\
\hline$F$ & total free energy \\
\hline$\Delta G_{m}$ & Gibbs free energy of mixing \\
\hline$H_{m}$ & enthalpy of mixing \\
\hline$k_{B}$ & Boltzmann's constant \\
\hline$m$ & mass \\
\hline$M$ & mobility \\
\hline$M_{0}$ & structure unit molecular weight \\
\hline$M_{n}$ & number average molar mass \\
\hline$M_{w}$ & weight average molar mass \\
\hline$N$ & degree of polymerization of polymer \\
\hline$N_{i}$ & number of droplets \\
\hline$p$ & pressure \\
\hline$P D$ & particle distribution \\
\hline$R(k)$ & amplification factor \\
\hline$S_{m}$ & entropy of mixing \\
\hline
\end{tabular}




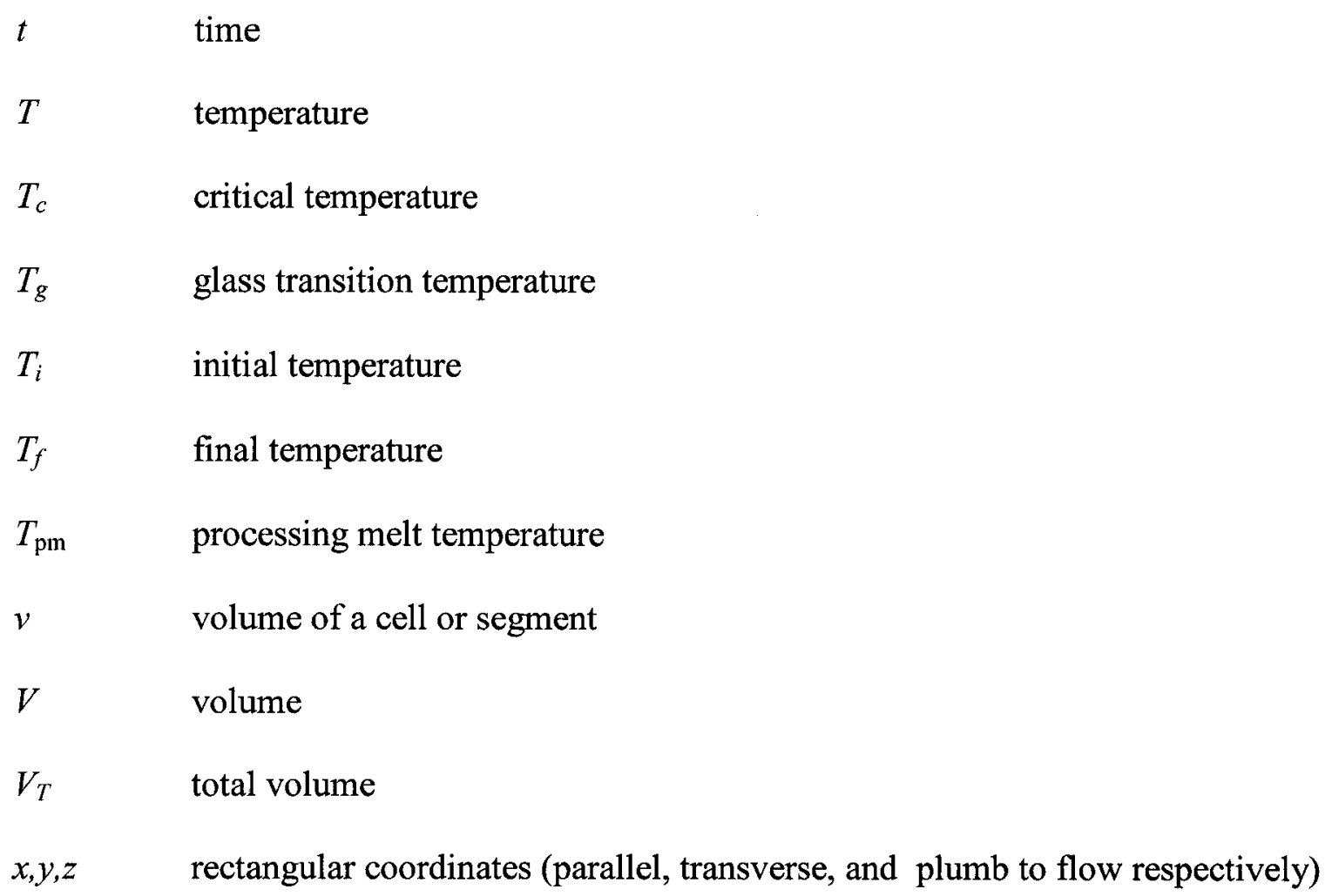




$\begin{array}{ll}\text { DSC } & \text { differential scanning calorimetery } \\ \text { LC } & \text { liquid crystal } \\ \text { LCP } & \text { liquid crystalline polymer } \\ \text { LCST } & \text { lower critical solution temperature } \\ \text { PLM } & \text { polarized light microscopy } \\ \text { SALS } & \text { small-angle light scattering } \\ \text { SEM } & \text { scanning electron microscopy } \\ \text { SD } & \text { spinodal decomposition } \\ \text { TIPS } & \text { thermally induced phase separation } \\ \text { TSE } & \text { twin screw extruder } \\ \text { UCST } & \text { upper critical solution temperature } \\ \text { XRD } & \text { X-ray diffraction }\end{array}$




\section{Chapter 1}

\section{Introduction}

\subsection{Introduction to Liquid Crystals}

Liquid crystals are certain organic materials that do not show a single transition from the solid to liquid phase, but rather exhibit a certain state of transitions involving a new phase. This new phase is called the liquid crystal mesophase, and has both solid-like molecular order and liquid-like fluidity.

There are two classification systems for liquid crystals (LCs). In the first system, LCs can be classified in three major groups. They are nematic, cholesteric and smectic. These types of structures are shown in Figure 1-1. The nematic phase, which is the Greek word for thread, has been formed when the molecules tend to align parallel to each other with the director $\mathbf{n}$ as shown in Figure 1-1. The director $\mathbf{n}$ is a unit vector that gives the preferred average molecular orientation in the neighborhood of any point. The most common examples of molecules forming the liquid crystal phase are closely associated with cholesterol, which is the reason why the second class is called cholesteric. Lastly, the third class is called smectic, which is the Greek word for soap. There are at least ten identified smectic phases and the best known are the smectic-A and smectic-C phases. For example, in multiple transition thermotropic (to be defined below) systems, the increase in temperature leads to changes from the most order to the least order state: crystal(k) $\rightarrow$ smectic (s) $\rightarrow$ nematic (n) $\rightarrow$ isotropic (i).

In the second classification system, LCs can be classified according to the method of phase transition. They are thermotropic and lyotropic liquid crystals. The term "thermotropic" arises because transitions involving these mesophases are most naturally effected by changing temperature. Cyanobiphenyls and cholesterol esters are examples of 

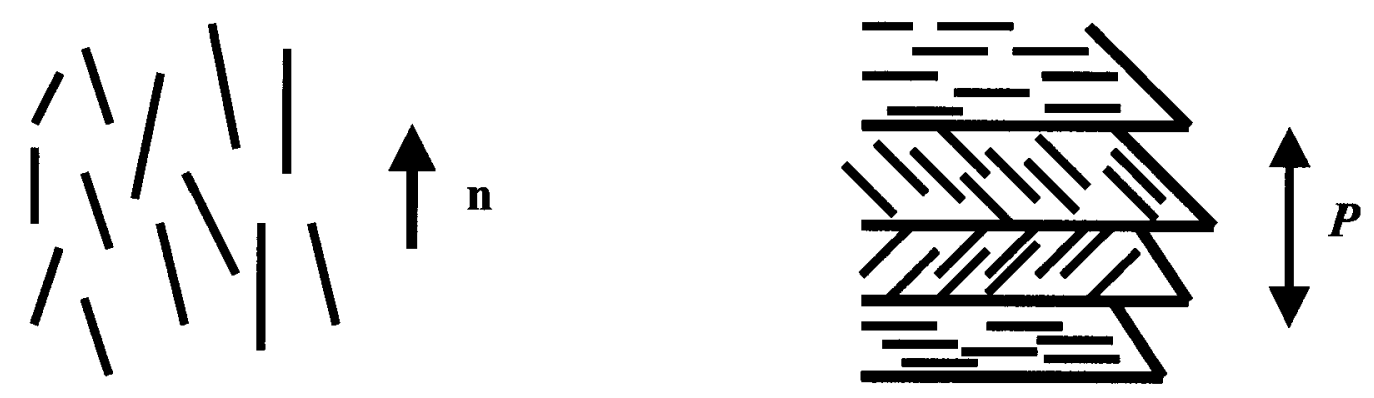

(A)

(B)

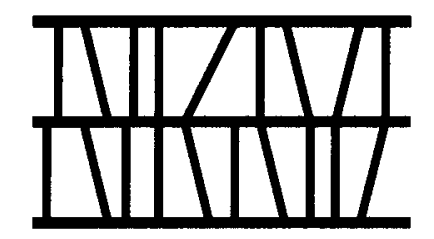

(C)

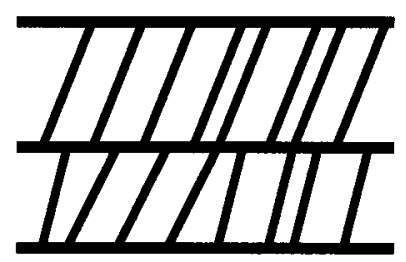

(D)

Figure 1-1: Schematic representations of the (A) nematic, (B) cholesteric, (C) smectic-A, and (D) smectic-C liquid crystalline phases. $\mathbf{n}$ is the director and $P$ is the period.

thermotropic ordered fluid mesophases, which are obtained through temperature changes. In this type of liquid crystal, every molecule participates on an equal basis in the long range ordering. On the other hand, lyotropic liquid crystals are obtained by concentration changes. Generally, solutions of rod-like entities in a normally isotropic solvent often form liquid crystal phases at sufficiently high solute concentrations. Deoxyribonucleic acid (DNA), certain viruses (e.g., tobacco mosaic virus (TMV)), and many synthetic polypeptides all form lyotropic mesophases when dissolved in an appropriate solvent (usually water) in suitable concentrations. 


\subsection{Liquid Crystalline Polymer/Polycarbonate Blends}

Polymer blends are mixtures of at least two polymers or copolymers. They are widely used in engineering applications [1], such as blends of thermoplastic polyesters poly(ethyleneterephthalate) (PET), poly( $p$-hydroxybenzoic acid) (PHB) with engineering plastics polycarbonate (PC), acrylonitrile-butadiene-styrene copolymer (ABS), styrenemaleic anhydride copolymer (SMA) and acrylonitrile-styrene-acrylates copolymer (ASA). There are two major reasons for polymer blending. The primary and most important reason is cost. For this reason, the manufacturer must use a material, which can be produced at a lower cost with properties meeting desired specifications, to remain competitive [2]. Secondly, polymer blending is a well-established strategy for improving material physical properties, such as impact resistance, toughness, high modulus and elasticity. Usually, the excellent properties of an expensive resin can be extended by blending with a cheaper polymer without the need to develop completely new polymers.

Blends of engineering thermoplastic polycarbonate (PC) and thermotropic liquid crystalline polymer (LCP) have recently received considerable attention $[2,3,4]$, because the blends can take advantage of the high performance engineering properties of both components. LEXAN polycarbonate, manufactured by General Electric Plastics, is an amorphous engineering thermoplastic that combines high levels of mechanical, optical, electrical and thermal properties. This outstanding combination of engineering properties and processing versatility have made it the ideal resin for many applications, including compact discs, light covers, automotive headlamp lenses and housings for electrical applications.

On the other hand, liquid crystalline polymers (LCPs) represent a new class of engineering plastics with unique chemical and physical properties [4]. For instance, LCPs are highly resistant to most solvents at moderate to elevated temperatures $\left(200^{\circ} \mathrm{C}\right)$. They have extremely rigid, rod-like molecules, which results in unique processing advantages compared with amorphous and semi-crystalline plastics. LCPs exhibit high ordered in both the melt and solid state. Therefore, LCPs find broad use in the electrical/electronic, health care, telecommunication and packaging industries. 
Although many macroscopic properties of LCPs are very advantageous, the costs associated with production of these materials are high. The market price for a commercial grade LCP is US\$12/lb. The blending of a conventional resin, such as LEXAN polycarbonate with a LCP can produce improvements in cost effectiveness and can yield novel chemical and physical properties. The spectrum of these composite materials exhibits a wide range of interesting peculiarities [4]. Since polycarbonate is an amorphous polymer, it has randomly oriented chains in both melt and solid phases. These amorphous polymers exhibit high impact strength, but relatively low stiffness and load bearing capacity. To compensate for poor mechanical performance, amorphous materials are usually polymerized to high molecular weights; however, this increases the melt viscosity and decreases the flowability. Addition of small amounts of LCP has been found to impart low melt viscosity and to minimize shrinkage during solidification. This is due to the highly ordered structure of LCPs. Because an outstanding significant feature of these blends is their ability to form a fibrillar structure and give a self-reinforcing effect after being processed, the blends are widely used in many automotive applications, in surgical devices and in telecommunications for network interface devices.

Despite poor interface adhesion and difficulty in controlling phase morphology, liquid crystalline polymer/polycarbonate blends can be obtained through a novel phase separation mechanism by spinodal decomposition (SD). The spinodal decomposition is defined as an active and irreversible process taking place spontaneously and continuously inside the unstable region of the thermodynamic phase diagram. The thorough study of SD theory will be presented in section 2.4, which could be well understood in terms of the Flory-Huggins and Cahn-Hilliard theories.

Our work is mainly concerned with the thermodynamic phase diagram for the LCP/PC blend system. Thus, it is of interest to determine the two-phase transition temperature points and construct a phase diagram based on these temperatures. Once this problem has been resolved, it is of further interest to evaluate the diagram in relation to phase separation theories. 


\subsection{Thesis Objectives}

The objectives of this research thesis are listed below:

1. To develop a practical experimental technique for the determination of the thermodynamic binary phase diagram of liquid crystalline polymer/polycarbonate blends.

2. To evaluate the effects of various factors on phase separation, including processing temperature and shear rate.

3. To characterize the effect of processing temperature on the morphology of liquid crystalline polymer/polycarbonate blends during the phase separation process.

4. To compare the experimental phase diagram of liquid crystalline polymer /polycarbonate blends with the theoretical phase diagram obtained using the Flory-Huggins theory.

5. To compare the experimental droplet size distribution of liquid crystalline polymer/polycarbonate blends with the theoretical droplet size distribution obtained using the Cahn-Hilliard theory.

\subsection{Thesis Organization}

Chapter 2 summarizes the relevant technical background. The experimental techniques generally used to obtain the thermodynamic phase diagram of binary liquid crystalline polymer/polycarbonate blend systems are described. A novel approach is introduced, which is based on the thermally induced spinodal decomposition (SD) 
method, for forming binary polymer blends. Two types of phase diagram for binary polymer blends are also introduced.

Chapter 3 describes the various experimental techniques used in this study to determine the phase diagram of liquid crystalline polymer/polycarbonate blend systems.

The phase diagram is presented in Chapter 4. The diagram and other results are discussed in terms of existing theories of phase separation.

Chapter 5 presents the general conclusions of this thesis and suggestions for future work. 


\section{Chapter 2}

\section{Technical Background}

This chapter introduces the basic phase separation method and theory of spinodal decomposition (SD). We describe a novel mechanism to form binary polymer blends by SD due to temperature variations. Two types of phase diagram for binary polymer blends are presented in detail. The experimental techniques to obtain these thermodynamic phase diagrams are introduced as well.

\subsection{Introduction}

As mentioned previously, a polymer blend is a mixture of at least two polymers or copolymers. Immiscible and miscible blends are the two major types. As can be seen in Figure 2-1 [5], these blends are differentiated according to the Gibbs free energy of mixing $\Delta G_{m}$. The majority of polymer blends are immiscible. These heterogeneous polymer blends have a positive $\Delta G_{m}$ value. In some cases, two polymers are soluble. However, they tend towards phase separation to form multiphase at some temperature and molecular weight. In many applications, miscibility of the phases is not desired or required. Therefore, phase separation methods have been one of the practical methods to obtain multi-component polymer blends. For example, the desired morphology of the blends can be obtained by controlling the polymer concentration and processing conditions such as temperature, shear rate and pressure. In order to obtain the heterogeneous mixtures and control their phase morphology, it is fundamentally important to understand the phase separation method. In addition, phase separation is an important field of polymer formation, modification and processing [6]. 


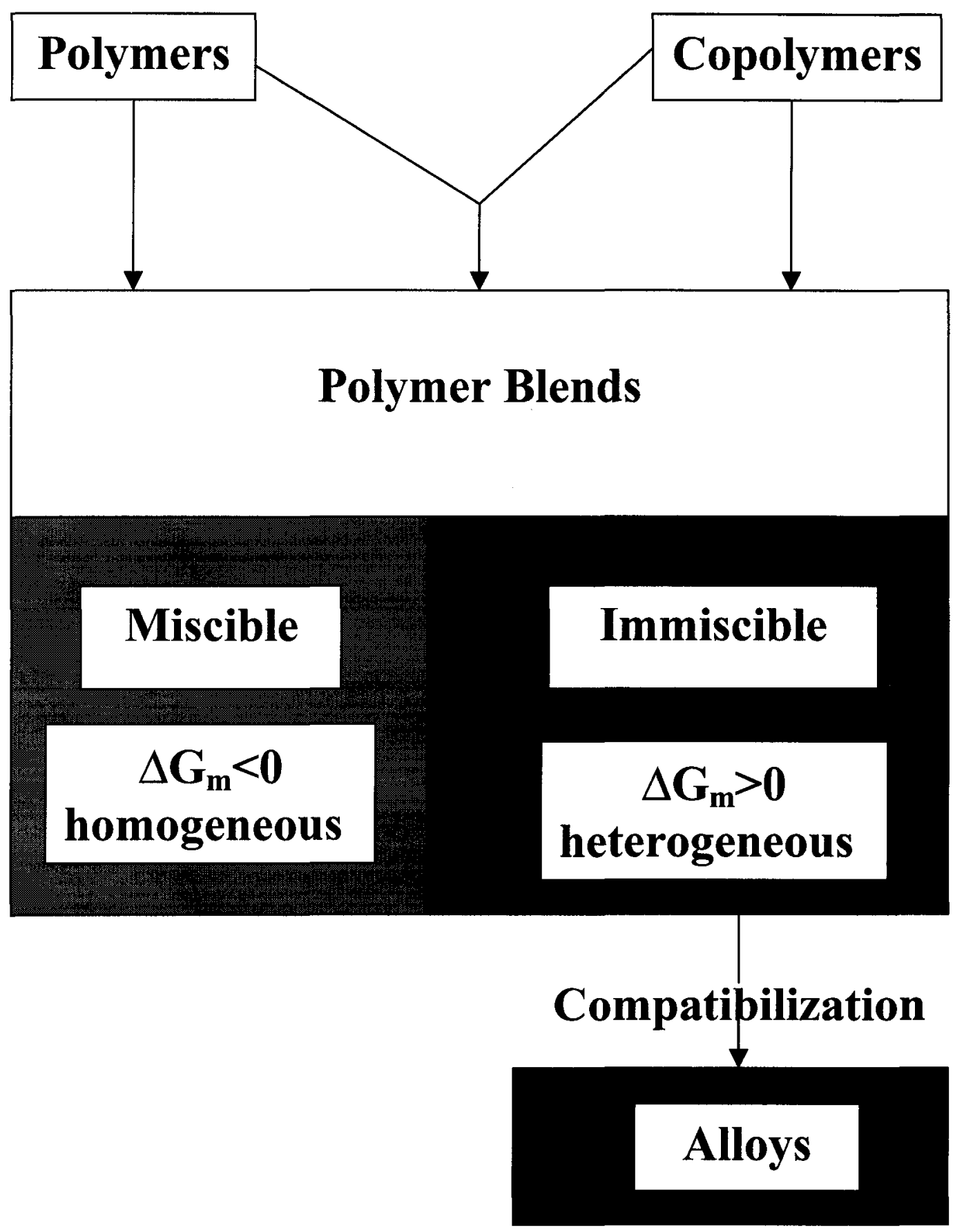

Figure 2-1: Schematic diagram of the interrelation between the different types of polymer blends [5]. 


\subsection{Phase Separation Thermodynamics}

Thermodynamics is a fundamental factor in determining polymer-polymer miscibility $[7,8]$. Based on the second law of thermodynamics, miscibility takes place when the Gibbs free energy of mixing is negative; i.e., $\Delta G_{m}<0$. In addition, the second partial derivative of free energy with respect to composition is positive; i.e., $\left[\partial^{2} \Delta G_{m} / \partial \phi_{i}^{2}\right]_{T, P, \phi_{j \neq i}}>0$, where $\phi_{i}$ is the volume fraction of the $i$ th component. The Gibbs free energy of mixing $\Delta G_{m}$ is expressed as:

$$
\Delta G_{m}=\Delta H_{m}-T \Delta S_{m}
$$

where $\Delta H_{m}$ and $\Delta S_{m}$ are the enthalpy and entropy of mixing, respectively. $T$ is the temperature. Generally, the distinctive property of polymers is their large molecular weight that can be used to control the miscibility of a multi-component mixture. The mixing entropy $\Delta S_{m}$ of a large molecular weight polymer almost equals zero. On the other hand, the enthalpy of mixing $\Delta H_{m}$ is always positive in most polymers, at least for nonpolar polymer systems [5]. Therefore, the Gibbs free energy of mixing is seldom negative, which means that phase separation always occurs in polymer blends.

In the case of binary polymer blend systems (components 1 and 2), the Gibbs free energy of mixing $\Delta G_{m}$ versus volume fraction of component $1, \phi_{1}$, diagram can be constructed as a function of temperature. As shown in Figure 2-2, the shape of the free energy of mixing curve and the onset of phase separation varies by changing the temperature values from $T_{1}$ to $T_{5}\left(T_{1}<T_{\mathrm{c}}<T_{3}<T_{4}<T_{5}\right) . T_{2}$ is considered as the critical temperature $T_{\mathrm{c}}$ shown in Figure 2-2. In phase separation mechanism, the miscible polymer blend at an initial temperature $T_{1}$ goes through the critical temperature $T_{\mathrm{c}}$, eventually becomes a totally immiscible system at temperature $T_{5}$. In the upper part of this diagram, the binodal (cloud-point) curve is formed by determining the projected points, which are shown in Figure 2-2. The dashed line is the common tangential line for the free energy curve $T_{5}$. Meanwhile, the spinodal curve is obtained by the projection of the inflection points. The thermodynamic requirements for binodal (equation 2-2) and spinodal (equation 2-3) can be given as, 


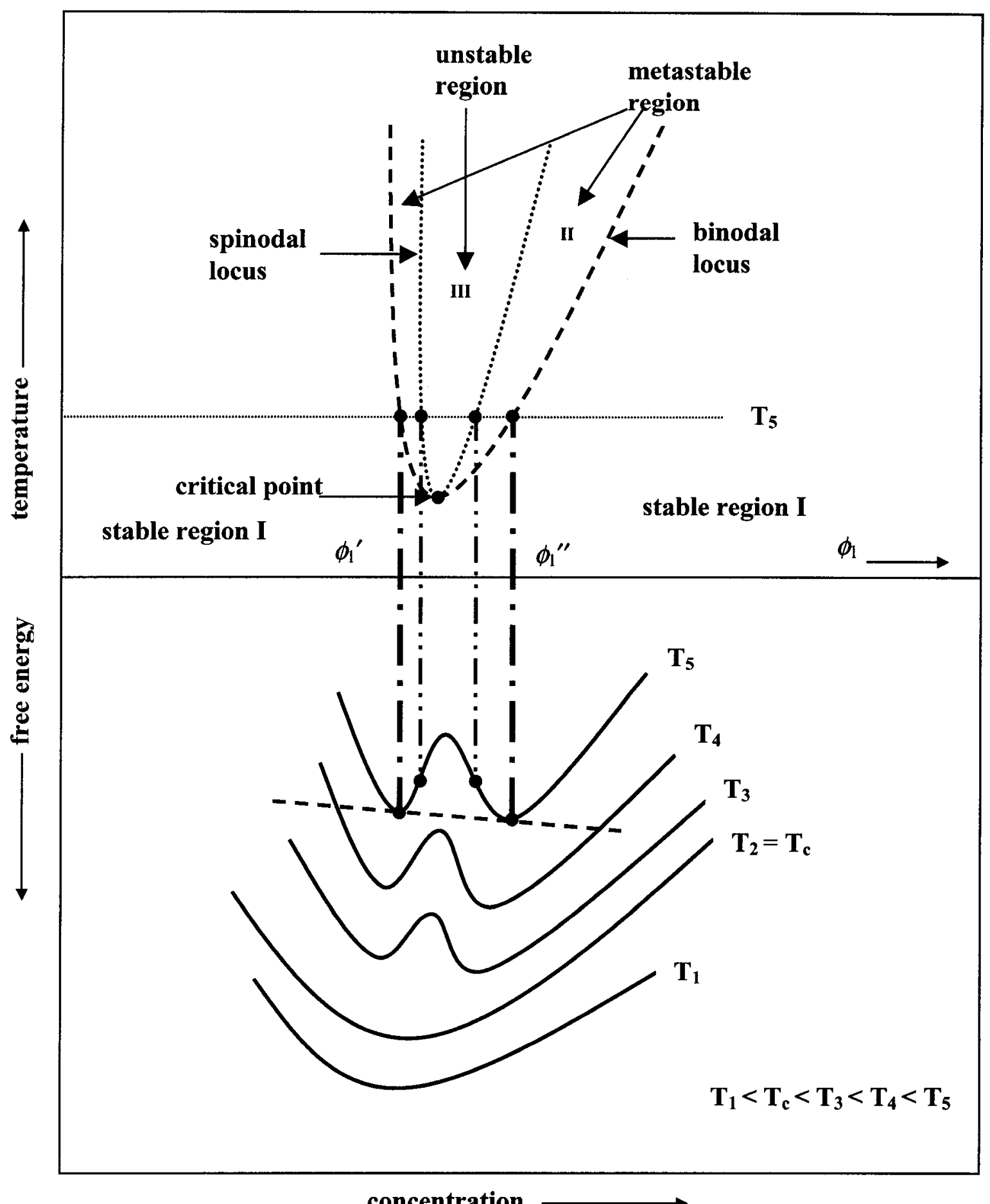

Figure 2-2: Schematic diagram of Gibbs free energy of mixing $\Delta G_{m}$ as a function of the volume fraction $\phi_{1}$ of a binary polymer blend. The dashed (dotted) curves represent the binodal (spinodal) lines. This diagram indicates the one phase stable region $\mathrm{I}$, the metastable region II and the unstable region III. 


$$
\begin{gathered}
\left(\partial \Delta G_{m} / \partial \phi_{1}\right)_{P, T, \phi_{2}}^{\text {first phase }}=\left(\partial \Delta G_{m} / \partial \phi_{1}\right)_{P, T, \phi_{2}}^{\text {second phase }} \\
\left(\partial^{2} \Delta G_{m} / \partial \phi_{1}^{2}\right)_{P, T, \phi_{2}}=0
\end{gathered}
$$

where $\Delta G_{m}$ and $\phi_{i}$ are the Gibbs free energy of mixing and the volume fraction of the $i$ th component, respectively. The lower half of Figure 2-2 shows that phase separation happens only when the slope change of volume fraction is positive and $\Delta G_{m}$ is negative.

In Figure 2-2, outside the binodal curve (region I), the system is a completely miscible, one-phase polymer blend. Inside the spinodal curve (region III), the system is unstable and undergoes spontaneous irreversible phase separation. The metastable region (II) is between the binodal and spinodal curves. The system in Figure 2-2 depicts a phase diagram exhibiting a lower critical solution temperature (LCST). The mixture can become miscible by lowering the temperature to region I. Depending on the nature of the polymers, binary polymer blends may display either upper critical solution temperature or lower critical solution temperature type of phase behavior.

The critical temperature $T_{\mathrm{c}}$, which is the intersection point of the binodal and spinodal curves, is an important quantity for binary polymer blend phase diagrams. It is defined as,

$$
\left[\partial \Delta G_{m} / \partial \phi_{1}\right]_{T, P, \phi_{2}}=\left[\partial^{2} \Delta G_{m} / \partial \phi_{1}^{2}\right]_{T, P, \phi_{2}}=\left[\partial^{3} \Delta G_{m} / \partial \phi_{1}^{3}\right]_{T, P, \phi_{2}}=0
$$

Thus, once the Gibbs free energy of mixing is known at various temperatures, the phase diagram can be defined.

\subsection{Phase Separation Methods}

In the phase separation methods, phase separation occurs when an initial singlephase blend enters the two-phase region. Phase separation phenomena in miscible polymer-polymer blends are generally brought about by variations in temperature, pressure, shearing, and composition. Among these techniques, temperature and solvent 
induced phase separation, which are also called TIPS and SIPS, respectively, are useful methodologies in forming membranes and processing many thermoplastic polymers. In the SIPS method, a single phase can be formed with the acid of an organic solvent to solubilize the polymers. Phase separation occurs when the organic solvent evaporates. Polymerization-induced phase separation (PIPS) takes place when the length of polymer chains increases due to heat or radiation. In PIPS, a homogeneous system is thrust into the two-phase region with increasing conversion and decreasing solubility.

It should be noted that both shear-induced phase separation and pressure-induced phase separation take place during the processing of polymer blends in melt extruders [6]. They are schematically represented in Figure 2-3. In shear-induced phase separation, a homogeneous mixture enters the two-phase region with increasing shear rate. Usually, phase separation takes place at high screw speeds in melt extrusion. However, pressure levels in twin screw extrusion are not strong enough to cause phase separation. In pressure-induced phase separation, pressure changes can be brought about uniformly and very fast throughout the bulk of a mixture. This technique can be observed in injectionmolding and it is also an unavoidable effect in near-critical or supercritical fluid process [6].
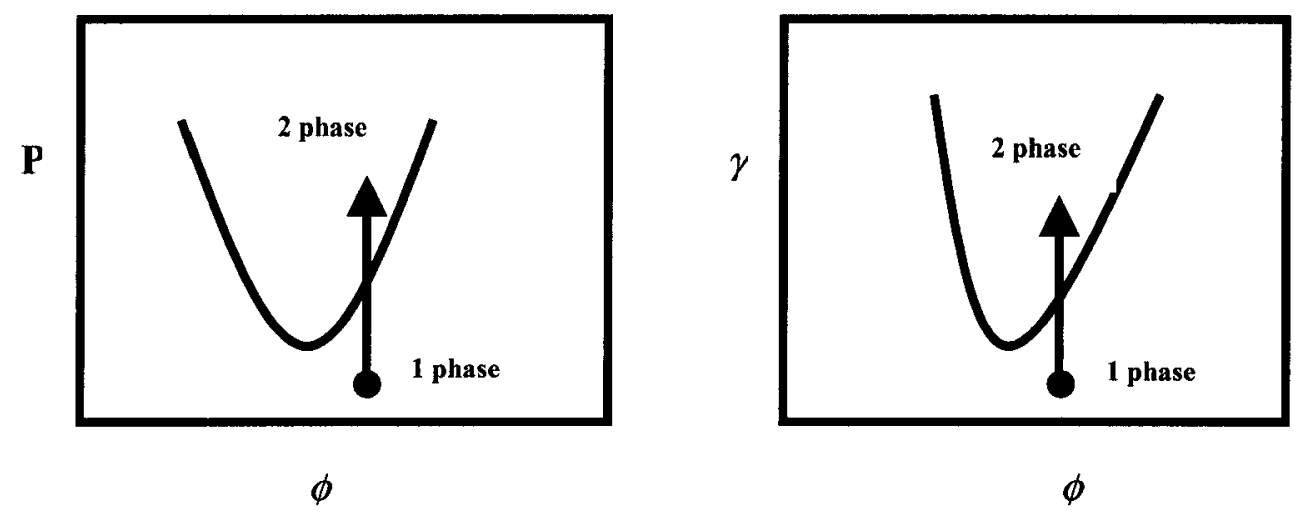

Figure 2-3: Schematic representation of phase separation processes. Left: pressureinduced phase separation, right: shear-induced phase separation. $\phi$ is polymer concentration, $\gamma$ is shear rate and $P$ is pressure. 


\subsubsection{Thermally Induced Phase Separation (TIPS)}

The phase diagram for the TIPS process is a plot of concentration $\phi$ as a function of temperature $T$. In the TIPS process, a single-phase mixture is prepared at a certain temperature. When the mixture is thrust into the unstable or metastable region due to temperature variation, usually one component separates from the other.

Figure 2-4 (a) shows schematically a typical phase diagram for a binary polymer blend with a lower critical solution temperature (LCST). The dashed (dotted) curve represents the binodal (spinodal) line, where $T_{i}, T_{f}, \phi_{0}$, and $\phi_{c}$ are initial temperature, final temperature, the average concentration and the critical concentration, respectively. The area between binodal and spinodal curves is called the metastable region, where phase separation occurs by nucleation and growth. At the beginning, a thermoplastic mixture in a homogeneous phase is formed at initial low temperature $T_{i}$ at some average concentration $\phi_{0}$ that is denoted by the dot. When the mixture is heated to high temperature $T_{f}$, phase separation takes place. When the thermoplastic solidifies, the phase separation is terminated. Two types of morphology can be obtained in the unstable region according to the average concentration $\phi_{0}$. If $\phi_{0}=\phi_{c}\left(\phi_{0} \neq \phi_{c}\right)$, then the interconnected structure (droplet-type morphology) forms. Figure 2-4 (b) shows another type of phase diagram for a binary polymer blend with an upper critical solution temperature (UCST). The basic principle is the same for both types. Phase separation occurs due to temperature variation. Besides the morphology, the droplet size in the TIPS process can also be controlled by the rate of cooling or heating. In addition, there are other factors affecting the droplet sizes, such as the rate of diffusion, viscosity, and chemical potential of both components. Although the TIPS method seems simple, care must be taken to consider the process history and high temperature due to the unstable region in $\mathrm{SD}$, which will be discussed in next section. 
(a)

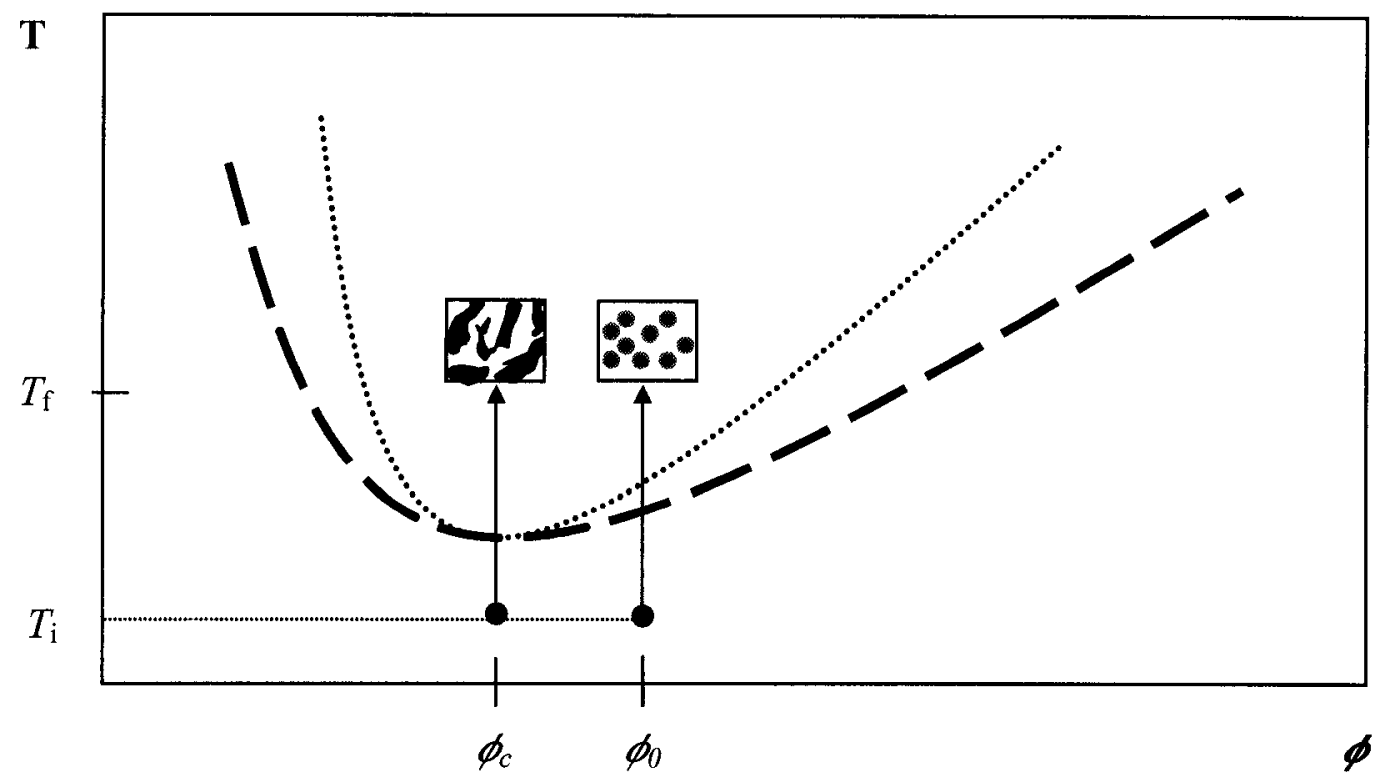

(b)

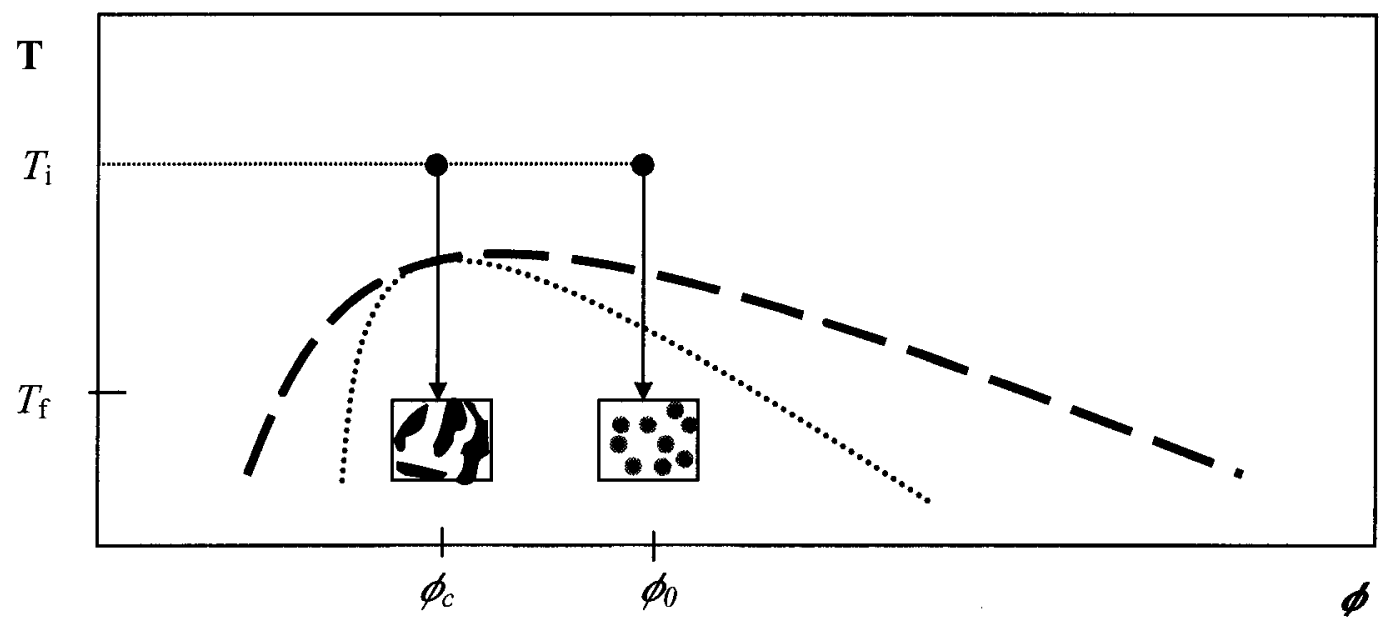

Figure 2-4: TIPS type phase diagram for the (a) lower critical solution temperature (LCST) and (b) upper critical solution temperature (UCST). The dashed (dotted) curves represent the binodal (spinodal) lines where $\phi_{o}$ and $\phi_{c}$ are the average and critical concentrations; $T_{i}$ and $T_{f}$ are the initial and final temperatures, respectively. The phase separation phenomena take place when the initially prepared one-phase mixtures are transferred into the two-phase region by TIPS (a) increasing $\mathrm{T}$ or (b) decreasing $\mathrm{T}$. 


\subsection{Spinodal Decomposition Theory}

Phase separation in the TIPS method often occurs via spinodal decomposition (SD) $[9,10]$. The phase separation mechanism for spinodal decomposition may be classified into the following three regimes: (a) early stage, (b) intermediate stage, and (c) late stage. These stages are schematically represented in Figure 2-5. In the early stage (S1), which occurs immediately after a temperature rises from the single-phase region I to the two-phase region III (see Figure 2-2). At the same time, fluctuations in the average concentration $\phi_{0}$ lead to a change in the Gibbs free energy that can only decrease due to the fact $\partial^{2} G_{m} / \partial \phi_{1}^{2}<0$. In the intermediate stage (S2), the nonlinear effects on the time evolution of the average concentration fluctuations become increasingly important with time. The droplet size and composition increase gradually with time. As a consequence, growth of the fluctuations is governed by the nonlinear time evolution equation. In the late stage (S3), phase separation is terminated by the minimization condition of the Gibbs free energy of mixing and the wavelength of the droplets is fixed by the scale of phaseseparated structure. In SD, the diffusion coefficient determined by the sign of the

curvature $\partial^{2} G_{m} / \partial \phi_{1}^{2}$ is negative. Thus, molecules diffuse toward higher concentrations from lower concentration.

\subsubsection{Cahn-Hilliard Equation}

The theory of phase separation by spinodal decomposition (SD) was first introduced by Cahn and Hilliard [11]. The Cahn-Hilliard equation is based on the assumption that the total free energy of an inhomogeneous, binary mixture is expressed as a sum of two terms:

$$
F=\int_{v}\left[f(\phi)+\frac{\kappa}{2}(\nabla \phi)^{2}\right] d v
$$

where $\phi$ is the volume fraction of one component in the binary mixture, $\kappa$ is the gradient energy parameter, and $f(\phi)$ is the free energy of a homogeneous mixture. 


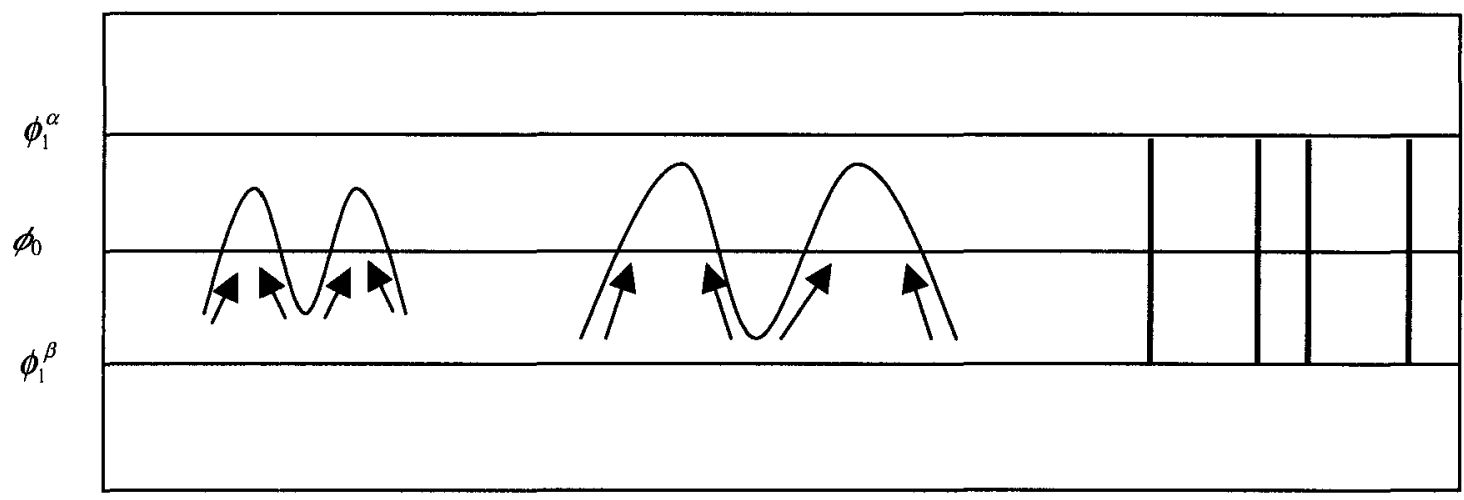

S1

S2

S3

Figure 2-5: Schematic representation of the three regimes for spinodal decomposition. $\phi_{0}$ is the average concentration, and $\phi_{1}^{\alpha}, \phi_{1}^{\beta}$ represent the concentration in phases $\alpha$ and $\beta$ in the early (S1), intermediate (S2) and late (S3) stages, respectively. The arrows indicate the direction of the diffusion of the molecules. The diffusion coefficient is negative in spinodal decomposition.

The linear $\mathrm{C}-\mathrm{H}$ equation can be given as:

$$
\frac{\partial \phi}{\partial t}=M\left[\left.\frac{\partial^{2} f(\phi)}{\partial \phi^{2}}\right|_{\phi_{0}} \nabla^{2} \phi-2 \kappa \nabla^{4} \phi\right]
$$

where $\phi_{o}$ is the initial average concentration. The general solution for Equation (2-6) is expressed as:

$$
\phi-\phi_{0}=\sum_{k}[A(k) \cos (\mathbf{k} \cdot \mathbf{r})+B(k) \sin (\mathbf{k} \cdot \mathbf{r})] e^{R(k) t}
$$

where $k_{i}=2 \pi / \lambda_{i}\left(\lambda_{i}\right.$ is the wavelength for fluctuation $\left.i\right)$ and

$$
R(k)=-M k^{2}\left[\left.\frac{\partial^{2} f(\phi)}{\partial \phi^{2}}\right|_{\phi_{0}}+2 \kappa k^{2}\right]
$$

$R(k)$ is the amplification factor whose value is positive in the unstable region. The wavelength is obtained from Equation (2-6) and is expressed as 


$$
\lambda_{m}=2 \sqrt{2} \pi\left[\left.\left(-\frac{1}{2 \kappa}\right) \frac{\partial^{2} f(\phi)}{\partial \phi^{2}}\right|_{\phi_{0}}\right]^{-\frac{1}{2}}
$$

The morphological features study, such as the phase structure type and droplet size distribution, is the most important aspect of the TIPS process. Depending on initial average concentration, two different types of morphology are formed: the interconnected structure morphology and the droplet-type morphology. Therefore, Equation (2-9) is a key methodology to predict the morphological features of polymer blends in off critical TIPS. The predicted droplet diameter $\left(d_{m} \propto \lambda_{m} / 2\right)$ can be calculated in advance in order that the desired and required phase structure can be obtained at an initial concentration. Figure 2-6 schematically shows relationship between the droplet diameter $d_{m}$ and the wavelength $\lambda_{m}$.

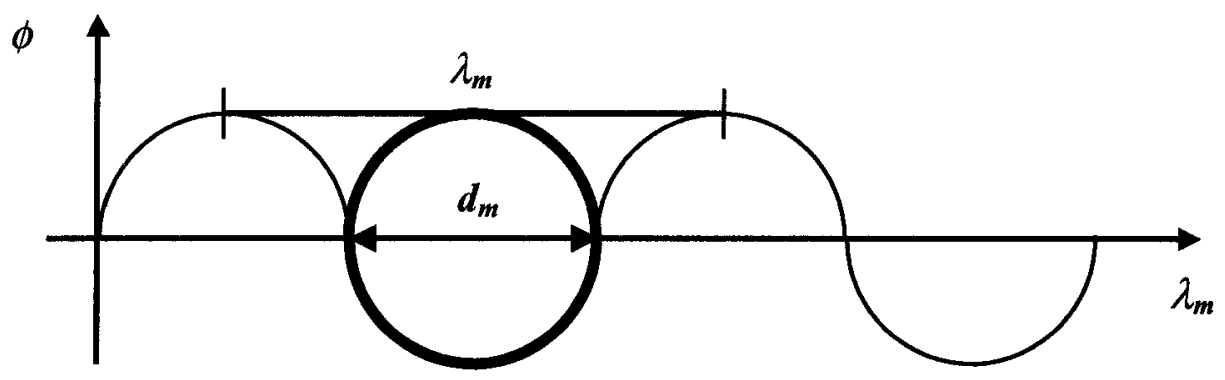

Figure 2-6: Schematic representation of the relationship for droplet diameter $d_{m}$ and wavelength $\lambda_{m} . \phi$ is the average concentration, and $\lambda$ is the wavelength. In twodimensions, the circle represents a polymer droplet, since the droplet diameter equals half of the wavelength $\left(d_{m}=\lambda_{m} / 2\right)$.

\subsubsection{The Flory-Huggins Theory and Phase Diagram}

The phase stability of a binary mixture of two components (binary polymer blends system) can be well understood in terms of the lattice theory of Flory [12] and Huggins [13]. Thus, the Flory-Huggins free energy Equation (2-10 and 2-11) is the most widely and successfully used theory in phase equilibrium studies [8]. The Flory-Huggins 
treatment represents the free energy density of mixing, $f$, as a sum of the configurational entropy and enthalpy of mixing [14]. The starting point of the model is the Gibbs free energy of mixing, $\Delta G_{m}$, given by Equation (2-1). For mixing of the two components to occur, $\Delta G_{m}<0$. According to the F-H theory, $\Delta S_{m}$ is

$$
\Delta S_{m}=-\frac{k_{B}}{v}\left[\frac{(1-\phi) \ln (1-\phi)}{N_{2}}+\frac{\phi \ln \phi}{N_{1}}\right]
$$

where $N_{1}$ and $N_{2}$ are the degrees of polymerization of components 1 and 2, respectively, $\phi$ is the volume fraction of component $1, k_{B}$ is Boltzmann's constant, and $v$ is the volume of a cell or segment.

The F-H enthalpy of mixing can be expressed as

$$
\Delta H_{m i x}=\frac{k_{B}}{v} T \chi \phi(1-\phi)
$$

where $\mathcal{X}$ is the well-known Flory-Huggins interaction parameter. The temperature dependence of $\mathcal{X}$ is often given by [8]

$$
\chi(T)=a+\frac{b}{T}
$$

where $a$ and $b$ are frequently taken to be constants. The $\mathcal{X}$ parameter measures the solubility of polymer blends; when the solubility power increases, $\mathcal{X}$ decreases to -1 . Equation (2-12) introduces the temperature dependence into the F-H equation, thus providing a direct $T-\phi$ relationship. The F-H free energy density of mixing is obtained by combining Equation (2-1) with Equations (2-10) and (2-11), which is expressed as [14],

$$
f(\phi)=\frac{k_{B} T}{v}\left[\frac{\phi}{N_{1}} \ln \phi+\frac{(1-\phi)}{N_{2}} \ln (1-\phi)+\chi \phi(1-\phi)\right]
$$

Based on the condition for phase equilibrium that the chemical potential of each component is the same in all phases at a specified temperature and pressure, the two binodal points are calculated by solving a pair of nonlinear algebraic equations. Under the same equilibrium condition, the two spinodal points at the same temperature are obtained 
by solving a quadratic equation $[8,15]$. At the critical point, the volume fraction $\phi_{c}$ and interaction parameter $\chi_{c}$ are given by [15]:

$$
\begin{gathered}
\phi_{c}=\left[1+\left(\frac{N_{1}}{N_{2}}\right)^{\frac{1}{2}}\right]^{-1} \\
\chi_{c}=\frac{1}{2}\left(N_{1}^{-\frac{1}{2}}+N_{2}^{-\frac{1}{2}}\right)^{2}
\end{gathered}
$$

\subsection{Thermodynamic Phase Diagram for Binary Polymer Blends Containing Liquid Crystalline Polymer (LCP)}

The phase behavior of blends containing a liquid crystalline polymer (LCP) has been widely studied using experimental techniques such as differential scanning calorimetery (DSC), scanning electron microscopy (SEM), small-angle light scattering (SALS), polarized light microscopy (PLM) and X-ray diffraction (XRD) [16-23]. However, the thermal properties of LCP/PC blends are complex due to their multiphase character. The multiphase behavior also reflects the processing history dependence of the dispersed phase properties. There are many practical difficulties to obtain the blend thermodynamic phase diagram. Therefore, numerous researchers have studied the miscibility behavior of the commercial blend system incorporating LCP copolyesters of poly(ethylene terephthalate) (PET) and $p$-hydroxybenzoic (PHB) with other engineering thermoplastic polymers [16-19,21-23]. Kimura and Porter [16] used DSC to study the miscibility of blends of PET/PHB with poly(butylene terephthalate) PBT. They found that the PHB-rich phase of the copolyester was immiscible with PBT, whereas the PETrich phase was miscible. This is because the copolyester PET/PHB itself exhibits two phases: one is a PHB-rich phase, the other is PET-rich. On the other hand, Huang et al. [24] reported that polycarbonate was only partially miscible with the PET-rich phase of the copolyester. 
The determination of the glass transition temperature $\left(T_{\mathrm{g}}\right)$ of polymer blends is a generally accepted way to confirm the miscibility of polymer blends [9]. Zhuang et al. [17] studied the blends of PET/PHB with thermoplastic polymers such as polystyrene (PS), polycarbonate (PC), and PET. Among these blends, the PC and PET blend systems were found to be partially miscible whereas PS blends were completely immiscible. Hsieh et al. [25] investigated the $T_{\mathrm{g}}$ of blends of polycarbonate (PC) and a liquid crystalline copolyester Vectra A950, which consists of $73 \mathrm{~mol} \%$ p-hydroxybenzoic acid (HBA) and 27 mol\% 2-hydroxy-6-naphthoic acid (HNA). Using both DSC and dynamic mechanical analysis (DMA) techniques, they showed that the blends were found to be generally immiscible when $T_{\mathrm{g}}$ of the PC phase increased. The variation of free volume behavior in the blends could be explained in terms of this phenomenon. The phenomenon has also been reported to be the reason for phase separation in blend systems with similar components [26-28]. Malik et al. [26] also used DSC to study the miscibility behavior in the blends of Vectra and PC (Lexan 130-111). The blends processed at $280^{\circ} \mathrm{C}$ were found to have limited miscibility due to the slightly lowered $T_{\mathrm{g}}$ in PC-rich phase. Turek et al. [27] also reported the miscibility of the PC (Lexan134) blended with 25\% Vectra. The miscibility was supported by the observation that the $T_{\mathrm{g}}$ of the PC-rich phase was slightly lower than that of the pure PC. However, Engberg et al. [28] studied the $T_{\mathrm{g}}$ of the PC-rich phase in PC (Lexan 141R) blended with low concentration (up to 40\%) Vectra system. The $T_{\mathrm{g}}$ increased since the blend system was immiscible. In addition to $T_{\mathrm{g}}$, the polymerpolymer interaction parameter $\chi$ of LCP in the LCP/PC blends was investigated by Lee $e t$ al. [29]. The studied blends were prepared by screw extrusion and were intensively investigated by DSC. From the measured $T_{\mathrm{g}} \mathrm{s}$ of the blends, the polymer-polymer interaction parameter $\chi$ in the blends was calculated by the " $T_{\mathrm{g}}$ method", which helps to determine the apparent PC weight fractions in the PC-rich and LCP-rich phases. Based on these experimental PC weight fractions and Flory's lattice theory, the $\chi$ parameters for flexible chain polymer (PC) and rod-like conformation (LCP) blends are evaluated to be $0.076 \pm 0.008$ at $250^{\circ} \mathrm{C}$.

Nakai et al. [18] and Kyu and Zhuang [19] investigated the phase behavior of solvent cast films of blends of $40 \mathrm{~mol} \%$ PET $/ 60 \mathrm{~mol} \%$ PHB with PET and PC. A singlephase blend was prepared with liquid crystalline copolyesters (60mol\% PHB/PET) and 
amorphous polycarbonate (PC) via a mixed solvent of 60/40 (by weight) phenol/tetrachloroethane [19]. The optically clear and homogeneous as-cast films were brought into the spinodal decomposition (SD) two-phase region when heated above the cloud point temperature. A binodal (cloud point) curve with a lower critical solution temperature (Figure 2-7 [19]) was constructed by annealing the films and identifying the cloud point temperatures using small-angle light scattering (SALS). Polarized light micrographs showed that the blends were grossly phase separated with a high level of interconnectivity, which is characteristic of spinodal decomposition. Figure 2-7 shows a typical phase behavior of LCP/PC blends. Most LCP/PC blends normally have the LCST type of phase diagram in terms of their physical characteristics, such as degree of polymerization, polymer-polymer interaction parameter, etc [4].

In summary, the essential characteristic features of LCP/PC blend phase behavior in literature may be described as follows:

1. Preparation of LCP/PC blends can be accomplished by either mechanical mixing or dissolution in co-solvent followed by film casting, freezing or spray drying;

2. The experimental techniques to study LCP/PC blend phase behavior involve differential scanning calorimetery (DSC), scanning electron microscopy (SEM), small-angle light scattering (SALS), polarized microscopy (PLM) and X-ray diffraction (XRD);

3. Most LCP/PC blends exhibit a lower critical solution temperature (LCST) type phase behavior. Thermally induced phase separation (TIPS) occurs via a spinodal decomposition (SD) mechanism;

4. PC and LCP can form either miscible or immiscible blends. The blends are found to be generally immiscible (miscible) when $T_{\mathrm{g}}$ of the PC phase increases (decreases). 


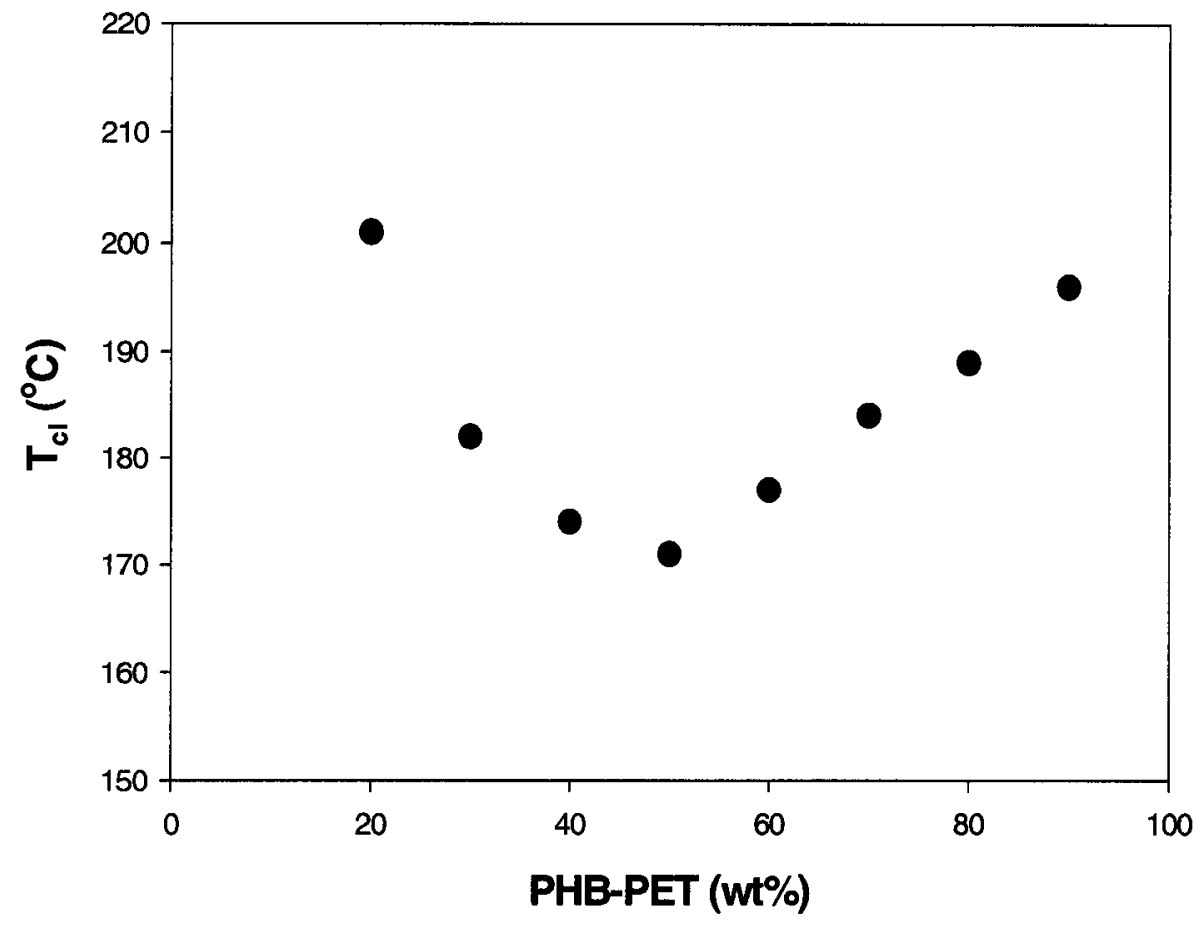

Figure 2-7: A cloud point phase diagram of PC/PHB-PET blends obtained at $2{ }^{\circ} \mathrm{C} / \mathrm{min}$ [19]. 


\section{Chapter 3}

\section{Experimental Techniques}

This chapter introduces various techniques such as twin screw extrusion blending, differential scanning thermal analysis and scanning electron microscopy to study the phase diagram of liquid crystalline polymer/polycarbonate blend systems. Both the mechanical mixing and co-solvent film casting for the preparation of blend samples are also presented.

\subsection{Resin Selection}

In this study, two commercial and readily available industrial grade resins were used. LEXAN 141-111N, a derivative of bisphenol A, is an amorphous, general-purpose polycarbonate (PC) (Figure 3-1A) manufactured by General Electric Plastics. The second resin is unfilled THERMX LCP LN001, which is a nematic liquid crystalline polymer (LCP). It consists of $80 \mathrm{~mol} \%$ poly(ethylene terephthalate) (PET) and $20 \mathrm{~mol} \% \mathrm{p}$ hydroxybenzoic acid (PHB) (Figure 3-1B). The LCP resin was supplied by Tennessee Eastman Kodak. The two resins were obtained in the form of pellets. Because of the hygroscopicity of the material, the pellets were always dried overnight at $100^{\circ} \mathrm{C}$ in a vacuum oven before use. A summary of the properties of the two resins is given in Table $3-1$. 
<smiles>CC(C)(c1ccccc1)c1ccc(OC(=O)Oc2ccc(C(C)(C)c3ccc(OC(=O)Oc4ccc(C(C)(C)c5ccccc5)cc4)cc3)cc2)cc1</smiles>

(A) Polycarbonate<smiles>[Y][Y](=O)C(C)(CC)Oc1ccc(C(=O)C2(C)COC2)cc1</smiles>

PHB

PET

(B) THERMX LCP LN001

Figure 3-1: Chemical structure of the polymers: (A) polycarbonate and (B) copolyester LCP. $n$ is the degree of polymerization. $\mathrm{X}$ and $\mathrm{Y}$ represent the mole fraction of PHB and PET, respectively.

Table 3-1: Material Properties of the Polymers Used*

\begin{tabular}{|l|c|c|}
\hline \multicolumn{1}{|c|}{ Properties } & LCP & PC \\
\hline$M_{0}(\mathrm{~g} / \mathrm{mol})$ & 182 & 254 \\
\hline$M_{\mathrm{w}}(\mathrm{g} / \mathrm{mol})$ & 36,942 & 64,000 \\
\hline$M_{\mathrm{n}}(\mathrm{g} / \mathrm{mol})$ & 10,365 & $24,000-25,000$ \\
\hline$M_{\mathrm{w}} / M_{\mathrm{n}}$ & 3.56 & $2.67-2.56$ \\
\hline Glass Transition Temperature $\left({ }^{\circ} \mathrm{C}\right)$ & 61.7 & 147.6 \\
\hline Melting Point $\left({ }^{\circ} \mathrm{C}\right)$ & 325 & NA \\
\hline Density $\left(\mathrm{kg} / \mathrm{m}^{3}\right)$ & 1.38 & 1.2 \\
\hline
\end{tabular}

*The number $\left(M_{\mathrm{n}}\right)$ and weight $\left(M_{\mathrm{w}}\right)$ average molar masses of LCP were measured by Eastman Kodak laboratories. The structured unit molar mass $\left(M_{0}\right)$ was calculated based on Figure 3-1. Glass transition temperature $\left(T_{\mathrm{g}}\right)$ data were obtained using DSC (Figure 3-2). Other data were as updated in the suppliers' data sheets. 


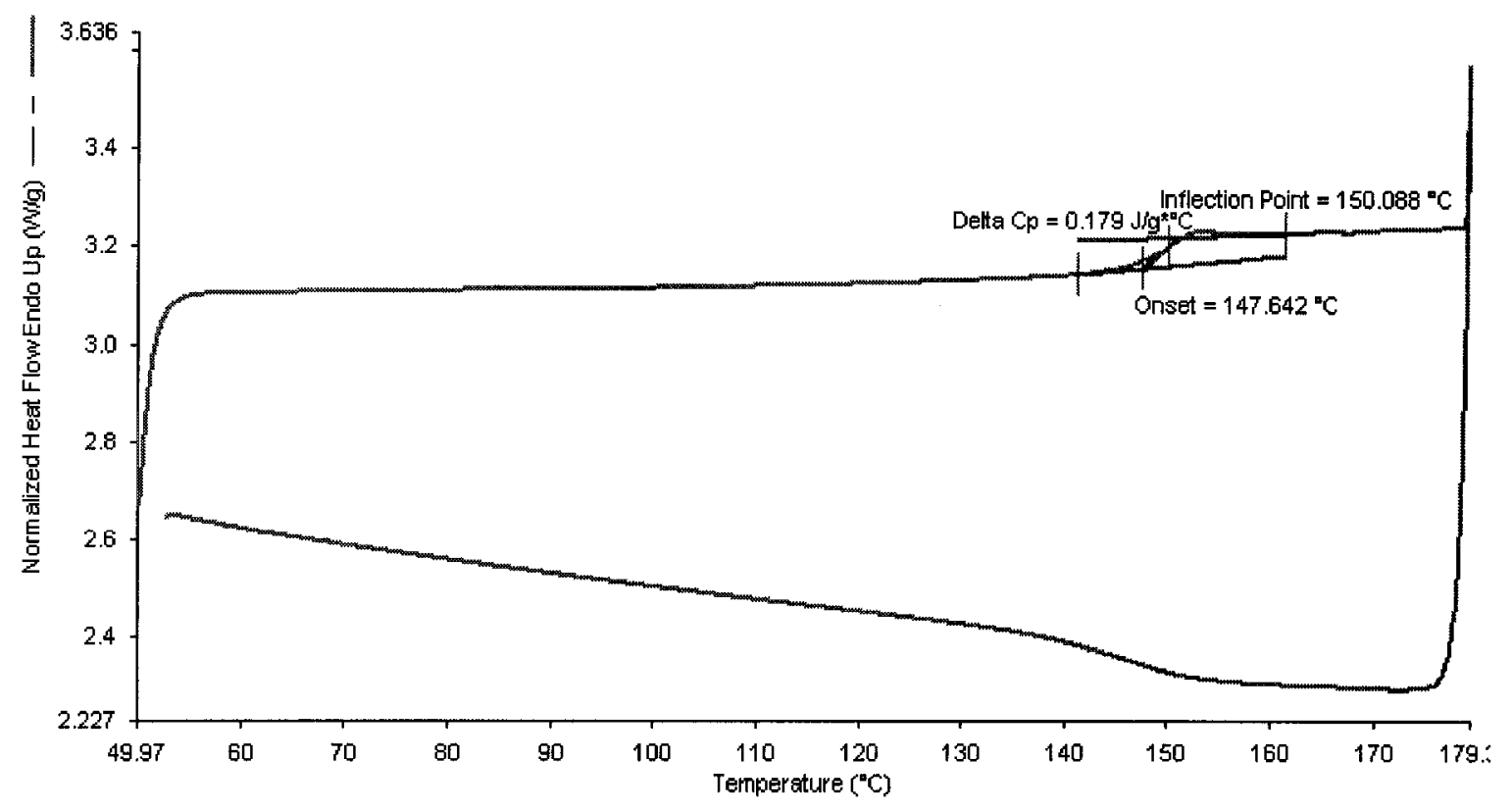

(A)

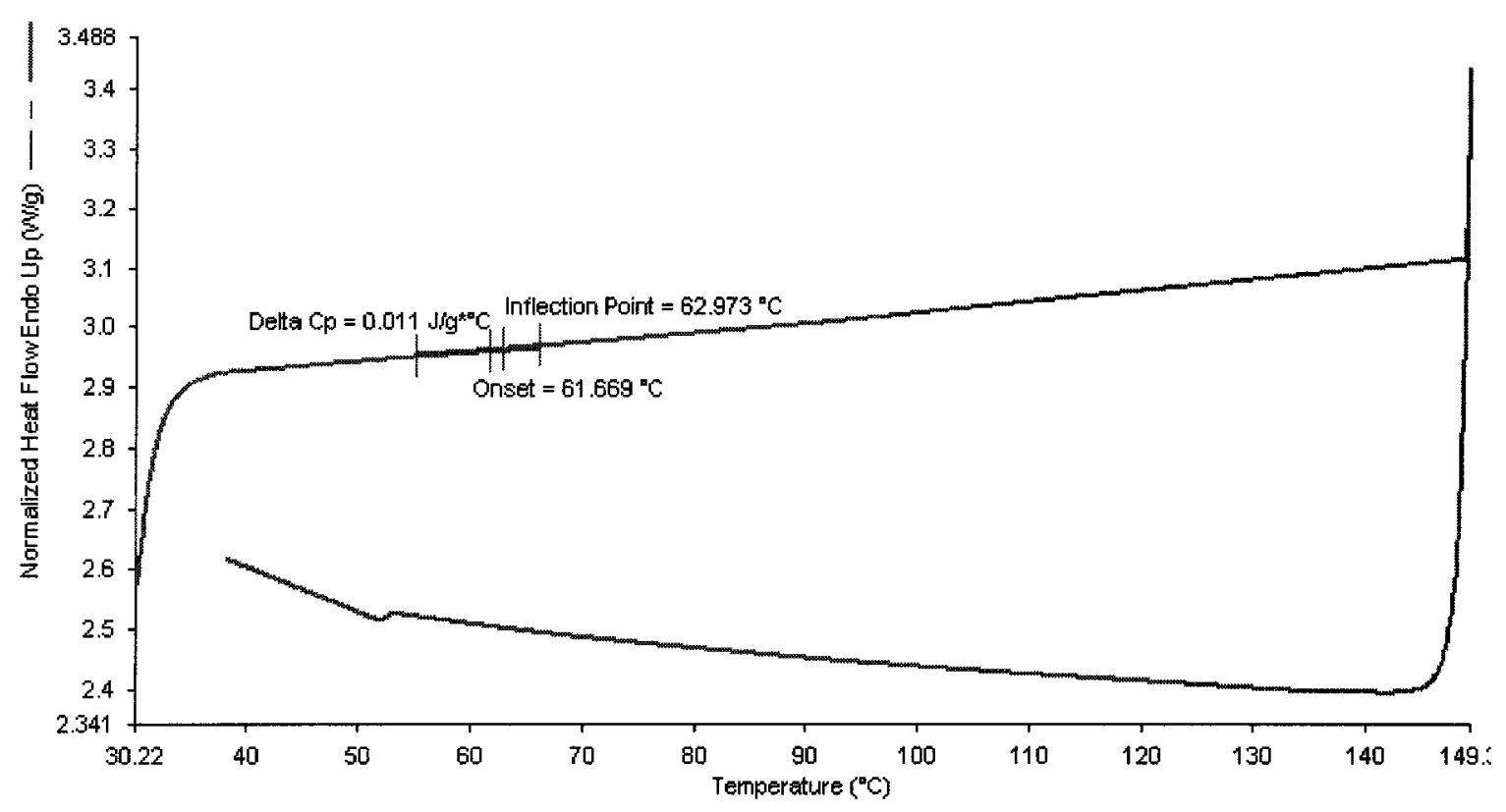

(B)

Figure 3-2: DSC thermograms for (A) PC and (B) LCP. 


\subsection{Blend Sample Preparation}

As discussed previously in section 2.5, the preparation of LCP/PC blends can be accomplished by either (1) mechanical mixing or (2) co-solvent film casting. For economic and environmental reasons, mechanical blending predominates over solvent casting in polymer processing [2]. However, the mixing effectiveness of solvent casting is much better than that of the mechanical blending process. Moreover, the majority of the LCPs are wholly aromatic, high-melting materials. This will limit the available temperature range (processing window) of the blending process. Therefore, a number of blends processing techniques were tried in this work.

\subsubsection{Haake Mixer}

A Haake Buchler - Rheocord System 40 batch mixer was used for mechanical mixing. This mixer consists of three independent temperature controlled sections. Temperature in every section is maintained at a constant level. The blend melt temperature is measured by a melt thermocouple immersed in the specimens. In addition, a high-resolution torque transducer is situated directly behind the mixer. The torque applied to the molten blend specimen is kept constant. Specimens can be readily taken out of the mixer for analysis. The specimen chamber has a capacity of about $50 \mathrm{~g}$. It is easy to clean due to its small capacity. No special preparation method is required to prepare the specimens. Specimen pellets as well as powder are introduced to the mixer without any loss of sample. Under normal operating conditions, intensive mixing and shearing action can be applied to the specimens. 


\subsubsection{Experimental Procedure}

The blending conditions are given in Table 3-2. The experimental procedure is outlined in the following chart:

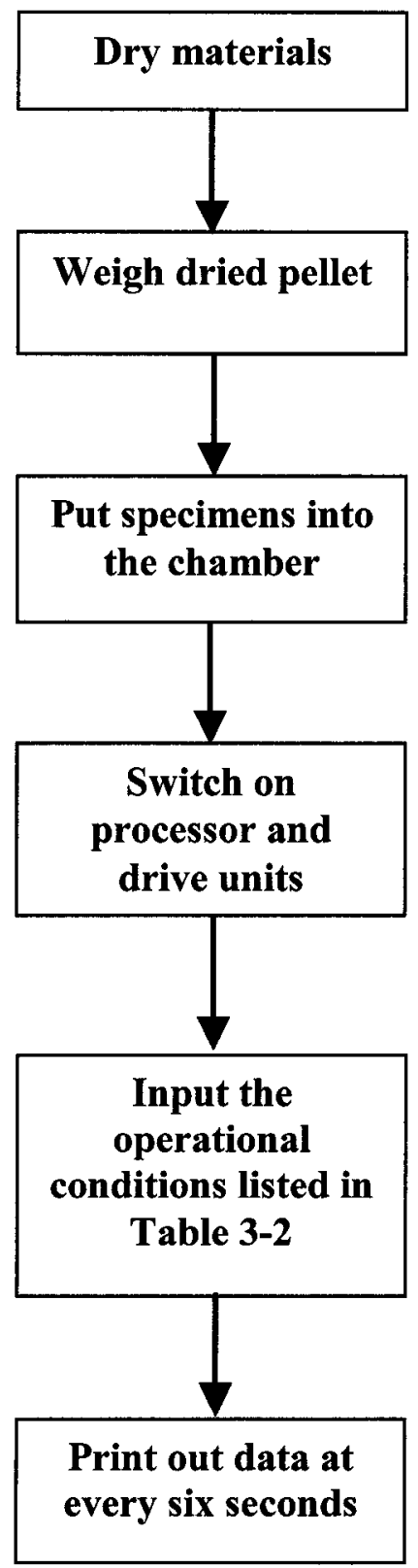


Table 3-2 Blending Conditions for LCP/PC Blends

\begin{tabular}{|l|l|}
\hline Condition & Value \\
\hline Zone 1 Temperature $\mathrm{T}_{1}\left({ }^{\circ} \mathrm{C}\right)$ & 330 \\
\hline Zone 2 Temperature $\mathrm{T}_{2}\left({ }^{\circ} \mathrm{C}\right)$ & 330 \\
\hline Zone 3 Temperature $\mathrm{T}_{3}\left({ }^{\circ} \mathrm{C}\right)$ & 330 \\
\hline Screw Speed (rev $\left.\mathrm{min}^{-1}\right)$ & 60 \\
\hline Residence Time $(\mathrm{min})$ & 6 \\
\hline Torque $(\mathrm{Nm})$ & 10,000 \\
\hline \hline
\end{tabular}

As mentioned before, there are three independent temperature controllers in the Haake mixer. The temperatures were all set at $330^{\circ} \mathrm{C}$ because the melting point of LCP is $325^{\circ} \mathrm{C}$. In addition, the temperature is also kept constant due to the small chamber capacity.

\subsubsection{Solvent Casting Technique}

The solvent casting technique is a standard method to obtain films of LCP/PC blends. This method is usually used to study the phase behavior of the LCP/PC blends $[18,19]$.

\subsubsection{Phenol and 1,1,2,2- tetrachloroethane Solvent System}

Phenol crystals (Code 5520-1) supplied by Caledon Co. have a melting point of $40.9^{\circ} \mathrm{C}$ and a boiling point of $181.8^{\circ} \mathrm{C} .1,1,2,2$-tetrachloroethane (98\% purity) supplied by Aldrich Chemical Co. Inc., has a melting point of $-43^{\circ} \mathrm{C}$ and a boiling point of $147^{\circ} \mathrm{C}$. 
The solvent casting experimental procedure is as follows:

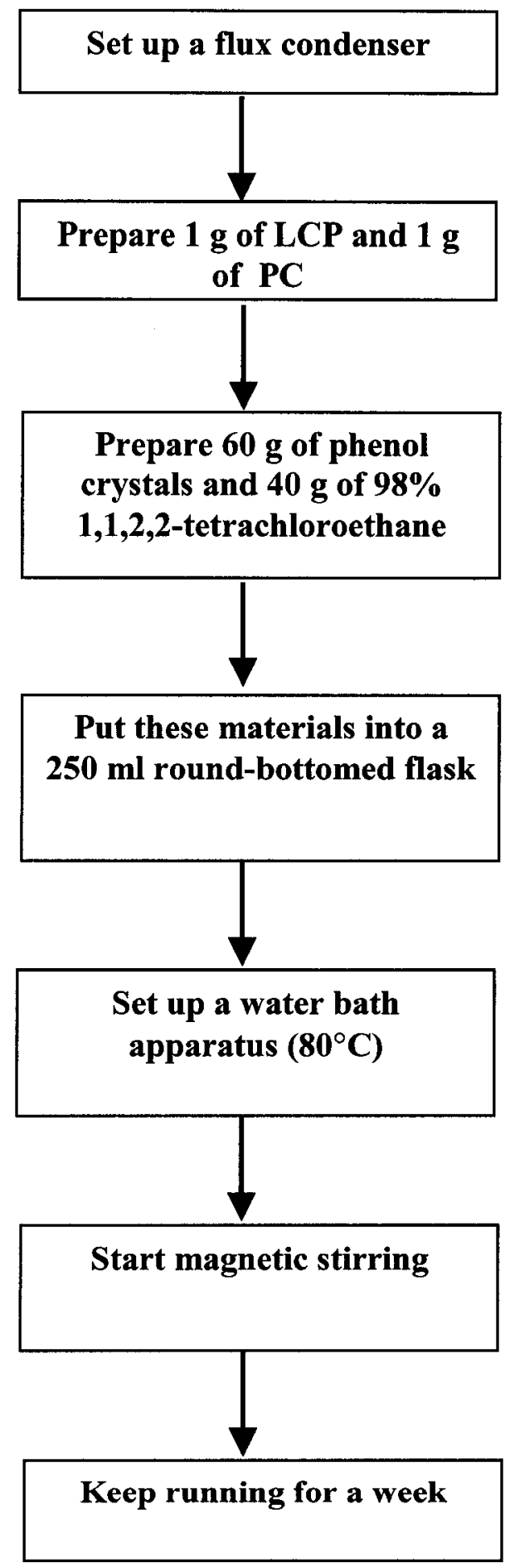




\subsubsection{Trifluoroacetic acid - Chloroform Solvent System}

Trifluoroacetic acid (D4901-500 UN2699), which was supplied by Fisher Scientific, has a melting point of $-15.2^{\circ} \mathrm{C}$ and a boiling point of $73^{\circ} \mathrm{C}$. Chloroform $(\mathrm{C} 298$ 1 UN1888), which was also supplied by Fisher Scientific, has a melting point of $-63^{\circ} \mathrm{C}$ and a boiling point of $61^{\circ} \mathrm{C}$.

The experimental procedure was exactly the same as described in section 3.2.2.1, except for the preparation of a mixed solvent of $100 \mathrm{ml}$ ( $20 / 80$ by volume) trifluoroacetic acid/chloroform.

For protection and as safety measure, the operator should wear a lab coat, safety glasses and plastic gloves during the operation.

\subsubsection{Twin Screw Extruder (TSE)}

The mechanical mixing was also carried out using a Berstorff ZE-25 twin screw extruder. The external diameter of the screw is $25 \mathrm{~mm}$ and $\mathrm{L} / \mathrm{D}$ (length/diameter of screw) is 28 [30]. The machine consists of conveying, shearing and mixing screw elements. In order to achieve high blending processing performance, the individual parts were assembled again so as to form an appropriate blending screw configuration (see appendix Figure A-1). These screw elements consist of conveying elements, kneading blocks and toothed blocks. The conveying elements push forward the pellets that flow gravitationally from the hopper into the internal screw channel. The kneading blocks provide higher shearing energy than the conveying elements, thus providing further mixing. The toothed blocks are the best mixing elements that ensure uniform distribution of the component, even at low concentrations. Thus, intensive mixing and shearing action may be achieved in the twin screw extruder. 


\subsubsection{Feeder Calibration}

Before operating the twin screw extrusion machine for the very first time, the processing part must be cleaned. For this purpose, polycarbonate is dosed into the feed opening manually and at low screw speed - approximately $50 \mathrm{rpm}$. The machine must not be running at maximum load, since it would be switched-off automatically due to excessive current consumption. After filling the processing part with polycarbonate over its total length, the machine should be operated at a higher speed for sufficient cleaning time until there are no impurities exiting the die.

The calibration of both feeders was performed after the cleaning process of the TSE barrel. Feed rate vs. feed speed is shown in Figure 3-3. The feed speed, which can be set on the switch desk board, is the motor speed of the hopper. The feed rate is obtained by measuring the rate of flow out of this hopper. For example, the feed speed of hopper \#1 was set at $100 \mathrm{rpm}$, and the ratio of hopper \#2 was set at 0.3 . The measured feed rates of hoppers \#1 and \#2 were $32 \mathrm{~g} / \mathrm{min}$ and $10 \mathrm{~g} / \mathrm{min}$, respectively. Therefore, the weight percentage under this condition was $23.8 \mathrm{wt} \%$ LCP $(10 /(32+10)=23.8 \%)$. This value is the actual percentage of LCP in the feed. However, it is hard to precisely obtain this desired actual value in every independent experiment. For example, if we intend to prepare a $25 \mathrm{wt} \%$ LCP blend sample, we can only obtain samples in the actual weight percentage range between $23 \%$ and $26 \%$ based on the reproducibility of the outputs using the setting conditions established in the calibration procedures. Hence, we take this desired value as the nominal value for a $25 \%$ blend. A summary of all blending ratio conditions is given in Table 3-3. All the LCP/PC blending samples used in this work were prepared based on this table.

As can be seen in Figure 3-3B, the calibration line is nonlinear especially in the central part. There are many effects caused by the operation of the machine itself, but the major reason for the nonlinear region is the slow motor speed of hopper \#2 during the calibration. However, the unstable flow rate in this nonlinear region introduces significant errors in obtaining the exact composition of the desired blends. In order to analyze the differences between actual values and nominal values of the output of the hoppers, a study of feeder calibration was performed (Figure 3-4). Initial weight of $3.0 \mathrm{~kg}$ 
Feed Rate vs. Feed Speed of Master Hopper \#1

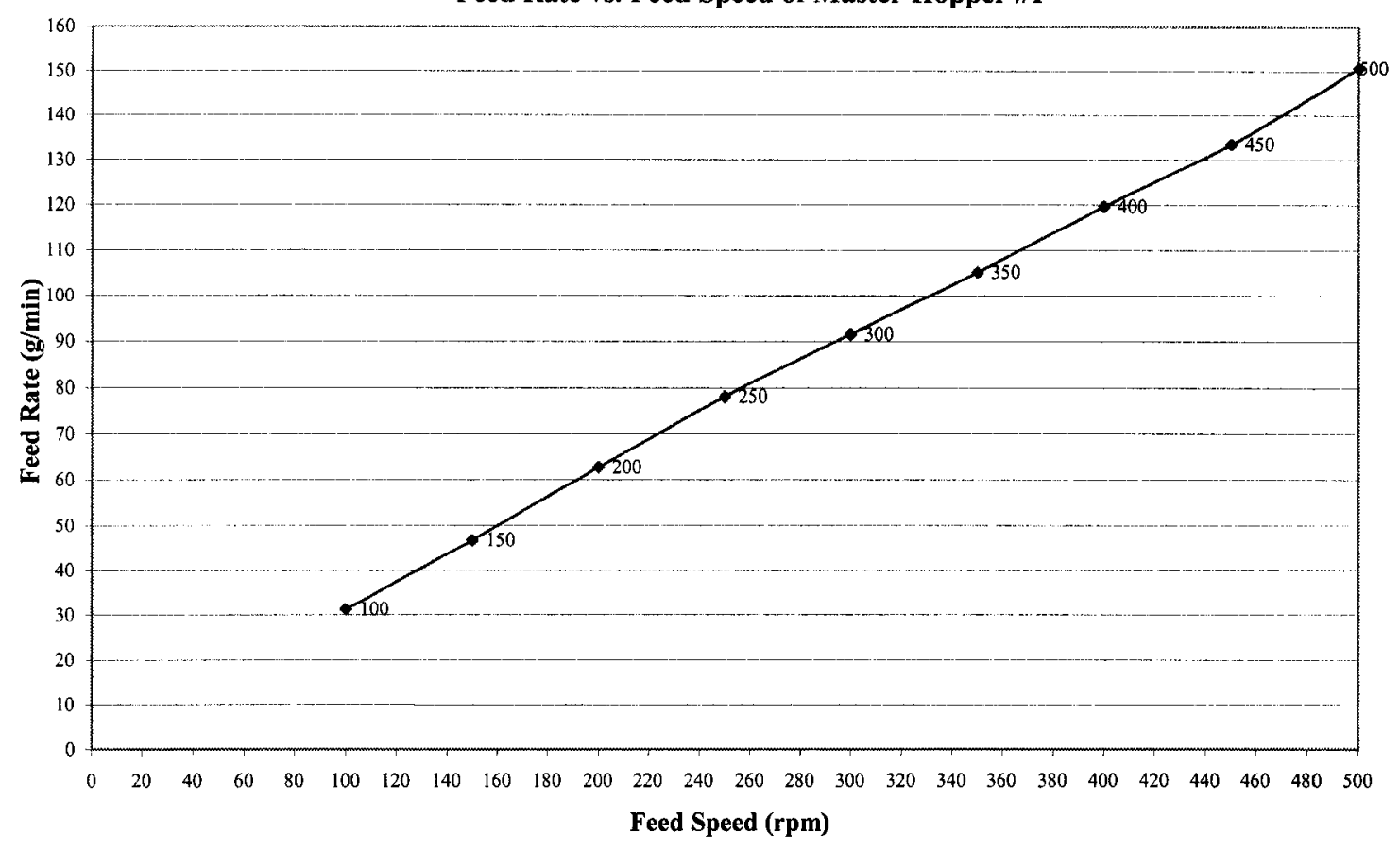

(A)

Feed Rate vs. Feed Speed of Hopper \#2

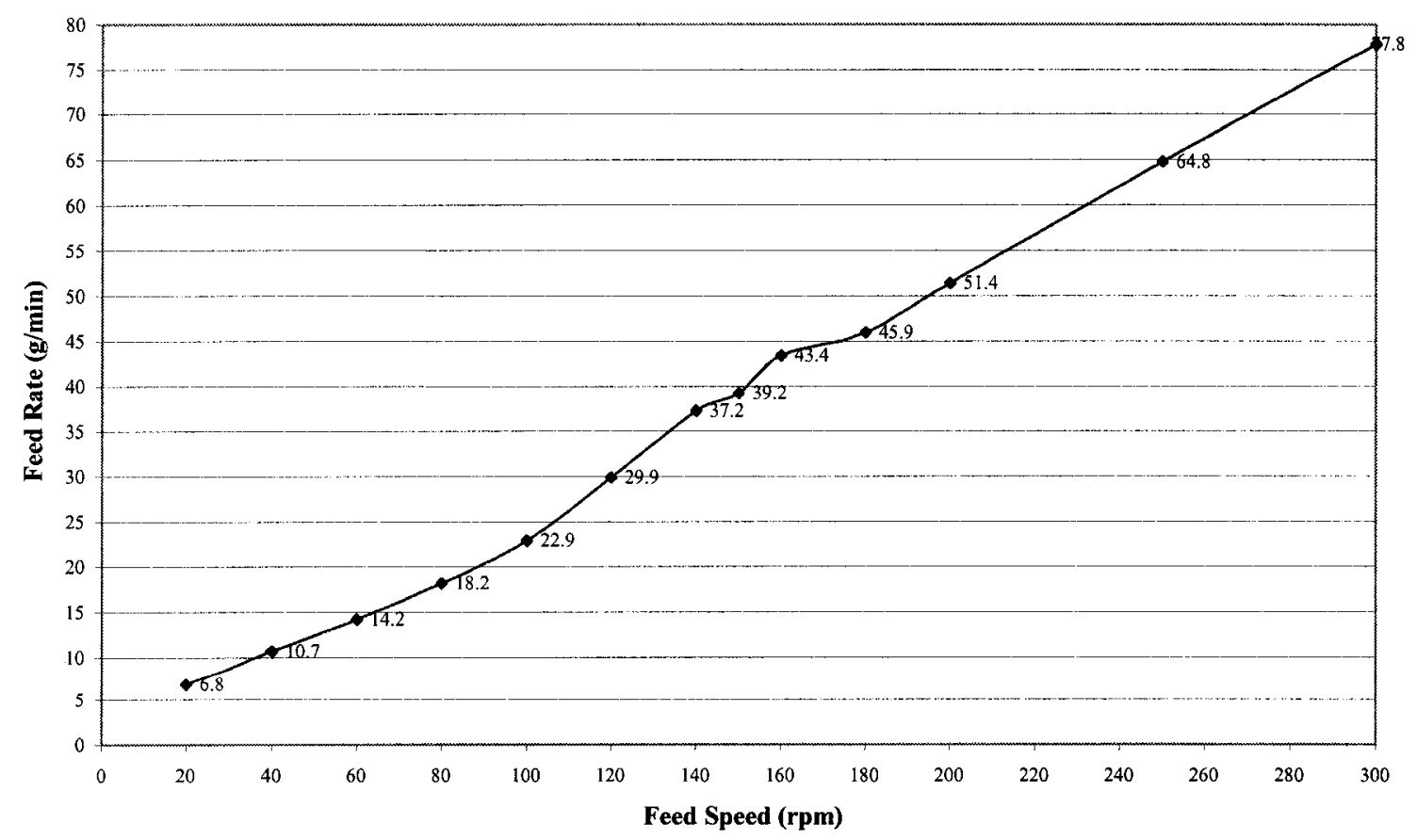

(B)

Figure 3-3: Feed rate vs. feed speed of TSE, (A) PC master hopper \#1 and (B) LCP minor hopper \#2. 
Table 3-3: Summary of Blending Ratio Conditions for LCP/PC Blend

(A)

\begin{tabular}{|c|c|c|}
\hline $\begin{array}{c}\text { Feeder \#1 (PC)* } \\
\text { Speed }\end{array}$ & $\begin{array}{c}\text { Feeder \#2 (LCP)* } \\
\text { Speed Ratio }\end{array}$ & LCP wt\%*** \\
\hline \hline $250 \mathrm{rpm}$ & 0.112 & $10 \%$ \\
\hline $200 \mathrm{rpm}$ & 0.19 & $15 \%$ \\
\hline $200 \mathrm{rpm}$ & 0.29 & $20 \%$ \\
\hline $100 \mathrm{rpm}$ & 0.3 & $25 \%$ \\
\hline $100 \mathrm{rpm}$ & 0.5 & $30 \%$ \\
\hline $100 \mathrm{rpm}$ & 0.8 & $40 \%$ \\
\hline $100 \mathrm{rpm}$ & 1.1 & $50 \%$ \\
\hline
\end{tabular}

(B)

\begin{tabular}{|c|c|c|}
\hline $\begin{array}{c}\text { Feeder \#1 (LCP) } \\
\text { Speed }\end{array}$ & $\begin{array}{c}\text { Feeder \#2 Ratio (PC)** } \\
\text { Speed Ratio }\end{array}$ & LCP wt\%*** \\
\hline $100 \mathrm{rpm}$ & 0.8 & $60 \%$ \\
\hline $100 \mathrm{rpm}$ & 0.56 & $70 \%$ \\
\hline $200 \mathrm{rpm}$ & 0.24 & $80 \%$ \\
\hline $200 \mathrm{rpm}$ & 0.16 & $85 \%$ \\
\hline $200 \mathrm{rpm}$ & 0.08 & $90 \%$ \\
\hline
\end{tabular}

* Initial weight of LCP is $1.0 \mathrm{~kg}$ and PC is $3.0 \mathrm{~kg}$.

** Initial weight of LCP is $2.0 \mathrm{~kg}$ and PC is $1.0 \mathrm{~kg}$.

*** These values are nominal values. 


\section{TSE Feeder Calibrations}

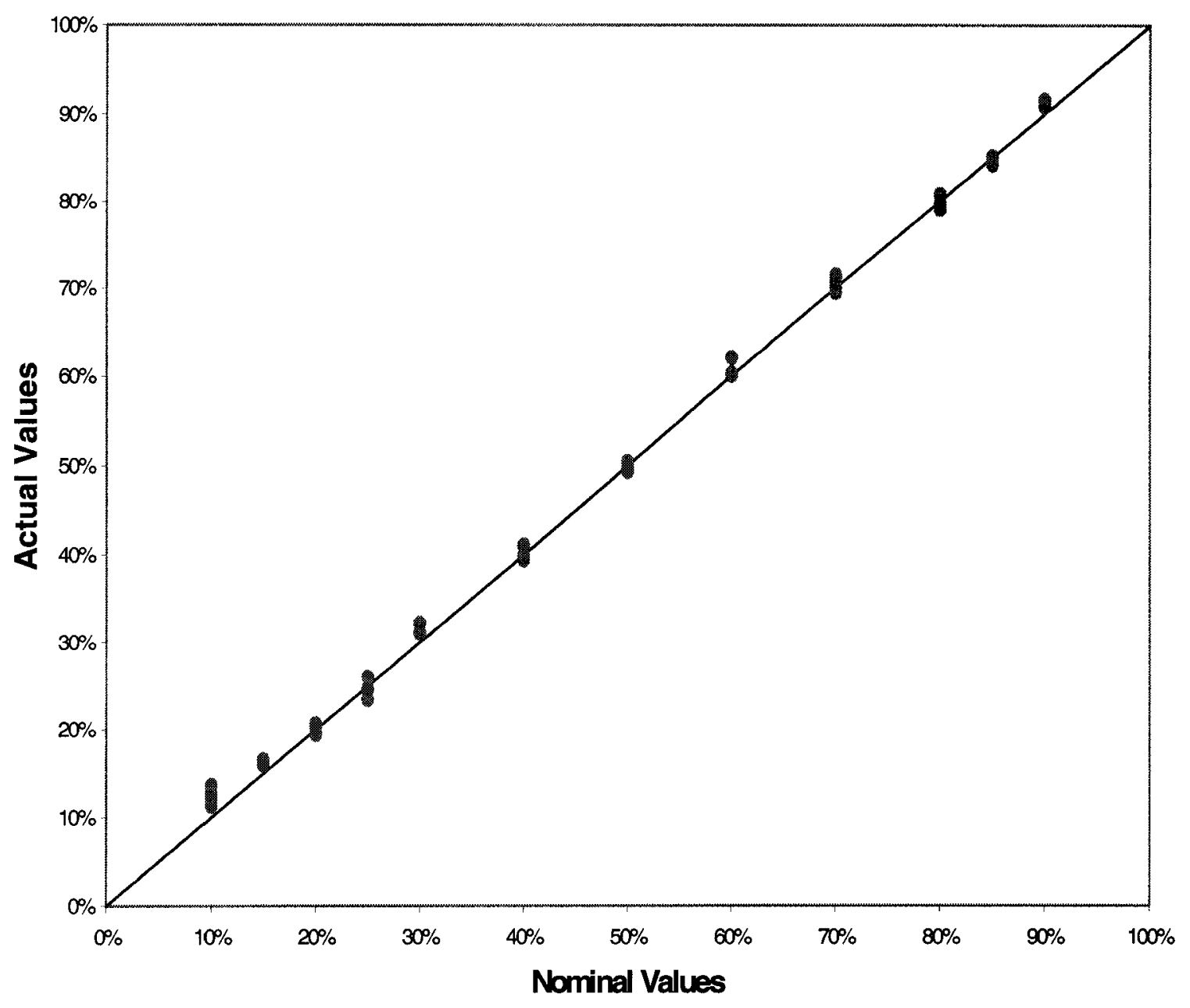

Figure 3-4: Twin screw extruder feeder calibrations for actual values vs. nominal values. 
PC and $1.0 \mathrm{~kg}$ LCP were put into feeders \#1 and \#2, respectively. The flow rate of each feeder was calibrated after the machine ran for twenty minutes. When the calibration for LCP percentage exceeded $50 \mathrm{wt} \%$, the hoppers for LCP and PC were switched and the initial weight was changed to $2.0 \mathrm{~kg}$ for LCP and $1.0 \mathrm{~kg}$ for PC. This is because LCP has become the principal component of the blends. It should be placed in the master hopper \#1. The pellet size and density influence the flow rate of the hopper. Therefore, the initial weights of LCP and PC were different. However, the calibration procedure was exactly the same.

As can be seen in Figure 3-4, the actual points are close to the diagonal line within the range $20-70 \mathrm{wt} \% \mathrm{LCP}$. It means that the weight percentages of the blends have very small errors within this region. In the lower LCP concentration region, we increased the feeder speed up to $250 \mathrm{rpm}$ to avoid the error. However, some problems in minimizing these errors persist, since there are still various intrinsic effects associated with operation of the machine at low LCP concentrations.

\subsubsection{Blending Process}

Before processing, all materials were dried overnight at $100^{\circ} \mathrm{C}$ in a vacuum oven to remove moisture. A Berstorff ZE-25 twin screw extruder was used for compounding. The materials were fed into the designated feeders. The rotational speed of the screws was kept constant at $80 \mathrm{rpm}$, and the melt temperature was set at different values depending on the weight percentage of LCP.

\subsubsection{Processing Melt Temperature $\left(T_{\mathrm{pm}}\right)$ Measurement}

The Berstorff ZE-25 twin screw extruder has five heating zones with which a temperature profile over the extruder can be established. The barrel zones are heated by means of aluminum heating elements, and can be heated or cooled by air. The 
temperature of each zone was measured by means of a thermocouple and transmitted to the control panel. Each temperature is controlled individually. The desirable processing temperature profile could be set on the control panel.

In order to study the effect of changes in melt temperatures on thermally induced phase separation, the temperature profile along the screw barrel was varied. A twin screw extruder run time program, which is the time record program of varying processing melt temperatures, was set up at the beginning. The lowest temperature is near the inlet (hopper) and the highest temperature is near the tip of the screw. The setting of temperature profile strongly depends on the weight ratio of LCP/PC blends due to the high melting point of LCP $\left(325^{\circ} \mathrm{C}\right)$. The higher in the LCP weight ratio, the higher will the setting be. Figure 3-5 shows a schematic plot of the processing melt temperatures for $25 \mathrm{wt} \% \mathrm{LCP} / \mathrm{PC}$ blend vs. time. Once the desirable setting temperature profile is reached and the processing melt temperature has been stable for at least five minutes, the blend specimen collecting process begins. We set five minutes, because the machine is stable during this period and the consumption of the expensive resins is minimized within this time limit. This collecting time is characterized by a horizontal straight line (see Figure 35 ), which represents a stable processing melt temperature. Figure 3-5 indicates when the desired specimen could be collected and the temperature of the specimen. Specimens were collected for further studies using DSC, PLM and SEM.

\subsection{Microstructural Analysis}

In order to study the blend phase morphology, polarized light microscopy (PLM) and scanning electron microscopy (SEM) were used to characterize the microstructure of the blends. The main purpose of microstructural analysis is to investigate and measure the degree of miscibility, the interaction of phases and the droplet type, shape and size. In general, phase size and particle size distribution can be revealed directly by microscopy. However, it is more difficult to obtain information on partial miscibility and interfacial interaction by microscopy. 


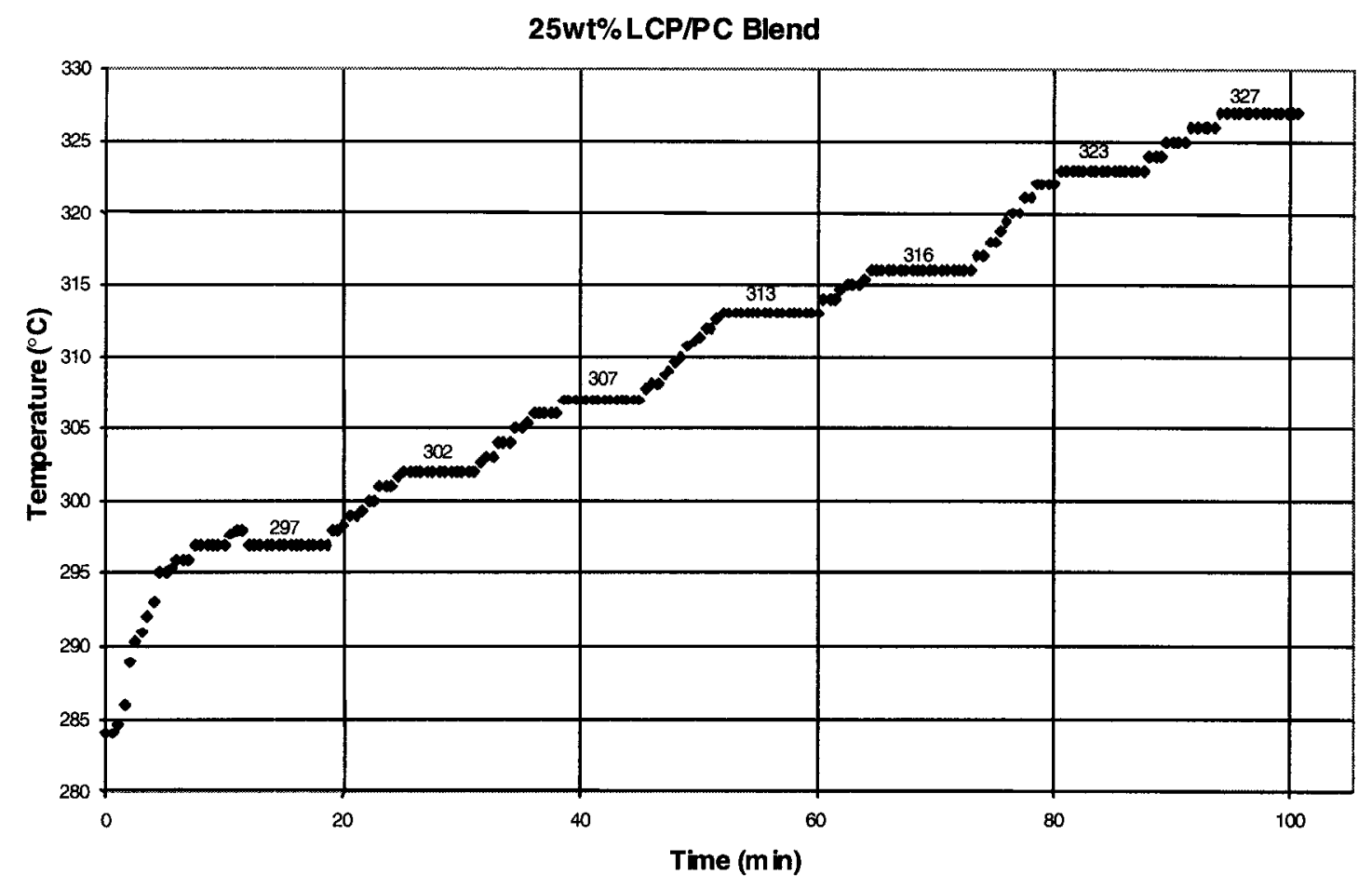

Figure 3-5: Processing melt temperatures of $25 \mathrm{wt} \% \mathrm{LCP} / \mathrm{PC}$ blend as a function of time.

\subsubsection{Polarized Light Microscopy (PLM)}

Due to relatively simple specimen preparation and easy operation, polarized light microscopy has become one of the most important techniques in the study of polymer blend phase morphology. However, PLM with its minimum resolution $(0.2 \mu \mathrm{m})$ can only be sufficient to study immiscible blend phase behavior. In order to improve the quality of images, the visibility of phases can be enhanced by contrast techniques, such as polarized light, phase contrast and others. 


\subsubsection{Apparatus}

An Olympus ${ }^{\circledR}$ BX50 system polarized light microscopy equipped with a THMS 600/HFS 91 stage was used to observe the phase morphology of LCP/PC blends. The polarized light microscope is shown in Figure 3-6 [31]. The equipment consists of a camera (not shown), eyepiece, observation tube, revolving nosepiece, objective, condenser and hot stage which can control temperature within $\pm 0.1^{\circ} \mathrm{C}$. The major problem of polarized light microscopy lenses is aberration and their quality which is dependent mainly on the degree of correction. In order to eliminate these negative effects and get better resolution, 20× magnification was used, because the light intensity would be diminished if higher magnifications were applied [3]. If magnification is lower than $20 \times$, the phase morphology is hardly to seen.

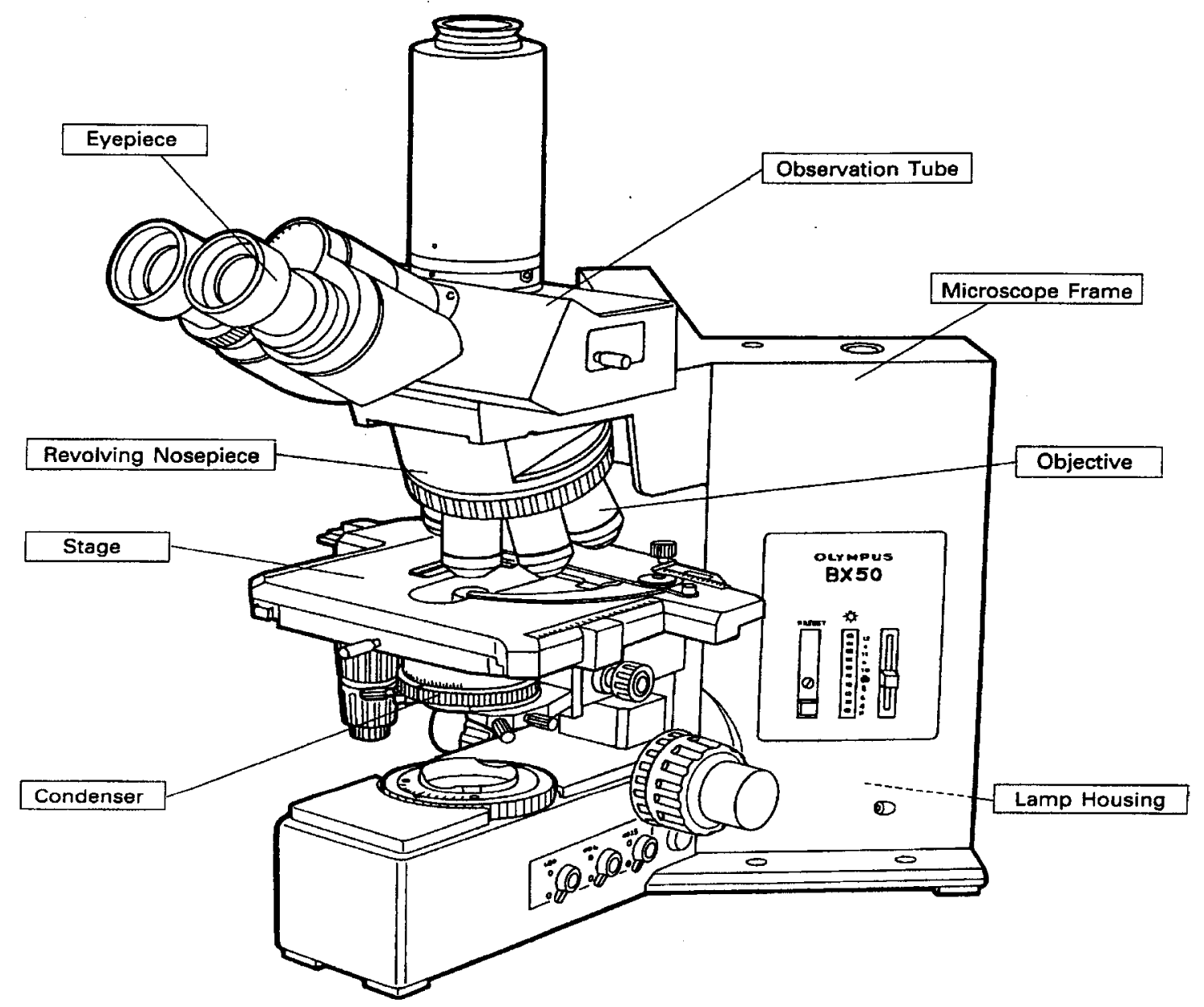

Figure 3-6: OLYMPUS ${ }^{(\mathbb{B}}$ BX50 Microscopy System [31]. 


\subsubsection{Sample Preparation}

Like other microscopic techniques, specimen preparation for polarized light microscopy is a major problem that affects the microstructure analysis results. Therefore, specimen preparation is a very important part of microscopy as the quality and the reliability of the results are dependent on the specimen.

All samples were microtomed after extrusion in the twin screw extruder. The observed surfaces are perpendicular to the flow direction and in the central parts of each extruded sample. The discussion of the observed surfaces (Figure 3-7) will be presented in section 3.3.2.2. For accurate results, it is important that the surfaces of the stage block, window and carrier must always be kept clean, because any particles of dust will cause air gaps between the block and the window resulting in temperature errors.

\subsubsection{Morphology of LCP/PC Blend}

In order to compare the morphologies in different mixing methods, Figures 3-8 and 3-9 are presented.

Figure 3-8 shows PLM micrographs of the surfaces of 30wt $\%$ LCP blends using the Haake mixer at different temperatures. The processing conditions for these specimens are given in Table 3-2. The particles seen in this figure are the LCP rich phase because $30 \mathrm{wt} \% \mathrm{LCP}$ is the minor phase of the blend. It seems that there is no major difference among these photographs.

Figure 3-9 shows PLM micrographs of 30wt\% LCP blends, which were prepared according to the conditions in Table 3-4. The observed surfaces are perpendicular to the flow direction and in the central parts of the extruded rods (see Figure 3-7). Figure 3-9A shows the morphology at $300^{\circ} \mathrm{C}, \mathrm{LCP}$ and $\mathrm{PC}$ have small phases in toughened and fibrillar-like phase structure. It does not look like the typical droplet two-phase structure. However, more detailed analysis is needed to identify the exact structure. Figure 3-9B shows that LCP has fine particulate structure at $325^{\circ} \mathrm{C}$, because LCP is the minor phase 

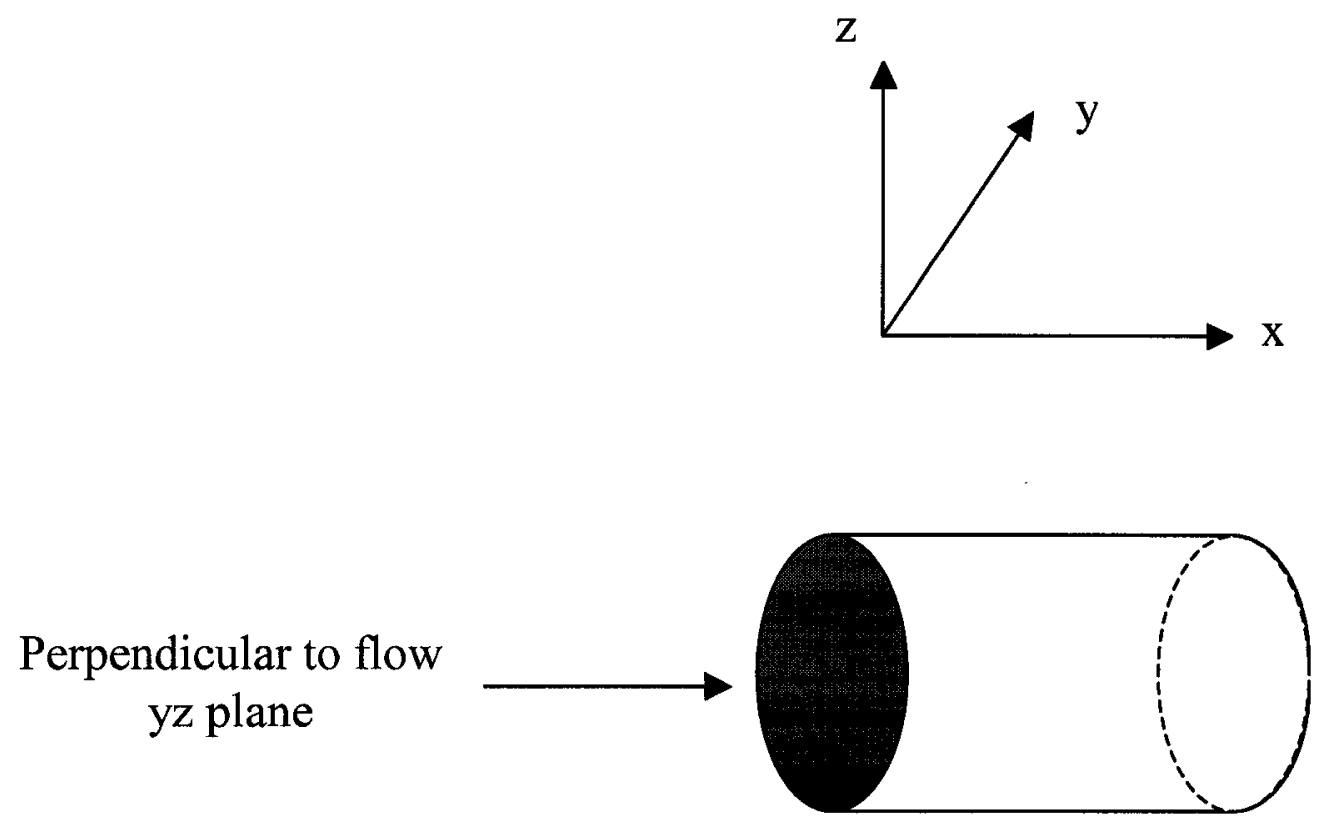

(A)

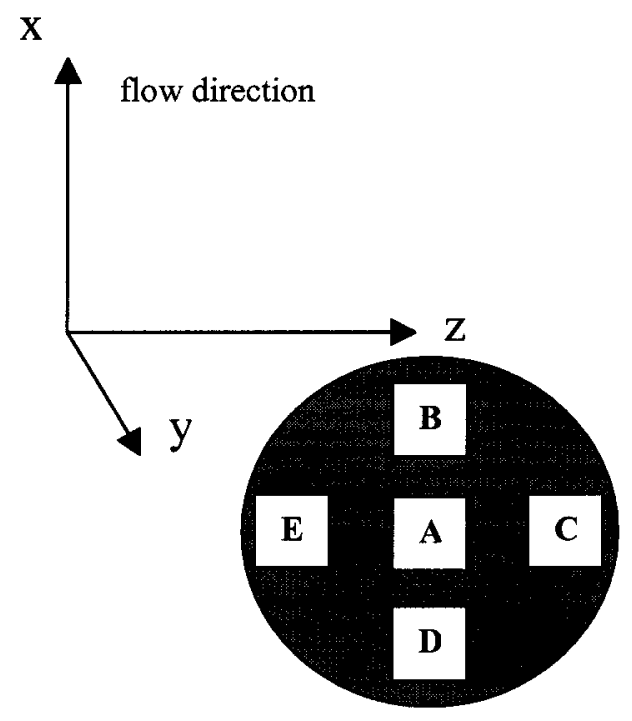

(B)

Figure 3-7: (A) Definition of the plane that is perpendicular to flow, and (B) the different locations investigated inside the twin screw extruded sample. 


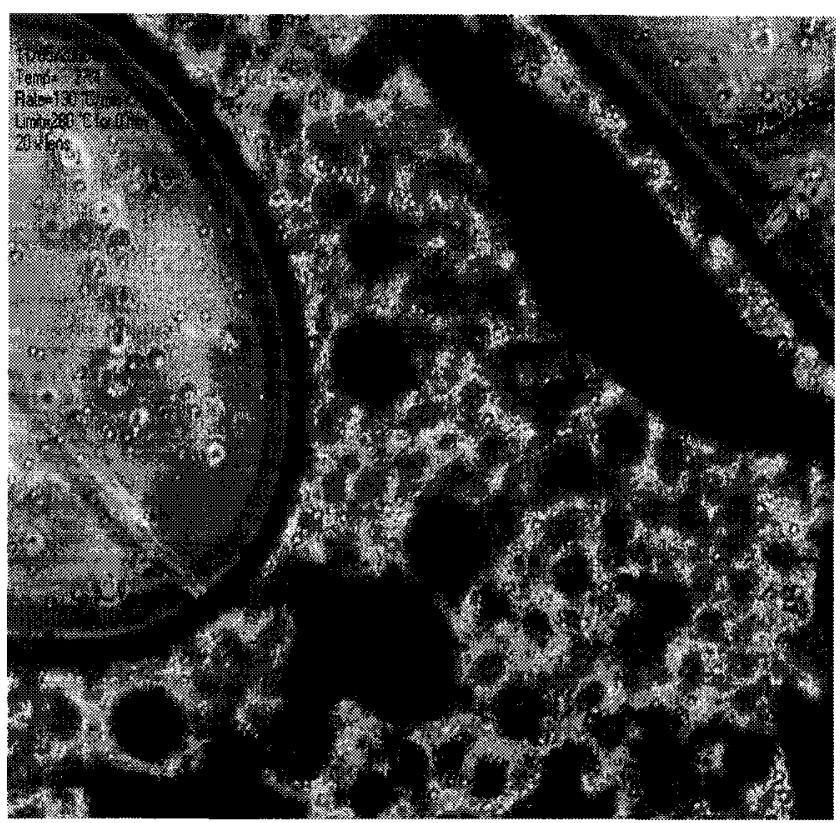

(A)

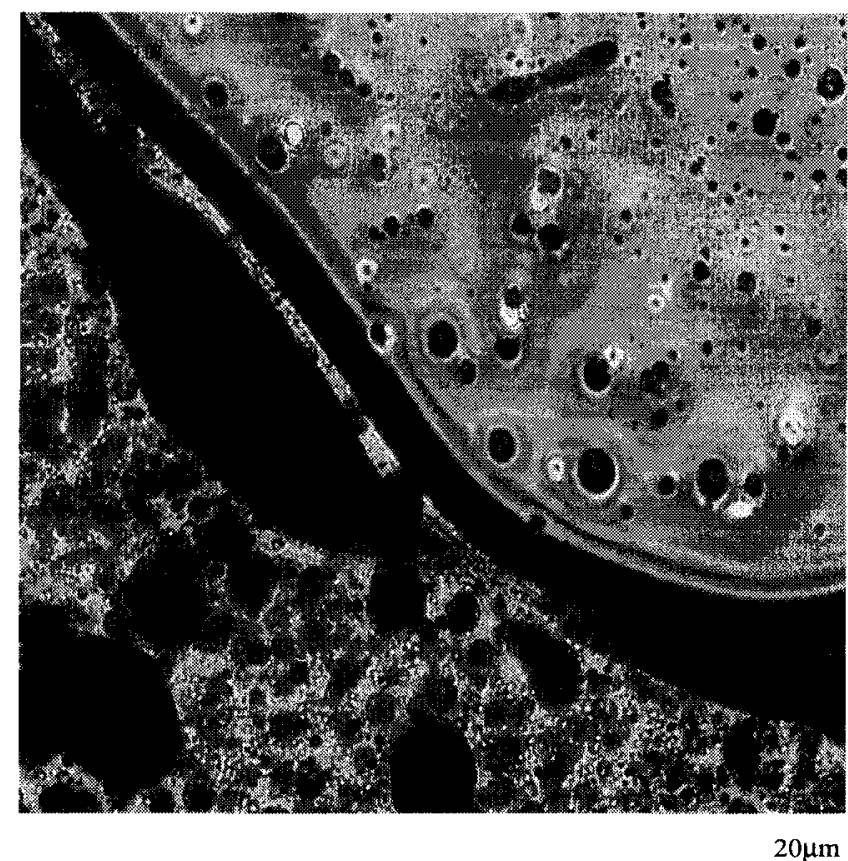

(B)

Figure 3-8: Polarized light microscopy (PLM) micrographs of the surfaces of 30wt\% LCP/PC blend using Haake mixer at hot stage temperature: (A) $27^{\circ} \mathrm{C}$, (B) $300^{\circ} \mathrm{C}$ (magnification: $\times 20$ ). 


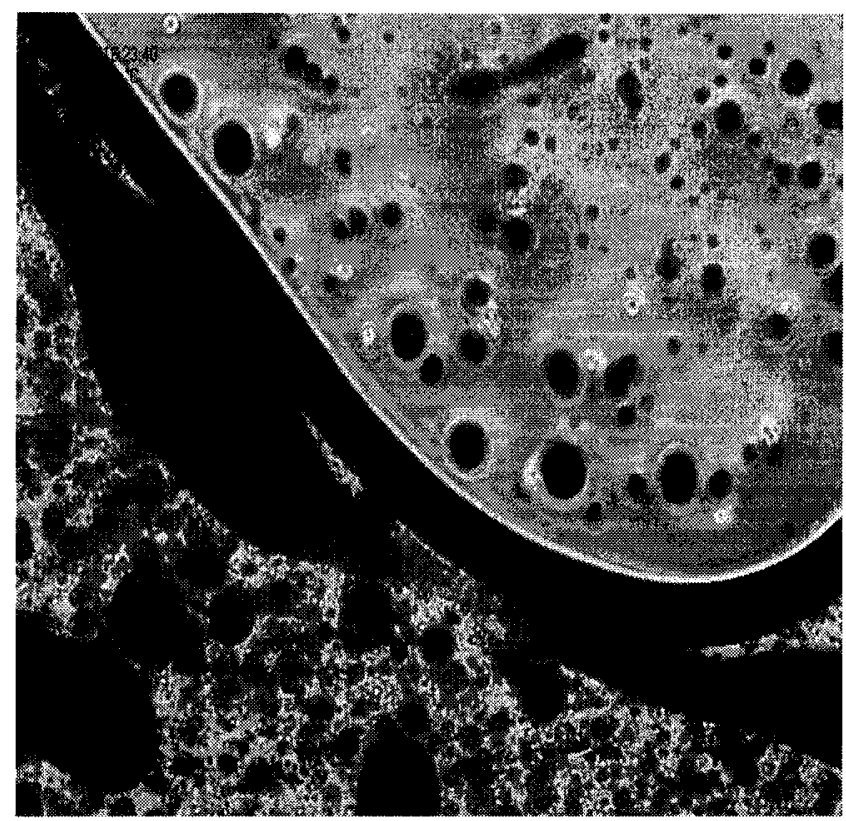

(C)

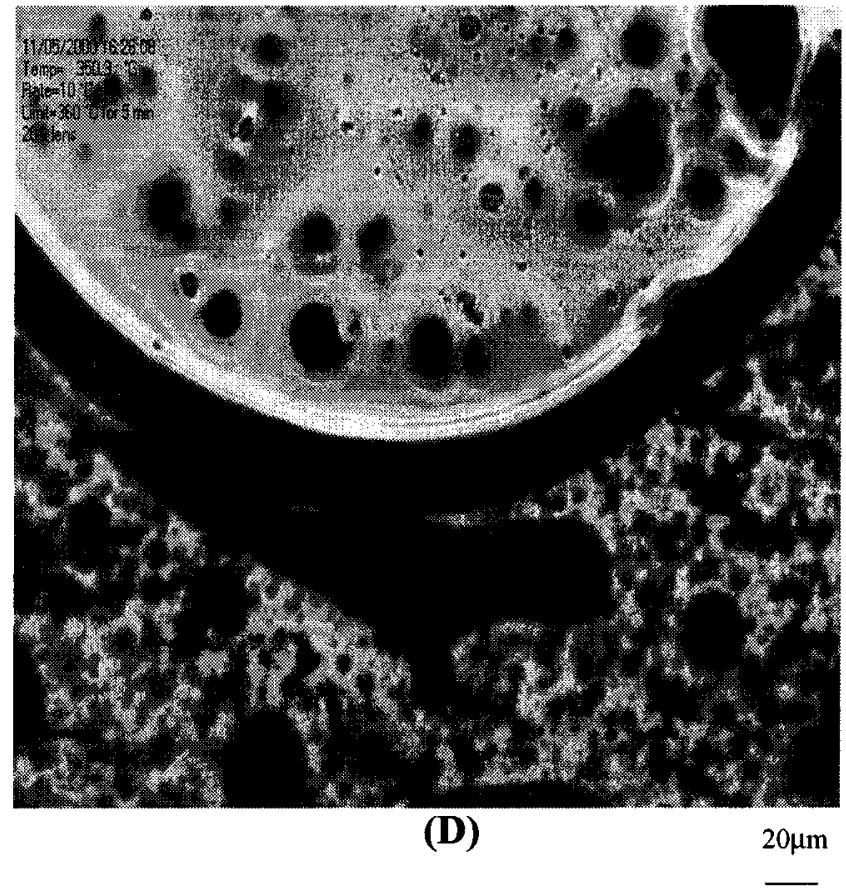

Figure 3-8: (continued) Polarized light microscopy (PLM) micrographs of the surfaces of $30 \mathrm{wt} \% \mathrm{LCP} / \mathrm{PC}$ blend using Haake mixer at hot stage temperature: (C) $325^{\circ} \mathrm{C}$, (D) $350^{\circ} \mathrm{C}$ (magnification: $\times 20$ ). 


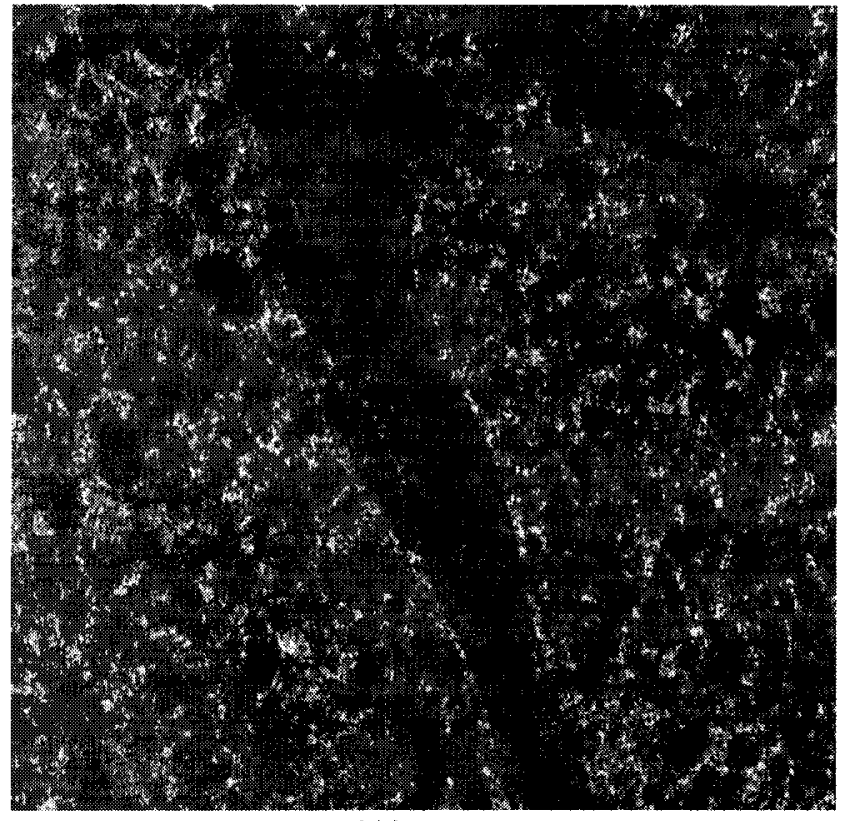

(A)

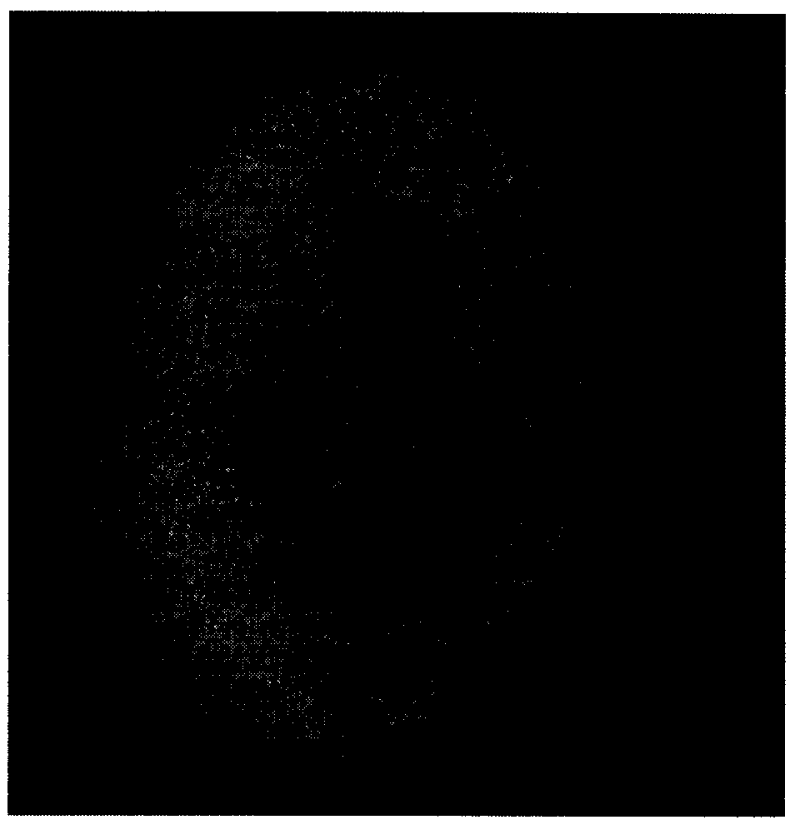

(B)

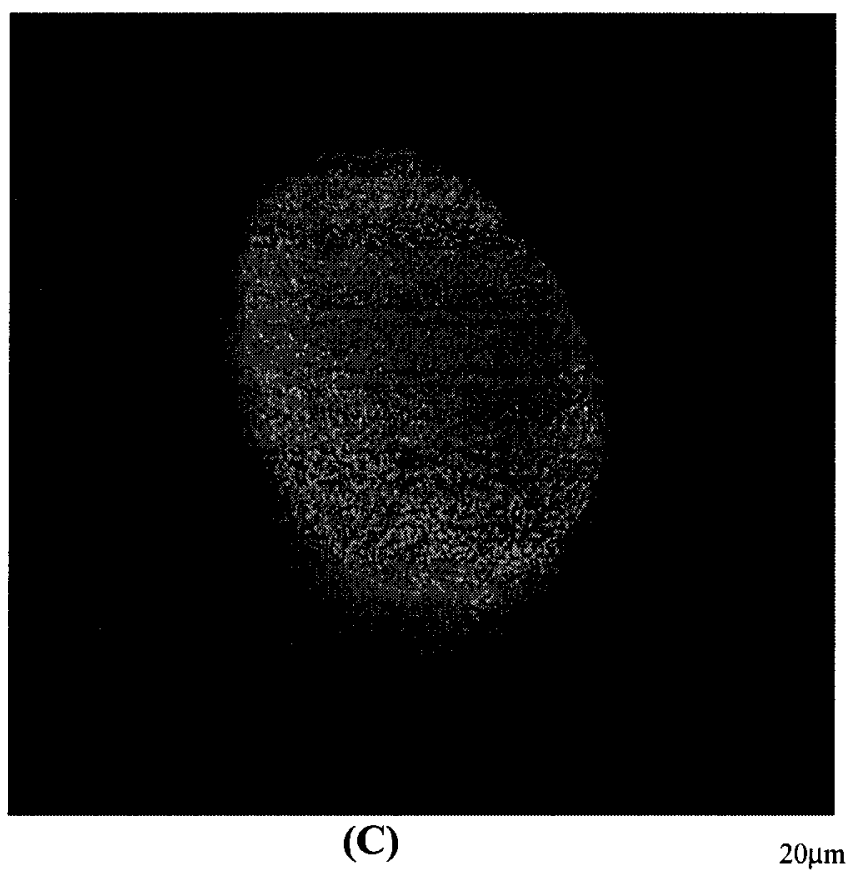

Figure 3-9: Polarized light microscopy (PLM) micrographs of the surfaces of 30wt\% LCP/PC blend after twin screw extrusion at processing temperatures: (A) $300^{\circ} \mathrm{C}$, (B) $325^{\circ} \mathrm{C}$ and $(\mathrm{C}) 350^{\circ} \mathrm{C}$ (magnification: $\times 20$ ). 
Table 3-4: Summary of Processing Conditions for 30\% LCP/PC Blending Samples

\begin{tabular}{|c|c|c|c|c|c|}
\hline $\begin{array}{c}\text { Serial } \\
\#\end{array}$ & $\begin{array}{c}\text { Barrel Temperature } \\
\text { Profile }\left({ }^{\circ} \mathbf{C}\right)\end{array}$ & $\begin{array}{c}\text { Screw Speed } \\
\left(\text { Rev Min }^{-1}\right)\end{array}$ & $\begin{array}{c}\# 1 \text { Feeder } \\
\text { Speed }\end{array}$ & $\begin{array}{c}\text { \#2 Feeder } \\
\text { Ratio }\end{array}$ & Figure (3-8) \\
\hline 1 & $270-280-290-300$ & 80 & 100 & 0.68 & $\mathrm{~A}$ \\
\hline 2 & $295-305-315-325$ & 80 & 100 & 0.68 & $\mathrm{~B}$ \\
\hline 3 & $320-330-340-350$ & 80 & 100 & 0.68 & $\mathrm{C}$ \\
\hline
\end{tabular}

of the blend at $30 \mathrm{wt} \%$. It appears like a typical droplet two-phase structure. The phase transition zones from LCP rich (droplet) to PC rich (matrix) phase can be observed. Figure 3-9C shows the blend surface at $350^{\circ} \mathrm{C}$ (processing temperature); photo $\mathrm{C}$ has smaller droplets than $\mathrm{B}$, and the droplets of $\mathrm{C}$ are dispersed better than in $\mathrm{B}$. However, both $B$ and $C$ have the same two-phase droplet-type morphology. 


\subsubsection{Scanning Electron Microscopy (SEM)}

\subsubsection{Introduction}

Scanning electron microscopy (SEM) is an advanced technique that produces a microscopic image from a scanned specimen surface (5 to $10 \mathrm{~nm}$ in diameter) by reflecting an electron beam. The working fundamentals of the SEM instrument are shown in Figure 3-10 [32]. A scanning electron beam impinges upon the specimen surface, the signals are detected, amplified and modulated in a cathode ray tube. These reflected signals are collected and constructed to form an image. The magnification of this image that appears on the screen is the ratio of a distance on the screen and the corresponding distance on the specimen.

A Joel 840A SEM (scanning electron microscope) was used throughout the study. The samples were viewed in one direction that is perpendicular to flow, yz plane (Figure 3-7). Different locations within the extruded samples were investigated. These are illustrated in Figure 3-7B. As morphological studies are very time consuming, the focus is on the central location denoted by symbol $\mathrm{A}$ in the figure. We selected the central location to study the morphology because this part has the minimum flow effects during processing. On the other hand, the central part also has the maximum elongation effect. However, due to the small diameter of the studied specimen (usually 2-4 mm), we can ignore this effect. Thus, the morphology of this part can represent the phase structure of the blend. The samples were placed inside the microscope chamber under high vacuum. An accelerating voltage of $15 \mathrm{kv}$ and a working distance of $39 \mathrm{~mm}$ were used. Magnifications of $2000 \times$ and $4000 \times$ were used.

\subsubsection{Sample Preparation}

In order to obtain clean and clear surfaces where other effects, such as sample charging, signal noise, etc, were minimized, two kinds of sample preparation methods 
were employed. Some samples were fractured after immersion in liquid nitrogen for at least five minutes. Others were microtomed at room temperature. Then, every sample was fixed onto a sample holder with silicone sealant so that the fractured or microtomed surface faced upwards. The next step was to coat each sample with a gold/palladium mixture. This makes them conductive and avoids sample charging that would cause deflection of the electron beam inside the microscope. The coating was applied by sputtering the metals under vacuum in a Hummer VI sputter coater.

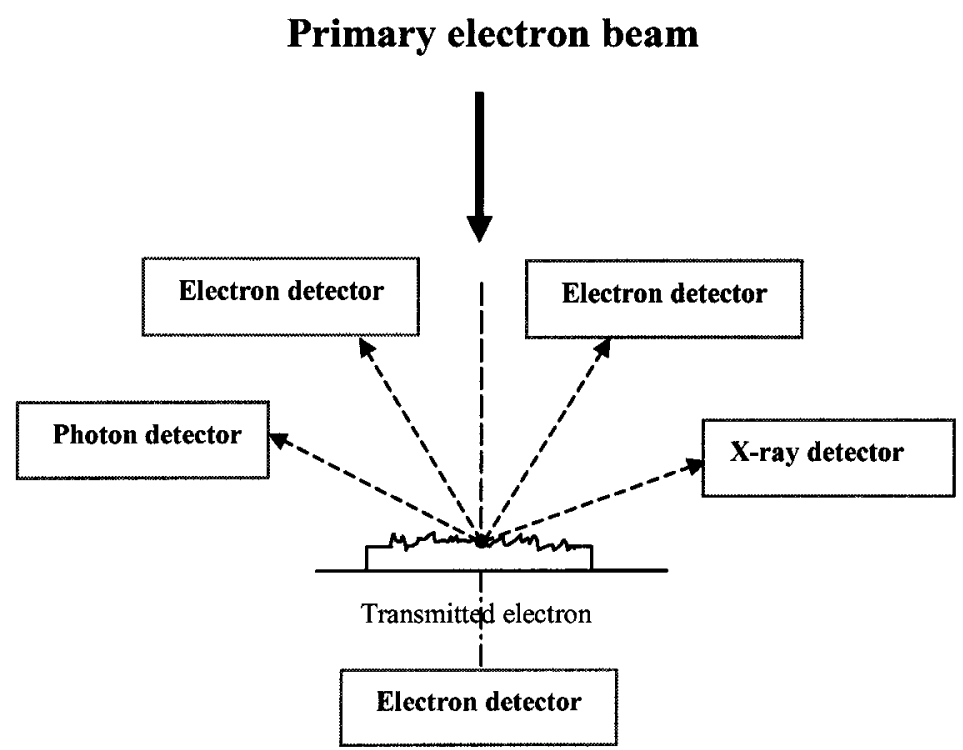

Figure 3-10: Information that can be generated in the SEM by an electron beam striking the sample [32]. 


\subsubsection{Morphology of LCP/PC Blend}

The SEM can be used to obtain morphological information from either immiscible or miscible blends where interfacial bonding is good and the phases are small. In Figure 3-11, it is easy to recognize the differences between morphologies $A$ and $B$, which obviously has two-phase droplet-type structure. Morphology A is similar to that of Figure 3-9A. It looks like a single-phase fibrillar structure. All components are mixed together without interphase. This can be confirmed from Figure 3-12. In these twodimensional images, morphology $\mathrm{A}$ has a smooth surface, which means that there is no other minor phase except the bulk phase. Meanwhile, morphology B has many holes on the surface. It means that morphology B represents a two-phase structure. The holes are LCP rich phase droplets, which were pulled out of this surface. A summary of the sample preparation conditions is given in Table 3-5. The image of fractured sample (Figure 311), which has three-dimensional information, is much easier to discern than that of the microtomed sample (Figure 3-12), which has only two-dimensional (2D) information. The 2D image loses some useful morphological information about the blend. Therefore, the fractured samples were used throughout the SEM study.

Table 3-5: Summary of LCP/PC Blend Sample Preparation Conditions for SEM

\begin{tabular}{|c|c|c|c|c|}
\hline $\begin{array}{c}\text { wt\% } \\
\text { LCP }\end{array}$ & $\begin{array}{c}\text { Blending } \\
\text { Conditions }\end{array}$ & Melt Temperature $\left({ }^{\circ} \mathrm{C}\right)^{*}$ & $\begin{array}{c}\text { Sample } \\
\text { Preparation }\end{array}$ & Figure \\
\hline 30 & TSE** & 300 & fractured & $3-11(\mathrm{~A})$ \\
\hline 30 & TSE & 325 & fractured & $3-11(\mathrm{~B})$ \\
\hline 30 & TSE & 300 & microtomed & $3-12(\mathrm{~A})$ \\
\hline 30 & TSE & 325 & microtomed & $3-12(\mathrm{~B})$ \\
\hline
\end{tabular}

* The melt temperature refers to the final temperature in TSE near the die exit. ** Twin Screw Extrusion (the processing condition is the same as Table 3-4). 


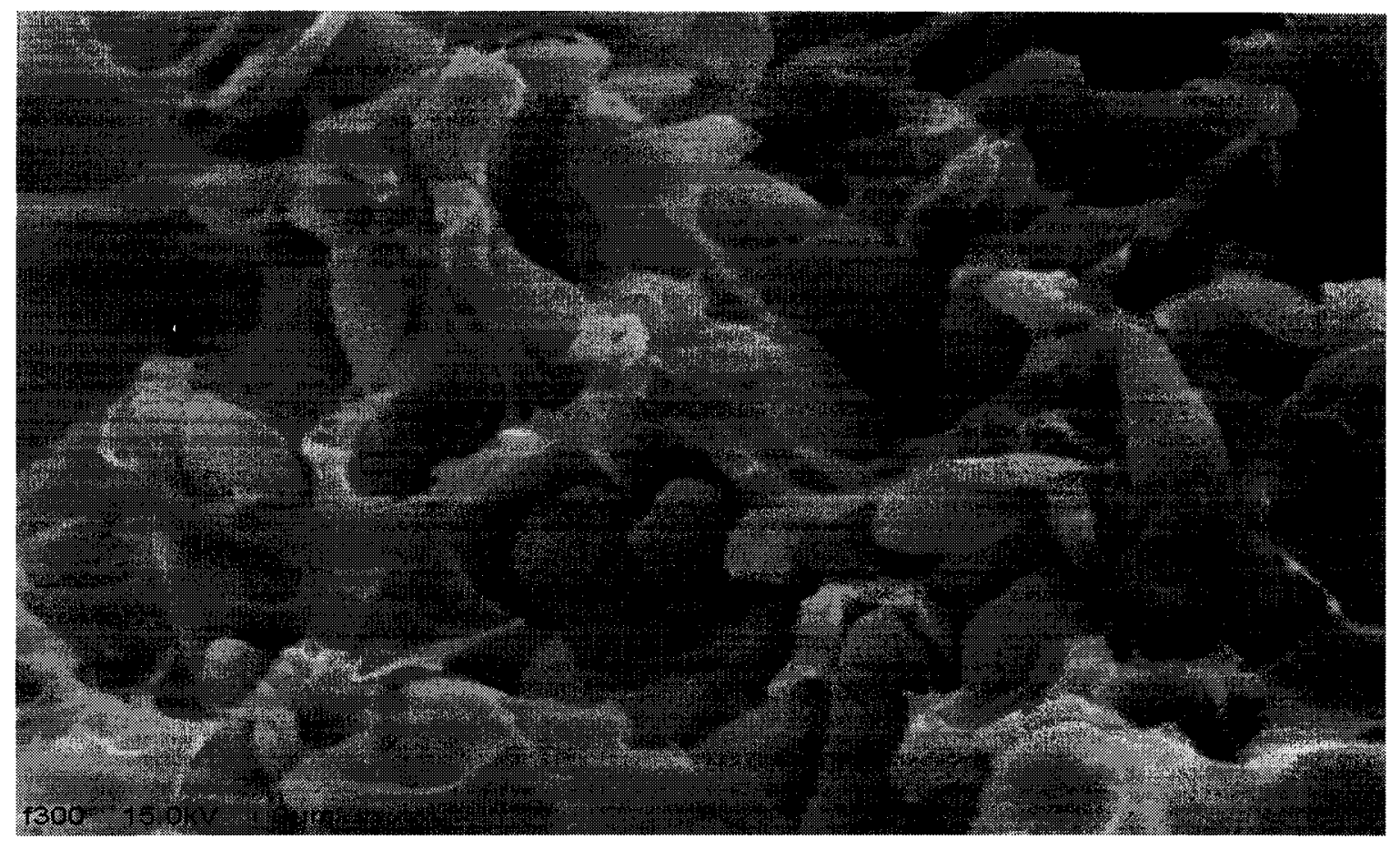

(A)

$5 \mu \mathrm{m}$

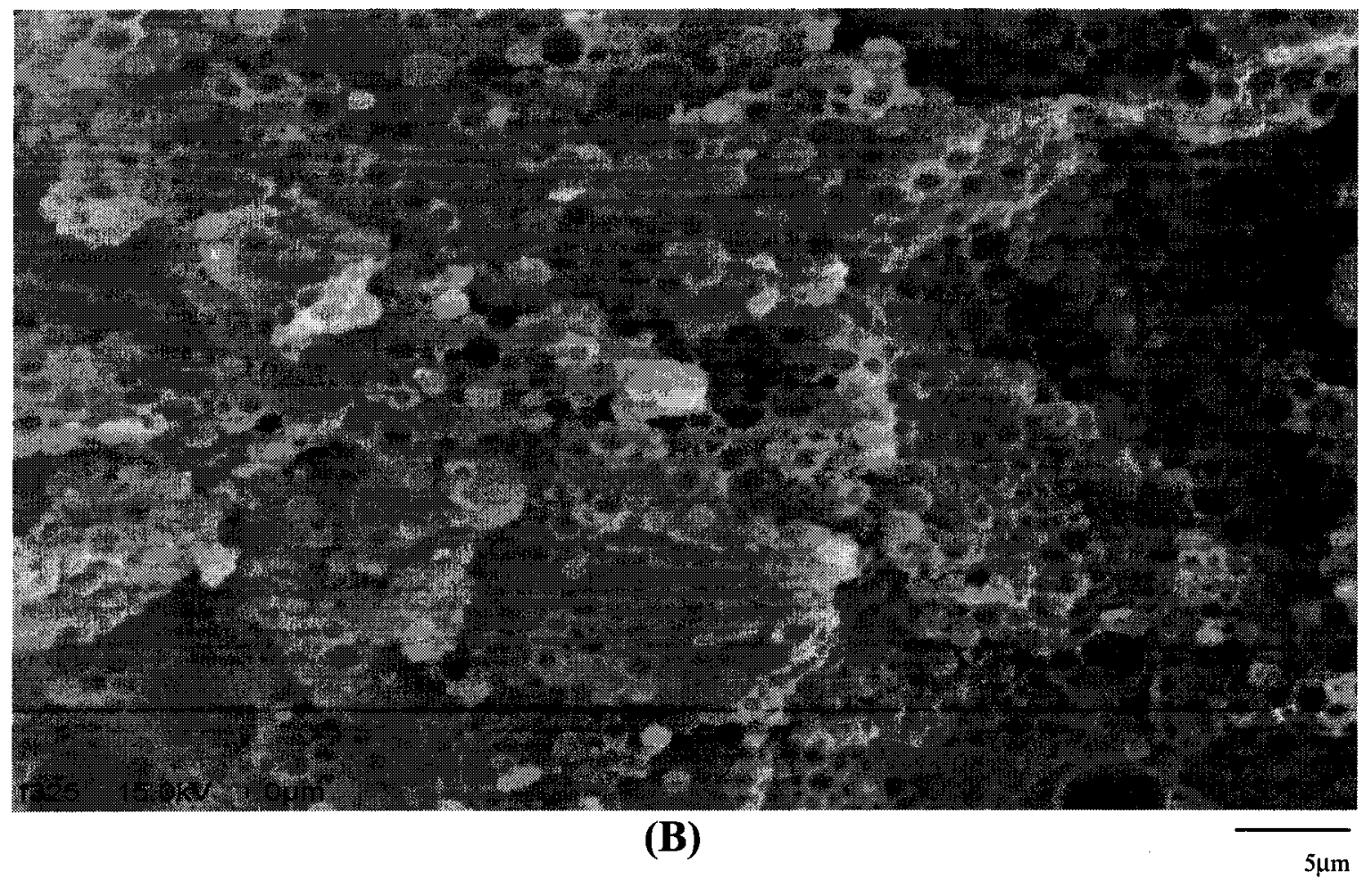

Figure 3-11: SEM micrograph of fractured 30wt $\%$ LCP blend (magnification $\times 2000$ ). 

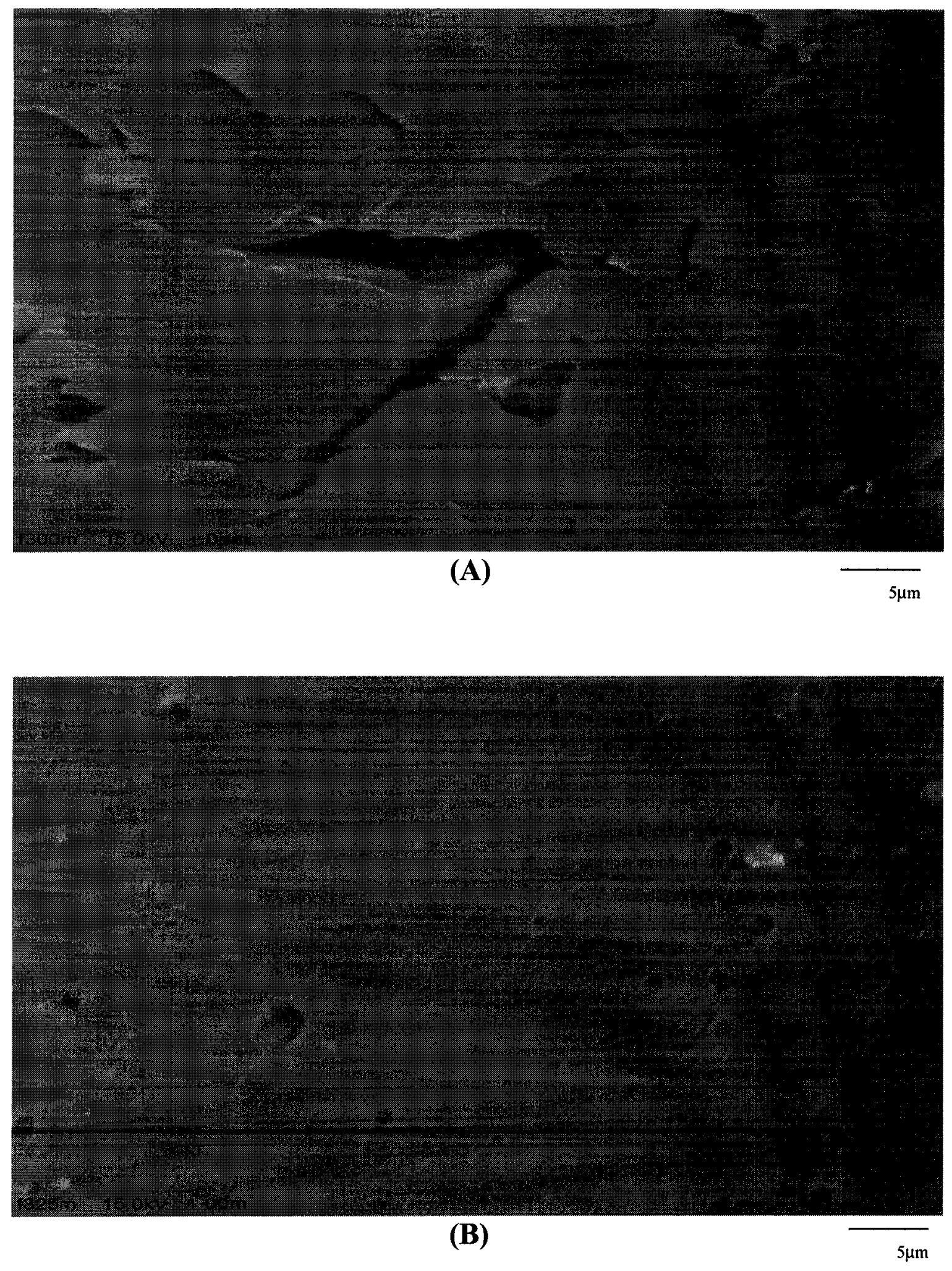

Figure 3-12: SEM micrograph of microtomed 30wt\% LCP blend (magnification $\times 2000$ ). 


\subsubsection{Image Analysis}

In order to quantify information in the SEM microphotographs, such as droplet size distribution, LECO 2005 image analysis system was used. The SEM grey image was stored in the memory of the computer and converted into a binary image. In this binary image, there were 254 color values (level 0 is black and 255 is white). However, it was difficult for the computer to perform automatic measurements on a 256 grey level image. The set of numerical data is highly dependent on the quality of the microphotograph from the SEM. Unfortunately, the SEM images were not sharp enough to perform image analysis automatically. The LCP particle gray value could not be distinguished from that of the PC matrix phase by the LECO 2005 system.

Consequently, the binary images were analyzed manually. This was a timeconsuming process. In order to obtain droplet size distribution of the dispersed phase, both the numbers and diameters of the dispersed particles were measured. Finally, the statistical results and plots of particle size distribution were obtained.

\subsection{Thermal Analysis}

\subsubsection{Differential Scanning Calorimetery (DSC) Pyris1}

Differential scanning calorimetery (DSC) is one of the most commonly used techniques in thermal analysis. There are two types of DSC instruments. One type is designed to measure the differences in heat input from the differences in temperature between the specimen and the standard reference material. On the other hand, the power compensating DSC relies on the measurement of a difference in temperature. The sample and reference are heated separately, while the difference in electrical power needed to maintain equal temperatures is recorded. 
The DSC Pyris1 used in this study is a power compensation type. The structure of this kind of instrument is shown in Figure 3-13 [33]. The base of the sample holder is surrounded by a reservoir of coolant, usually ice water or liquid nitrogen. The sample and reference holders are heated individually. When a temperature difference is detected between them caused by a thermal event in the specimen, energy is supplied until the temperature difference is less than a threshold $0.01{ }^{\circ} \mathrm{C}$. Thus, the energy input per unit time is recorded as a function of temperature or time. The temperature scanning range of DSC Pyris1 is from -160 to $+600{ }^{\circ} \mathrm{C}$. Standard reference materials, such as indium and zinc are used to calibrate temperature and energy. In addition, the DSC instrument can perform scanning rates from 0.3 to $320{ }^{\circ} \mathrm{C} / \mathrm{min}$ on heating and cooling. However, the maximum reliable scanning rate is $60^{\circ} \mathrm{C} / \mathrm{min}$.

\subsubsection{Glass Transition Temperature $\left(T_{\mathrm{g}}\right)$ Measurement}

The glass transition temperature $T_{\mathrm{g}}$ of a polymer is a second-order transition that represents the polymer passing from the hard rigid solid to the rubbery state. This is an important temperature, because it indicates the transition point between the solid and rubbery states. Therefore, determination of $T_{\mathrm{g}}$ in the blend in relation to those of the pure components has become the most commonly used method for establishing miscibility in polymer-polymer blends or partial phase mixing in such blend systems [2,9]. For example, an immiscible blend will exhibit two separate $T_{\mathrm{g}} \mathrm{s}$ between those of the pure components. This results in two phases: component $A$-rich phase and component $B$-rich phase. While a miscible polymer blend will exhibit only a single glass transition temperature between the $T_{\mathrm{g}}$ 's of the pure components.

In this work, $20^{\circ} \mathrm{C} / \mathrm{min}$ heating and cooling rates were used throughout the DSC experiments. The blend samples and reference compartments were purged continuously with extra dried pre-purified nitrogen at a flow rate of $20 \mathrm{ml} / \mathrm{min}$. The manual baseline was set up for every new experimental run. This can be done by running a heating scan from $50^{\circ} \mathrm{C}$ to $350^{\circ} \mathrm{C}$ at the rate of $20^{\circ} \mathrm{C} / \mathrm{min}$. A baseline was run with two empty pans in both the reference and sample holders. 
Pt sensors

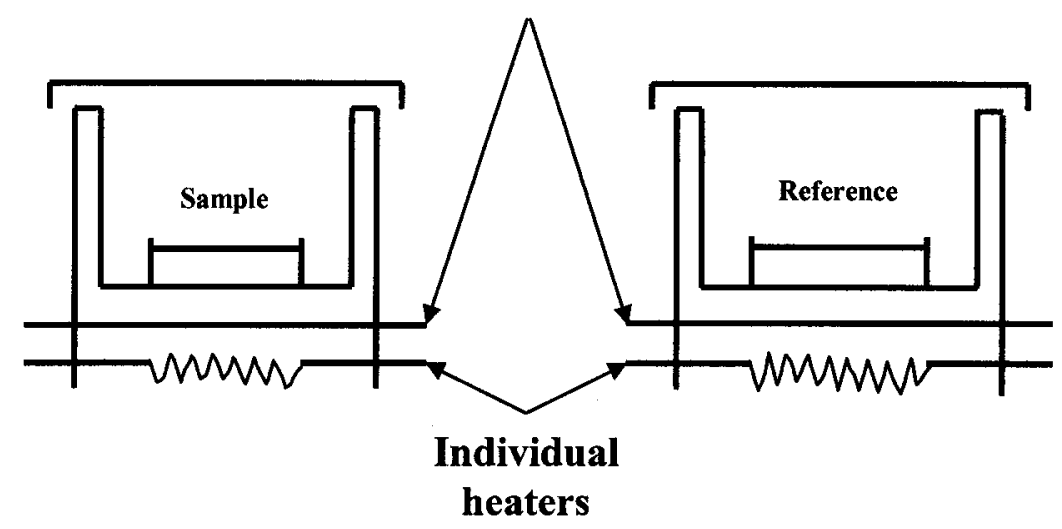

Differential temperature control loop Sample temperature

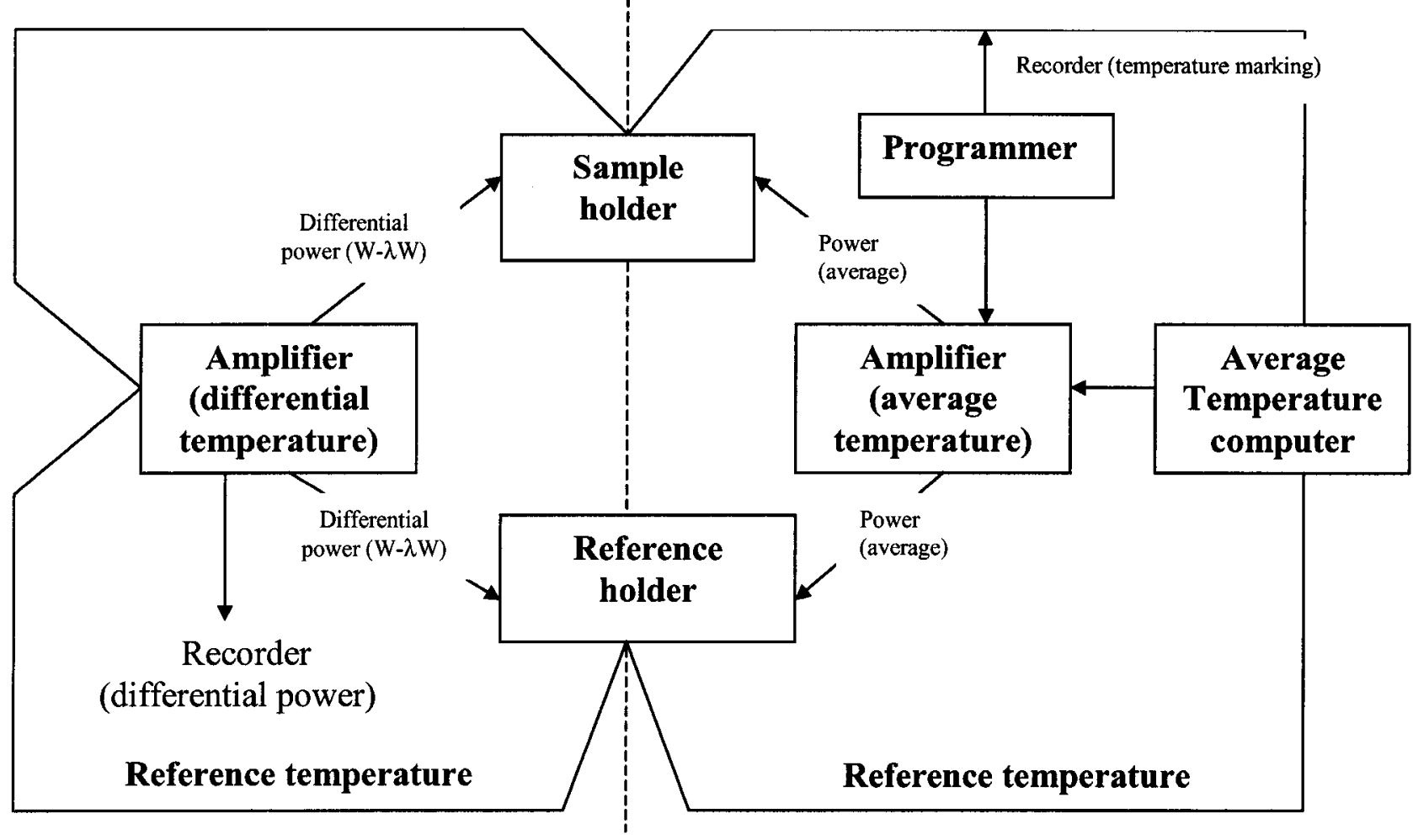

Figure 3-13: A schematic representation of a power compensating DSC instrument and its operation [33]. 
The DSC thermograms were normalized to take into account the weight of the samples, which varied from 5 to $8 \mathrm{mg}$. All curves and data were obtained from the second scanning, in order to eliminate the thermal history. The procedure of the automatic subtraction of the baseline and the calculation of the $T_{\mathrm{g}}$ value was used for all the runs. A Sartorius Supermicro Balance was used in conjunction with the DSC to weight blend samples with a precision of $\pm 10^{-4} \mathrm{mg}$.

\subsubsection{Phase Transition Temperature Calculation}

Nonlinear regression using Sigmaplot ${ }^{\circledR} 5.0$ software was employed to fit the experimental $T_{\mathrm{g}}$ data points. The Sigmoid 4 parameter regression equation was selected, it was found to fit the data successfully. It has the form:

$$
y=y_{0}+\frac{a}{1+e^{-\left(\frac{x-x_{0}}{b}\right)}}
$$

where $a$ and $b$ are fitting parameters, $x_{0}$ is the phase transition temperature, and $y_{0}$ is the dimensionless glass transition temperature.

The inflection point of this curve represents the phase transition temperature of the LCP/PC blend. It represents the $T_{\mathrm{g}}$ of the blend, as will be discussed in section 4.2.1. This point was obtained by setting the second derivative of Equation (3-1) equal zero.

$$
\begin{aligned}
& y^{\prime}=\left[\frac{a}{1+e^{-\frac{\left(x-x_{0}\right)}{b}}}\right]^{\prime}=\frac{a}{b} \times \frac{1}{\left[1+e^{-\frac{\left(x-x_{0}\right)}{b}}\right]^{2}} \times\left[e^{-\frac{\left(x-x_{0}\right)}{b}}\right] \\
& y^{\prime \prime}=\frac{2 a}{b^{2}} \times\left[e^{\frac{\left(x-x_{0}\right)}{b}}\right]^{2} \times \frac{1}{\left[1+e^{-\frac{\left(x-x_{0}\right)}{b}}\right]^{3}}-\frac{a}{b^{2}} \times\left[e^{-\frac{\left(x-x_{0}\right)}{b}}\right] \times \frac{1}{\left[1+e^{-\frac{\left(x-x_{0}\right)}{b}}\right]^{2}}
\end{aligned}
$$

If $y^{\prime \prime}=0$, then $e^{-\frac{\left(x-x_{0}\right)}{b}}=1$,

$$
x=x_{0}-b \ln 1
$$


$x_{0}$ is the phase transition temperature of the blend under consideration.

\subsection{Discussion of Experimental Techniques}

The solvent casting method is not applicable to the LCP/PC blend under study, because it was not possible to dissolve the LCP used in this study in either of the mixed solvent systems (see section 3.2.2.1 and 3.2.2.2). There are a number of reasons for this problem, which are:

1. LCP, especially fully aromatic ones such as THERMX LCP LN001, are highly crystalline and resistant to solvent attack;

2. The limited solubility of LCP is the major problem; the tendency to crystallize limits the quantity that can be solubilized;

3. The complex chemical structure of copolyester LCP, including some possible cross-linked structures;

4. The molecular weight and melting point of the LCP used in this study are much higher than for other commercial grade LCP.

It has been suggested that there are some other solvents known in the literature as having at least some degree of dissolving power towards LCPs. Tennessee Eastman Kodak, the supplier of the LCP used in this study, suggested that hexafluoroisopropyl alcohol (HFIP) or mixtures of HFIP with chlorinated solvents such as methylene chloride or chloroform (volatile solvents) could dissolve the LCP at low concentrations of solute $(0.5 \%$ or $0.1 \%)$. This mixture could be effective at ambient temperature if allowed sufficient time, and the application of heat would accelerate the dissolution process. However, it was decided to avoid such hazardous solvents. 
The mechanical blending for LCP/PC blends was accomplished by the Haake mixer and twin screw extruder. The twin screw extruder is more suitable for the LCP/PC blends studied. From the microscopic analysis of the extruded blend samples (Figure 3-8 and 3-9), it is clearly observed that the minor LCP phase of twin screw extruded blends is more finely dispersed, that is, the average particle size is smaller than for Haake blends. In addition, the twin screw extruded blends have a more uniform dispersion of the minor phase, which represents the result of more intensive mixing action. Overall, the microscopic experimental results suggest that the twin screw extruded blends have been mixed more intensively than that using the Haake mixer.

Polarized light microscopy (PLM) and scanning electron microscopy (SEM) are the major techniques for the assessment of morphology of liquid crystalline polymers and their blends. However, we have selected only SEM as the main technique for assessing the morphology. The resolution of a SEM is typically between 10 and $30 \mathrm{~nm}$, while that of the PLM is limited to $0.2 \mu \mathrm{m}$, which is only sufficient to study phase behavior of some immiscible blend systems. Furthermore, SEM sample preparation is relatively simple. The fractured or etched surfaces of specimens are coated with a thin layer of conductive material prior to examination, in order that the electron beam inside the SEM can deflect signals to construct an image. Finally, SEM can produce, not only detailed topographical images that are obtained by recording the scattered secondary electrons, but also large and sharp images with large topographical variations. Therefore, the final image can be converted to light intensity contrast using available techniques to coordinate the variations in absorption coefficient, sample thickness, refractive index, birefringence and so on.

In this work, we used DSC, because it is routinely performed to study polymer blend phase transition temperatures and thermodynamic characteristics. The advantages of DSC thermal analysis over other analytical methods can be summarized as follows:

1. DSC specimen preparation is relatively simple, almost any physical form is acceptable;

2. A small amount of sample (1-10 mg) is required; 
3. The analysis can be performed over a wide temperature range;

4. Temperature can be controlled to within $\pm 0.1^{\circ} \mathrm{C}$;

5. DSC is a suitable instrument for measuring all transition temperatures for a polymer by studying the changes of enthalpy accompanied with physical and chemical changes;

6. The run time program can vary from several minutes to several hours;

7. The DSC instrument is easy to operate. 


\section{Chapter 4}

\section{Results and Discussion}

This chapter introduces a novel method to determine the thermodynamic phase diagram for LCP/PC blends. The thermally induced phase separation of the blends is discussed in detail. The experimental results are compared with theoretical results obtained using the Flory-Huggins and Cahn-Hillard theories. The reproducibility of the result and error estimation are also discussed.

\subsection{Introduction}

As discussed in the previous chapter, the experimental techniques selected in this study were the DSC and SEM. In DSC thermal analysis, it was found that the glass transition temperature $T_{\mathrm{g}}$ is a function of processing melt temperature $T_{\mathrm{pm}}$, as defined in section 3.2.3.3. Moreover, the SEM results could be used to confirm those of DSC by observation of phase morphology. Also, the SEM results produce information regarding the microstructural morphology and its dependence on processing conditions. Thus, the above techniques are useful for obtaining the thermodynamic phase diagram, which relates the microstructural morphology of the blend to the processing melt temperature. It will be shown that the present work supports the findings of other researchers [16-23]. It also provides some novel additional contributions: (1) a practical experimental method has been established using TSE, DSC and SEM techniques to determine the thermodynamic phase diagram for the LCP/PC blend, and (2) the dependence of the blend $T_{\mathrm{g}} \mathrm{s}$ on the processing melt temperatures $T_{\mathrm{pm}} \mathrm{s}$ is evaluated carefully. The dependence of blend $T_{\mathrm{g}}$ on the processing melt temperature $T_{\mathrm{pm}}$ has not been considered 
by other researchers. Thus, the experimental techniques and the results of this study provide more insight regarding thermally induced phase separation of the blend.

\subsection{Thermodynamic Phase Diagram for LCP/PC Blends}

\subsubsection{Determination of Phase Transition Temperatures}

In order to study the effects of thermally induced phase separation of LCP/PC blends, the thermal effect was produced by varying the processing melt temperature $T_{\mathrm{pm}}$. As mentioned before, the determination of the glass transition temperatures $T_{\mathrm{g}}$ of polymer blends by thermal analysis method is a generally accepted way to evaluate the miscibility

of polymer blends $[2,8,10]$. Therefore, the influence of processing melt temperatures $T_{\mathrm{pm}}$ on the blend $T_{\mathrm{g}}$ was studied. In this work, the glass transition temperature $T_{\mathrm{g}}$ is the onset value that is calculated by finding the intersection of the extrapolated tangent at the first limit and the extrapolated tangent at the inflection point (see Figure 4-1). Figure 4-1 demonstrates the typical DSC behavior near $T_{g}$ for most polymers. Figure 4-2 shows the actual DSC thermograms of the blend containing $25 \mathrm{wt} \% \mathrm{LCP}$, as obtained with DSC Pyris1. The calculation of the onset $T_{\mathrm{g}}$ values was automatically done by DSC (see Figure 3-2). A summary of all the processing conditions of different LCP concentrations with the corresponding $T_{\mathrm{g}}$ detected by the DSC is given in Table 4-1.

The $T_{\mathrm{g}}$ values were plotted as a function of processing melt temperatures $T_{\mathrm{pm}} \mathrm{s}$, as shown in Figure 4-3 (A) and (B). LCP weight concentrations in the range 15\%-70\% were investigated. We only focused on this concentration range to avoid the complex phase behavior near the limits of the concentration range ( 0 and $100 \%)$. In order to clarify and simplify the analysis, the data were divided into two groups $15 \%-30 \%$ and $40 \%-70 \%$. 


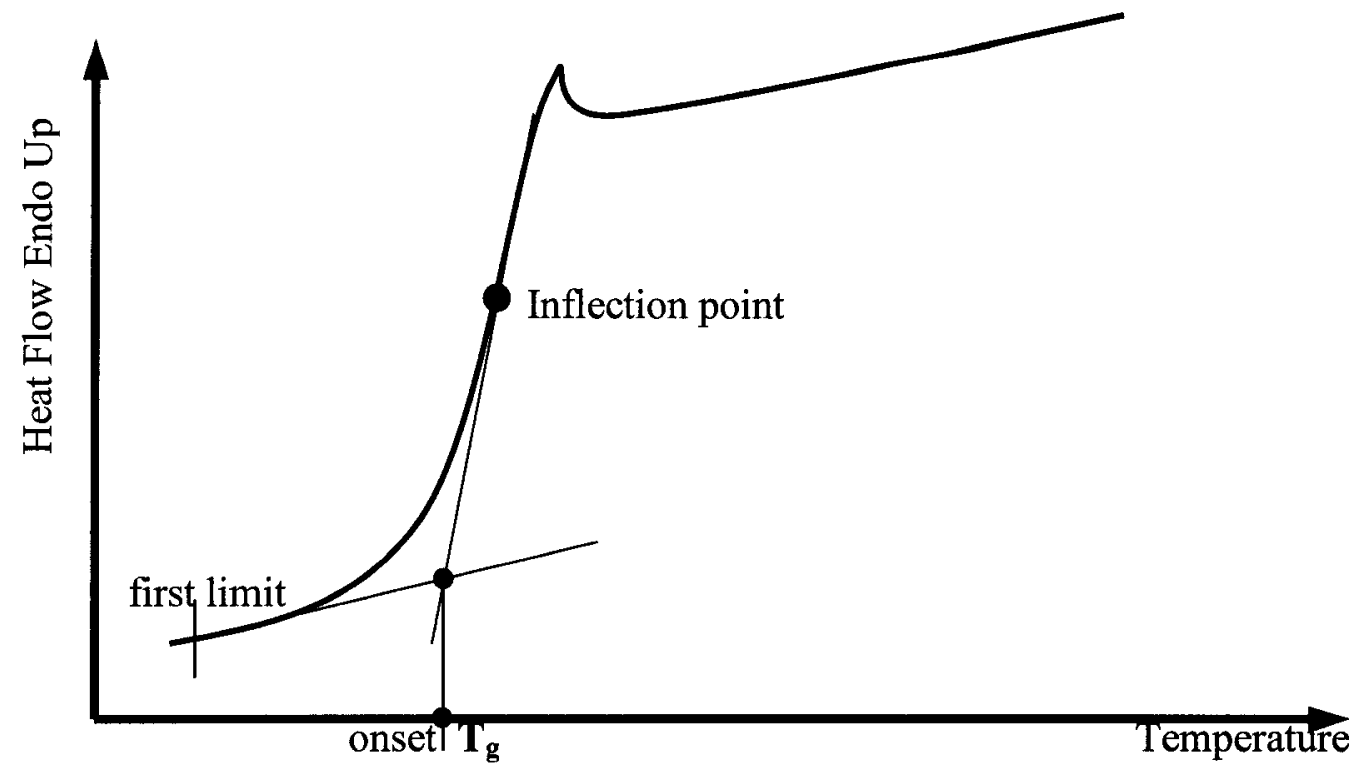

Figure 4-1:Schematic diagram of the onset glass transition temperature $T_{\mathrm{g}}$ obtained by DSC Pyris1.

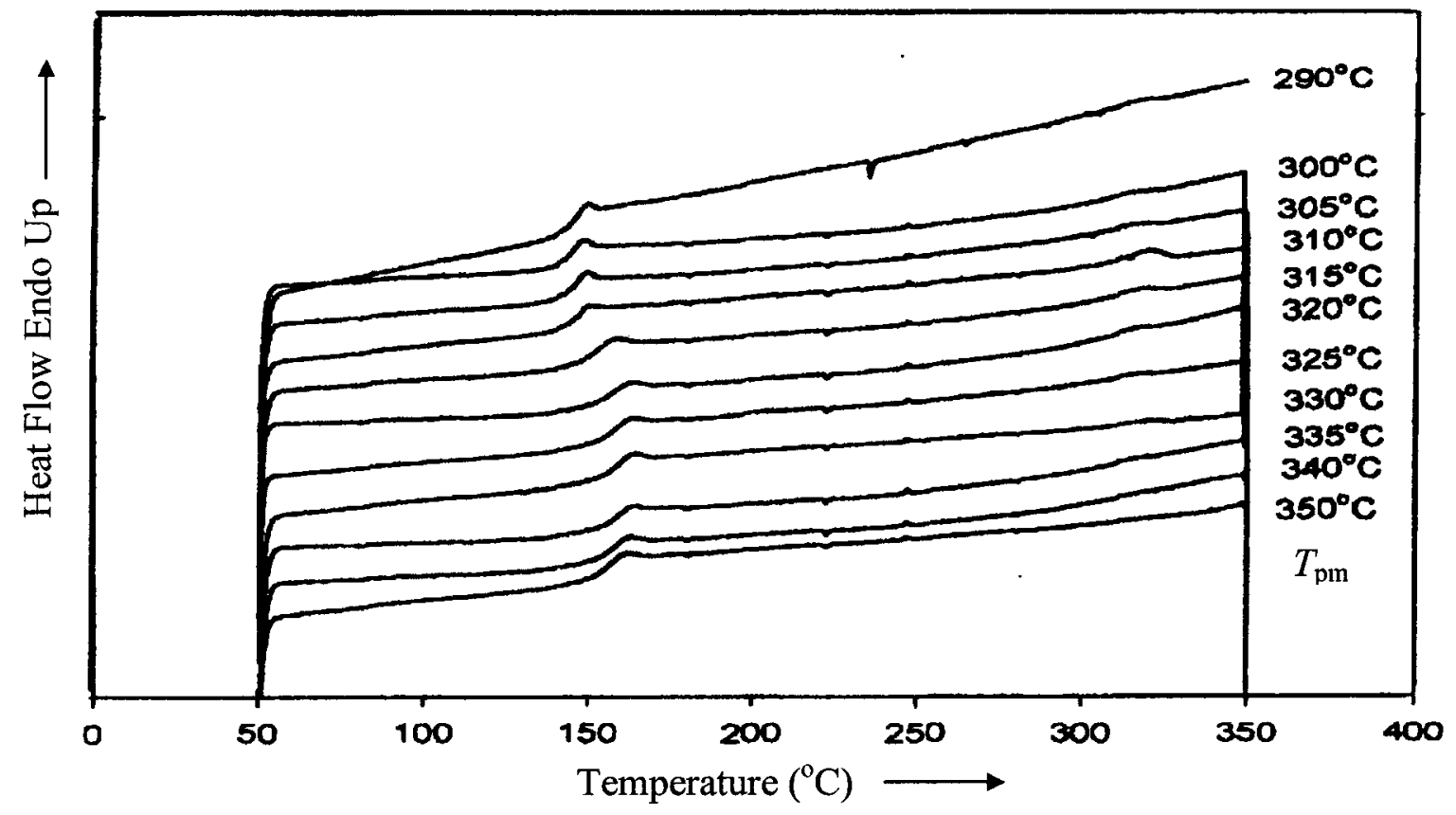

Figure 4-2: DSC thermograms of the blend containing $25 \mathrm{wt} \% \mathrm{LCP}$ after being mixed for different processing melt temperatures $T_{\mathrm{pm}} \mathrm{s}$ in twin screw extrusion. 
Table 4-1: LCP/PC Blend Processing Conditions and their Corresponding $T_{\mathrm{g}}$ Data

\begin{tabular}{|c|c|c|c|c|c|c|c|c|c|}
\hline \multirow{3}{*}{$\begin{array}{l}\text { wt\% } \\
\text { LCP } \\
15\end{array}$} & \multicolumn{9}{|c|}{ Processing Melt Temperature $T_{\mathrm{pm}}\left({ }^{\circ} \mathrm{C}\right)^{*}$} \\
\hline & \multicolumn{9}{|c|}{ Onset $T_{g}\left({ }^{\circ} \mathrm{C}\right)$} \\
\hline & 295 & 305 & 310 & 315 & 320 & 325 & 330 & 340 & 350 \\
\hline & 142.9 & 143.1 & 143.0 & 144.0 & 146.5 & 147.8 & 146.7 & 147.2 & 149.0 \\
\hline \multirow[t]{2}{*}{20} & 301 & 307 & 312 & 317 & 322 & 328 & 334 & 337 & \\
\hline & 146.2 & 147.1 & 149.0 & 151.1 & 153.2 & 152.2 & 153.9 & 154.8 & \\
\hline \multirow[t]{2}{*}{25} & 300 & 305 & 310 & 315 & 320 & 325 & 330 & 335 & 340 \\
\hline & 141.4 & 142.1 & 144.1 & 146.2 & 148.5 & 151.9 & 153.0 & 152.3 & 152.0 \\
\hline \multirow[t]{2}{*}{30} & 290 & 295 & 300 & 305 & 310 & 315 & 325 & 350 & \\
\hline & 138.4 & 140.3 & 140.6 & 141.3 & 145.6 & 149.2 & 152.3 & 155.7 & \\
\hline \multirow[t]{2}{*}{40} & 290 & 300 & 305 & 310 & 320 & 325 & 335 & 340 & 350 \\
\hline & 139.8 & 139.8 & 138.2 & 139.6 & 151.2 & 150.6 & 152.7 & 152.6 & 152.7 \\
\hline \multirow[t]{2}{*}{50} & 280 & 290 & 300 & 310 & 320 & 325 & 330 & 335 & 340 \\
\hline & 135.4 & 135.9 & 136.8 & 137.0 & 141.7 & 147.6 & 147.6 & 148.6 & 151.4 \\
\hline \multirow[t]{2}{*}{60} & 307 & 311 & 317 & 319 & 325 & 330 & 340 & & \\
\hline & 141.0 & 141.2 & 141.8 & 142.7 & 145.0 & 147.6 & 149.0 & & \\
\hline \multirow[t]{2}{*}{70} & 305 & 311 & 315 & 319 & 329 & 332 & 341 & 345 & \\
\hline & 138.0 & 140.4 & 140.0 & 139.9 & 143.0 & 147.3 & 148.0 & 148.2 & \\
\hline
\end{tabular}

* Other processing conditions in twin screw extrusion, such as screw speed, feeder rate and so on, are the same as presented in section 3.2.3. 
LCP/PC Blend $T_{g}$ vs. $T_{p m}\left({ }^{\circ} \mathrm{C}\right)$

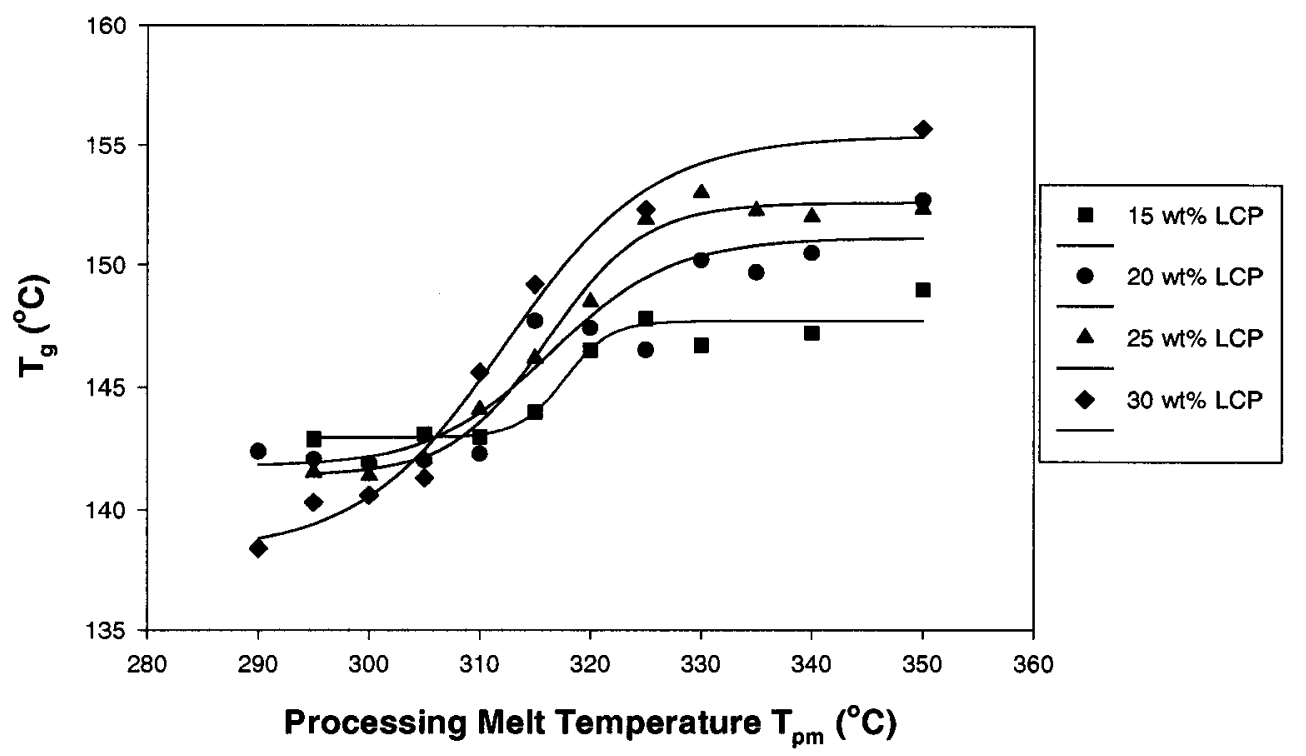

(A)

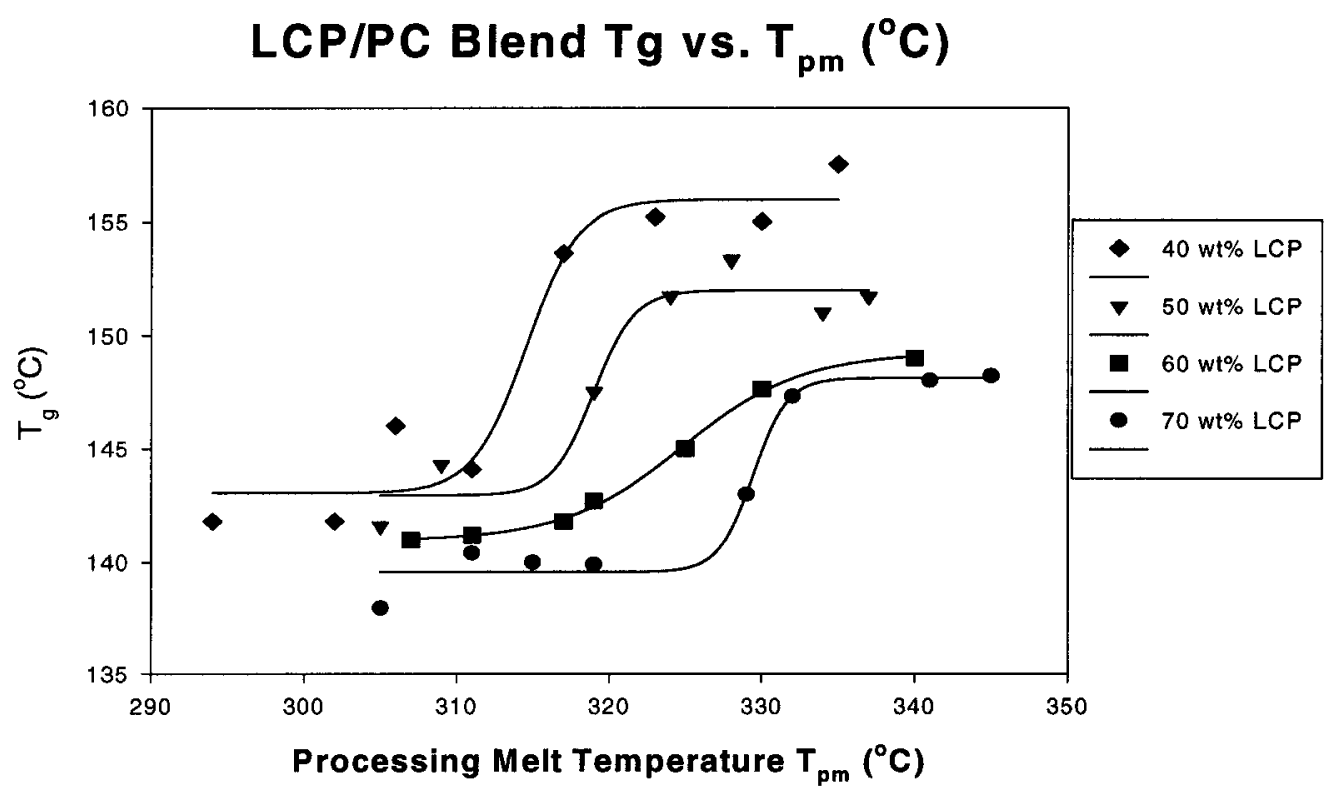

(B)

Figure 4-3: Glass transition Temperatures $T_{\mathrm{g}}$ vs. $T_{\mathrm{pm}}$ for different LCP wt\%. 
It can be seen from Figure 4-3 that the blend shows variable glass transition temperature $T_{\mathrm{g}}$ values, depending on the processing melt temperature $T_{\mathrm{pm}}$. In general, $T_{\mathrm{g}}$ increases with $T_{\mathrm{pm}}$ for the same LCP concentration. Table 4-1 shows that the blend $T_{\mathrm{g}} \mathrm{s}$ cross the $T_{\mathrm{g}}$ of pure $\mathrm{PC}$, which is $147.6^{\circ} \mathrm{C}$ (see Figure $3-2 \mathrm{~A}$ ), at a certain value of $T_{\mathrm{pm}}$ for a given LCP concentration in the blend. The blend $T_{\mathrm{g}} \mathrm{s}$ increase slightly when processed above this temperature. For instance, in the $25 \mathrm{wt} \%$ blend, this temperature is located between $315^{\circ} \mathrm{C}$ and $320^{\circ} \mathrm{C}$. The corresponding blends $T_{\mathrm{g}} \mathrm{s}$ of this temperature range are $146.2^{\circ} \mathrm{C}$ and $148.5^{\circ} \mathrm{C}$, respectively (see Table $4-1$ item $25 \%$ columns 4 and 5). Consequently, the phase transition temperature occurs between $315^{\circ} \mathrm{C}$ and $320^{\circ} \mathrm{C}$.

In Figure 4-3A, the inflection points of the various curves are close to each other, but it is seen that the highest inflection point value is for the $15 \mathrm{wt} \% \mathrm{LCP}$ blend and the lowest is for the $30 \mathrm{wt} \%$ blend (see Table 4-2). Also, the low part of each curve becomes lower with the increase of LCP weight fraction from $15 \%$ to $30 \%$. However, the upper part of the curve becomes higher with the increase of LCP weight fraction. Figure 4-3B and Table 4-2 show that the highest inflection point value is for the $70 \mathrm{wt} \% \mathrm{LCP}$ blend and the lowest is for the $40 \mathrm{wt} \%$ blend. Both the upper and lower parts of the curve become lower with the increase of LCP weight fraction from $40 \%$ to $70 \%$. The lower (upper) parts relate to the miscible (immiscible) blend, because the blend $T_{\mathrm{g}} \mathrm{s}$ decreased (increased). (We shall discuss this phenomenon later in conjunction with Figure 4-4.)

The phase behavior of the blend leads to the above variations in blend $T_{\mathrm{g}} \mathrm{s}$. On the other hand, these variations can help us to determine the phase transition points according to the $T_{\mathrm{g}}$ criterion. If the blend has a LCST, the inflection point value for the blend $T_{\mathrm{g}}$ curves should decrease as the concentration of LCP initially increases. After reaching a certain LCP concentration, the inflection points should increase with increasing LCP concentration. In fact, this is the behavior depicted in Figure 4-3. The inflection points decrease from $15 \%$ to $30 \%$ and then increase from $40 \%$ to $70 \%$.

Table 4-2 Summary of Calculated Transition Temperatures for LCP/PC Blend

\begin{tabular}{|c|c|c|c|c|c|c|c|c|}
\hline $\mathrm{wt} \%$ LCP & 15 & 20 & 25 & 30 & 40 & 50 & 60 & 70 \\
\hline $\begin{array}{c}\text { Temperature } \\
\left({ }^{\circ} \mathrm{C}\right)\end{array}$ & 317.7 & 316.5 & 316.2 & 312.4 & 314.6 & 319.0 & 325.0 & 329.4 \\
\hline
\end{tabular}


It is well known that a miscible blend shows a single $T_{\mathrm{g}}$ intermediate between those of the pure components in isolation [9, 34]. An immiscible blend will generally exhibit two separate $T_{\mathrm{g}} \mathrm{s}$. In the present case, especially because a wholly aromatic LCP is one of the blend components, the $T_{\mathrm{g}}$ shifts slightly toward that of the LCP suggesting miscibility, whereas $T_{\mathrm{g}}$ of the PC phase increases suggesting generally immiscibility [2628]. However, LCP is a highly crystalline polymer. It is difficult to observe the $T_{\mathrm{g}}$ of LCP in the blend, because of the absence of disordered LCP chains in the blend. Therefore, the $T_{\mathrm{g}} \mathrm{s}$ obtained and discussed here are $T_{\mathrm{g}} \mathrm{s}$ of the LCP/PC blend.

In order to obtain the two-phase transition temperatures in the blends, a nonlinear Sigmoid 4 parameter regression, Equation (3-1) discussed in section 3.4.4, was employed. This provides a good fit of the DSC experimental data points. In order to measure how well this regression model describes the data, the correlation coefficient, $R^{2}$, was determined. $R^{2}$ value near 1 indicates that the equation provides a good fit. For the present DSC data, $R^{2}$ equals 0.989 .

The inflection point of the fitting curve is considered as the two-phase transition temperature, because the second derivative at this point is equal to zero. This point represents the temperature for the change from miscible to immiscible blend behavior. For instance, the two-phase transition temperature for $25 \mathrm{wt} \% \mathrm{LCP}$ can be obtained by setting the second derivative of Equation (3-1) equal zero, all parameters were calculated as follows: $a=11.17, b=4.36, x_{0}=316.2, y_{0}=141.4$. Thus, the phase transition temperature for $25 \mathrm{wt} \%$ LCP blend is $316.2^{\circ} \mathrm{C}$. This value is located in the range $315-$ $320^{\circ} \mathrm{C}$, as discussed previously. A summary of the calculated two-phase transition temperatures is given in Table 4-2.

The variability of $T_{\mathrm{g}}$ for immiscible LCP/PC blends has been the subject of other studies [25-28]. So far, the reason for the increase of $T_{\mathrm{g}}$ is not fully understood. It has been suggested that transesterification is one of the factors $[25,28]$. However, the variation of free volume behavior during thermally induced phase separation could be the major cause of the fluctuating $T_{\mathrm{g}}$ of the PC-rich phase [25]. This is because of the increase of the interfaces between PC and LCP at higher processing melt temperature, which is in accordance with the consideration that the blends are immiscible. As for 
miscible blends, the decrease of the interfaces between PC and LCP strengthens the solubility of each isolated component.

In order to further evaluate the $T_{\mathrm{g}}$ behavior of these blends, the $T_{\mathrm{g}} \mathrm{s}$ of the blends were plotted as a function of LCP weight fraction. In Figure 4-4, the square points and the diamond points represent, respectively, the inflection point $T_{\mathrm{g}}$ values and the values indicated by the lower parts of the curves shown in Figure 4-3. The inflection point $T_{\mathrm{g}} \mathrm{s}$ are constant, which means that the blends undergo phase separation and appear predominantly immiscible. These $T_{\mathrm{g}}$ values are similar to the $T_{\mathrm{g}}$ of the pure PC's. Meanwhile the lower line $T_{\mathrm{g}}$ values decrease about $8 \mathrm{~K}$ with the increase of LCP weight fraction by 0.7 . This phenomenon reflects the typical phase behavior of partially miscible blends, indicated by the shift of $T_{\mathrm{g}}$ slightly toward that of LCP, with increasing LCP concentration. (See discussion above where the lower (upper) of the curves in Figure 4-3 indicate miscible (immisible) blends.)

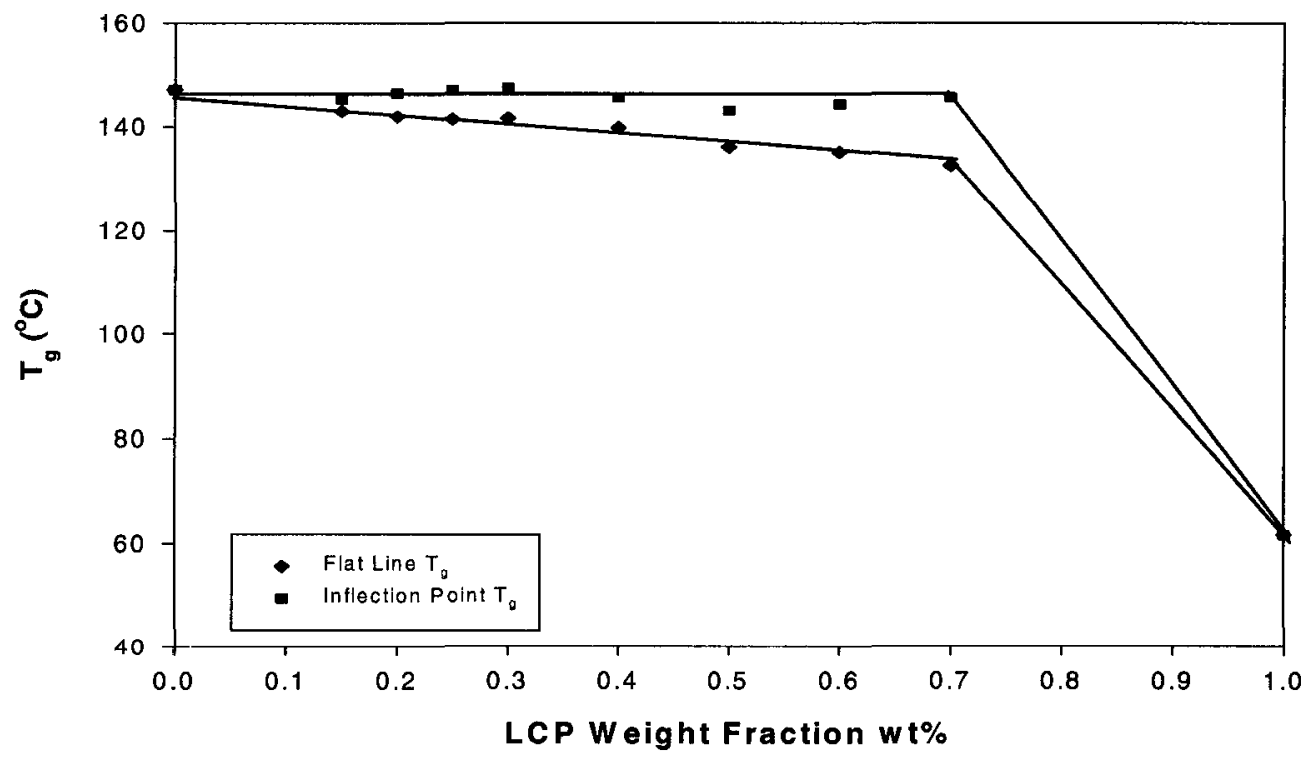

Figure 4-4: $\mathrm{LCP} / \mathrm{PC}$ Blend $T_{\mathrm{g}}$ values as a function of LCP weight fraction. 


\subsubsection{LCP Volume Fraction Phase Diagram}

The volume fraction is a typical variable used in thermodynamics to characterize multiphase polymer blends. It can be applied to many basic thermodynamic concepts and theories of composite materials and phase transformations. The volume fraction defines the fraction of the volume filled with particles. For a specimen of total volume $V_{T}$, the volume fraction $\left(V_{V}\right)_{\alpha}$ of $\alpha$ particles is defined as:

$$
\left(V_{V}\right)_{\alpha}=\sum_{i=1}^{N} \frac{\left(V_{i}\right)_{\alpha}}{V_{T}}
$$

where this summation is over all $N$ particles in the volume of the specimen, $V_{T}$. The volume of $\alpha$ particle is given as:

$$
\left(V_{i}\right)_{\alpha}=\frac{m_{i}}{\rho_{i}}
$$

where $m_{i}$ is the mass and $\rho_{i}$ is the density of $\alpha$ particle, respectively. For example, the volume fraction of $1 \mathrm{~g} 15 \mathrm{wt} \% \mathrm{LCP} / \mathrm{PC}$ blend can be calculated as follow:

LCP volume $V_{1}=\frac{m_{L C P}}{\rho_{L C P}}=\frac{1 \times 15 \%}{1.38}=0.1087 \mathrm{~cm}^{3}$

PC volume $V_{2}=\frac{m_{P C}}{\rho_{P C}}=\frac{1 \times(1-15 \%)}{1.20}=0.7083 \mathrm{~cm}^{3}$

LCP volume fraction $\left(V_{V}\right)_{L C P}=\frac{V_{1}}{V_{1}+V_{2}}=13.3 \%$

A summary of the studied LCP weight fraction converted to volume fractions is given in Table 4-3.

Table 4-3: Summary of LCP Weight Fraction Converting to Volume Fraction

\begin{tabular}{|c|c|c|c|c|c|c|c|c|}
\hline $\begin{array}{c}\text { wt } \% \\
\text { LCP }\end{array}$ & 15 & 20 & 25 & 30 & 40 & 50 & 60 & 70 \\
\hline $\begin{array}{l}\text { Vol\% } \\
\text { LCP }\end{array}$ & 13.3 & 17.9 & 22.5 & 27.1 & 36.7 & 46.5 & 56.6 & 67.0 \\
\hline
\end{tabular}


The thermodynamic phase diagram for the LCP/PC blend (Figure 4-5) was obtained by combining the results of all experimental techniques, such as TSE, DSC and SEM. The diagram contains all experimental data points involved, including the reproducibility experiments.

The phase diagram is established on the transition temperature $T$ versus the volume fraction $\phi$ of one component at constant pressure $p$. This diagram usually gives information about the types of phases that can exist and/or coexist with other phases formed by components of the system. As can be seen in Figure 4-5 (note that there are two overlapping points at $22.5 \mathrm{vol} \%$ ), the blend system has a lower critical solution temperature (LCST). As discussed in section 2.3.1, two phases are formed. One is twophase droplet-type morphology and the other is homogeneous single-phase morphology. The morphology of this blend will be discussed in the next section.

The diagram obtained in this work is similar to that of Kyu and Zhuang (Figure 27) [19]. In their case, they obtained the diagram via solvent casting. Figure 2-7 shows the curve to be concave upwards with a minimum at the 50/50 (weight\%) concentration. The critical point is at $170^{\circ} \mathrm{C}$, lower than the melting point of their PHB-PET material $\left(T_{\mathrm{m}}=\right.$ $190^{\circ} \mathrm{C}$ ) [19]. In our case, the diagram was obtained via twin screw extrusion. It has the critical point at the $30 / 70$ (weight) LCP composition and at the temperature of $312.4^{\circ} \mathrm{C}$, also lower than the melting temperature $\left(T_{\mathrm{m}}=325^{\circ} \mathrm{C}\right)$ of our PHB-PET polymer (Table 31). This temperature is much higher than the $T_{\mathrm{g}}$ of pure $\mathrm{PC}$, which is $147.6^{\circ} \mathrm{C}$. Therefore, the segmental motion of the blend is sufficient to cause phase separation, even though the melting point of LCP is not reached. In addition, the position of the critical point is dependent on the degrees of polymerization $\left(N_{1}, N_{2}\right)$ of both components [8]. When $N_{1}>$ $N_{2}$, the critical point shifts to the left of the diagram. When $N_{1}=N_{2}$, the critical point is at the center. When $N_{1}<N_{2}$, it shifts to the right of the diagram. Finally, in spite of substantial effects, we could not find the transition temperature at $10 \mathrm{wt} \% \mathrm{LCP}$ concentration, as Kyu and Zhuang [19] did. This is mainly because of the complex phase behavior of the blend near the limiting conditions at low LCP concentration. 


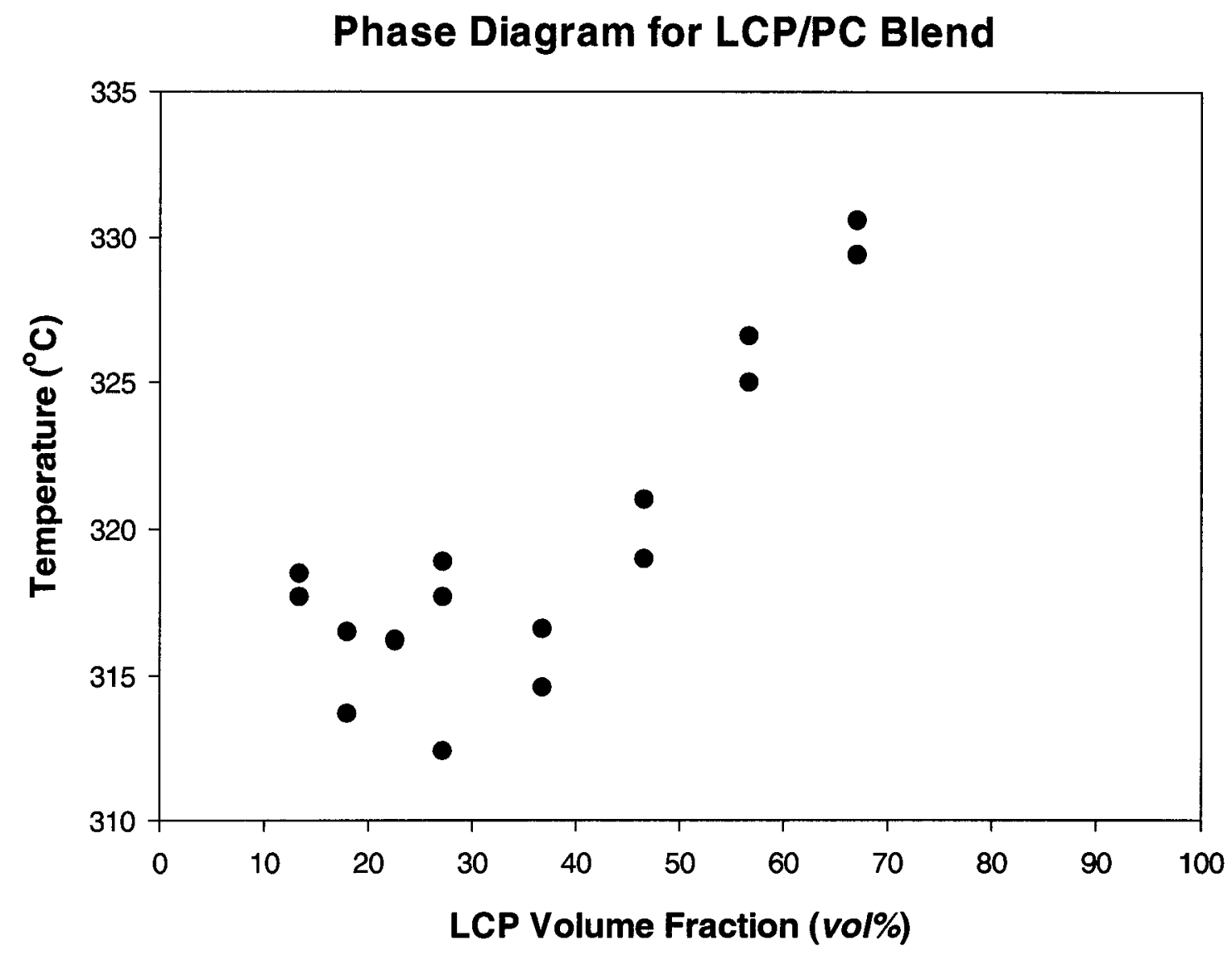

Figure 4-5: Phase Diagram for LCP/PC blend. 


\subsubsection{Morphology}

In this section, we discuss the morphology of the blend in terms of the SEM and PLM results.

Both sides of the curve (Figure 4-5) for each LCP concentration (15\%-70\%) were investigated by SEM. The SEM results have confirmed those of DSC and characterized them in visible phase morphology. Figure 4-6 shows the SEM photomicrographs of fractured surfaces of extruded strands for the $30 \mathrm{wt} \% \mathrm{LCP}$ blend. Several observations can be made from Figure 4-6. Firstly, two types of morphology are observed. From (A) to (D), the blends show a homogenous co-continuous phase; while from (E) to (G), the blends have a dispersed droplets two-phase morphology. This phenomenon has already been discussed in section 3.3.2.3. Secondly, the LCP/PC blend undergoes thermally induced phase separation, because it transforms from a homogenous single-phase (Figure 4-6A-D) to a dispersed droplets two-phase (Figure 4-6E-G), as the blend goes from the lowest processing melt temperature $\left(290^{\circ} \mathrm{C}\right)$ to the highest temperature $\left(350^{\circ} \mathrm{C}\right)$. Phase separation seems to occur via spinodal decomposition, because the droplet size and shape are uniform visually. (We shall present the evidence of the droplet size distribution later in section 4.4.) The photomicrographs provide a clear visualization of the phase separation mechanism of the blend. Thirdly, the SEM microphotographs provide visible morphological evidence in support of the results of the DSC thermal analysis. As discussed in section 4.2.1, the blend $T_{\mathrm{g}}$ decreased slightly at the processing melt temperature $305^{\circ} \mathrm{C}$ (Figure 4-6D), reflecting a miscible blend. When the processing melt temperature increased to $315^{\circ} \mathrm{C}$, the blend $T_{\mathrm{g}}$ increased and phase separation occurred (see Table 4-1 and Figure 4-6E). This confirms that the phase transition temperature is between $305^{\circ} \mathrm{C}$ and $315^{\circ} \mathrm{C}$. In addition, the higher is the processing melt temperature, the smaller is the droplet size obtained. Recall that in section 2.3.1, the droplet size is dependent on the rate of heating or cooling and the rate of diffusion, viscosity, and chemical potential of both components. According to the Cahn-Hilliard Equation (2-9) and the Flory-Huggins Equation (2-13), the predicted wavelength at an initial

concentration $\phi_{0}$ is a function of temperature, $\lambda_{m} \propto T^{-\frac{1}{2}}$. Normally, $d_{m} \propto \lambda_{m} / 2$, therefore 


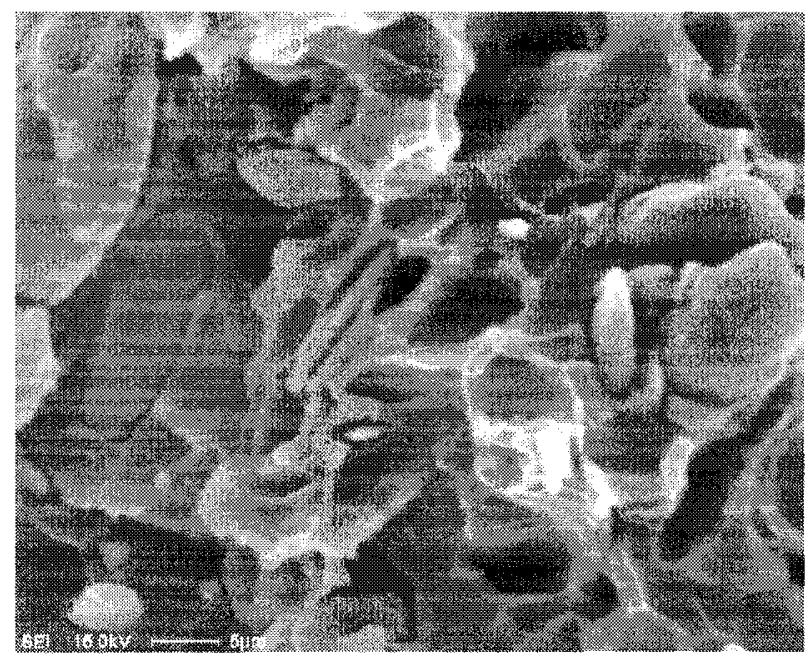

(A)

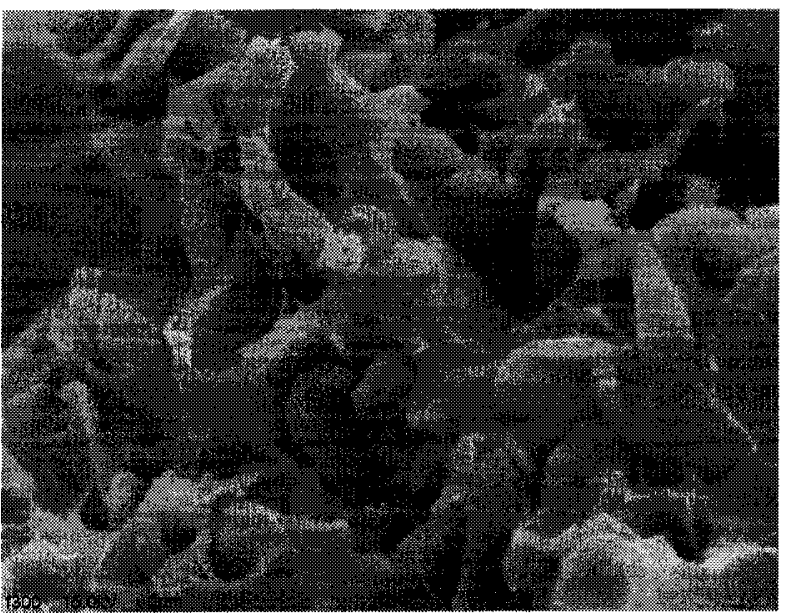

(C)

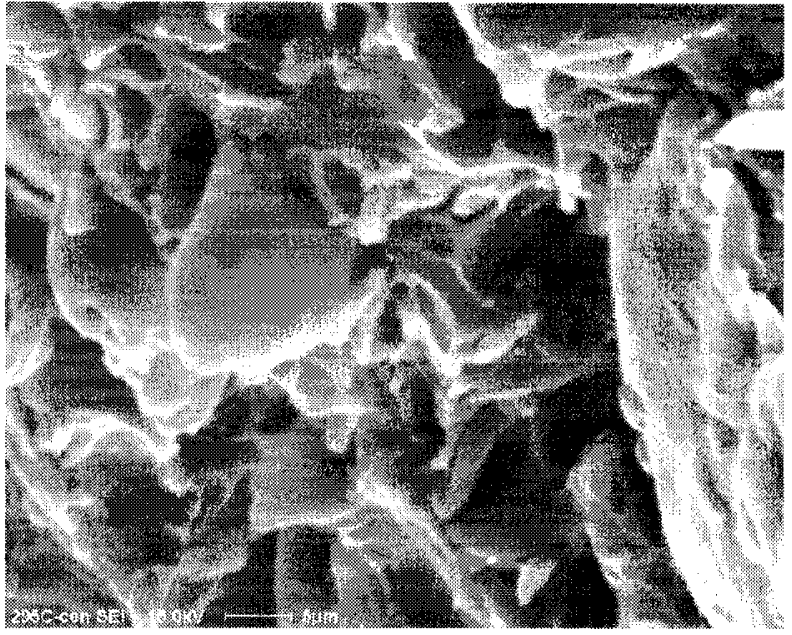

(B)

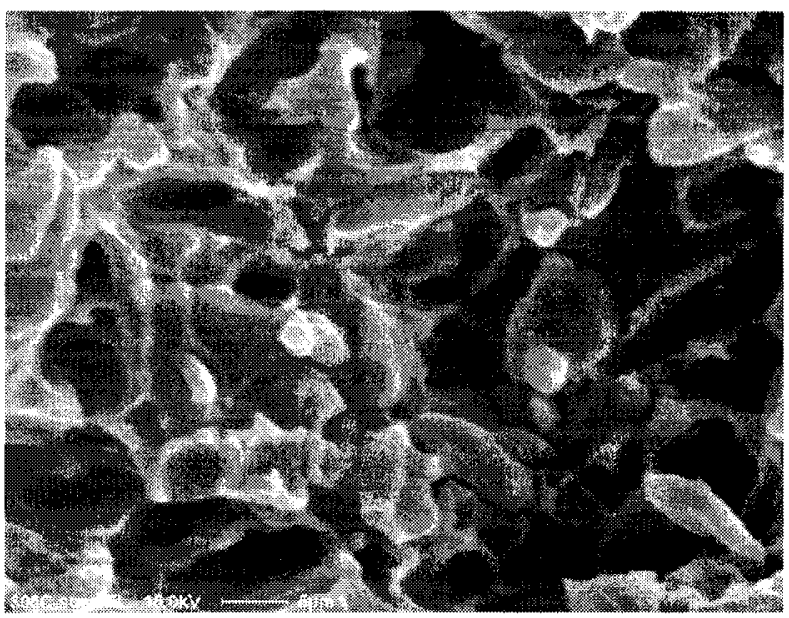

(D)

$5 \mu \mathrm{m}$

Figure 4-6: SEM micrographs of the fractured surfaces of $30 \mathrm{wt} \% \mathrm{LCP}$ blend extruded in twin screw extrusion at (A) $T_{\mathrm{pm}}=290^{\circ} \mathrm{C}$, (B) $T_{\mathrm{pm}}=295^{\circ} \mathrm{C}$, (C) $T_{\mathrm{pm}}=300^{\circ} \mathrm{C}$, (D) $T_{\mathrm{pm}}=$ $305^{\circ} \mathrm{C}$ (magnification $\times 2000$ ). 


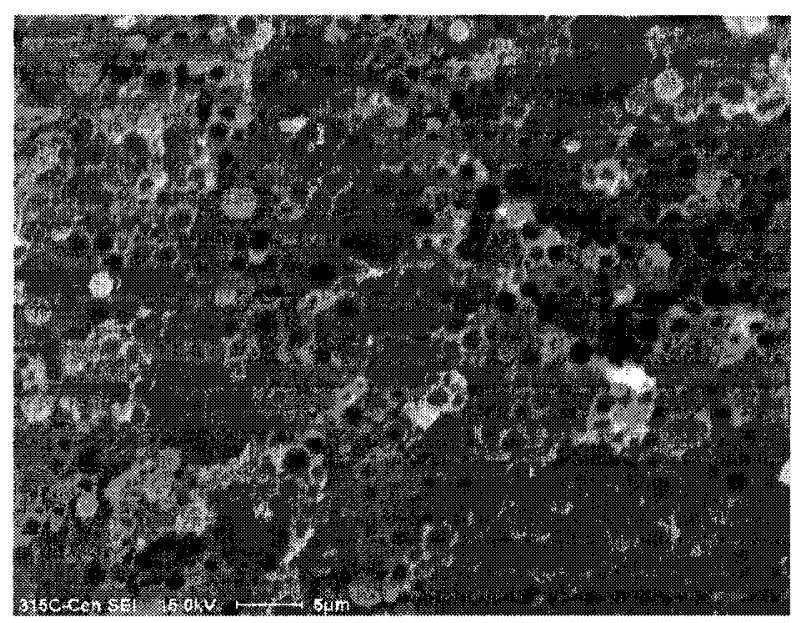

(E)

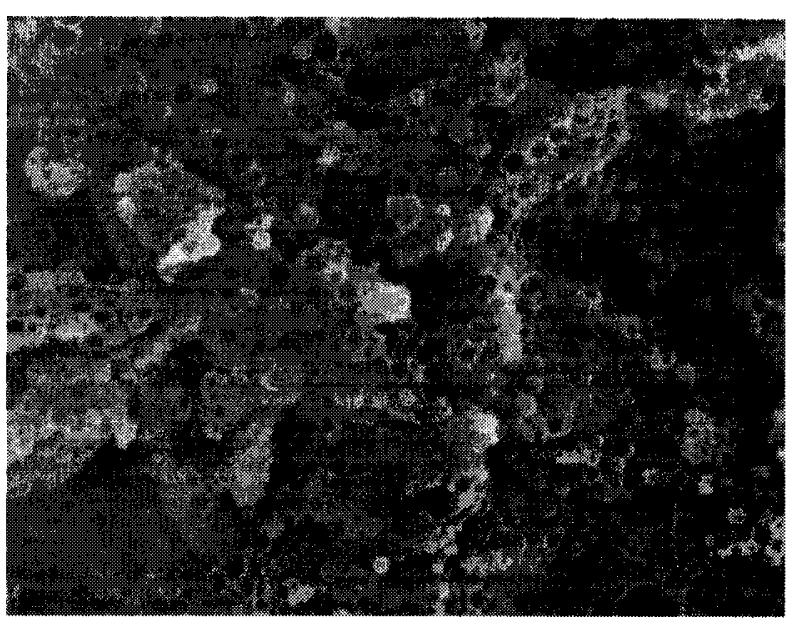

(F)

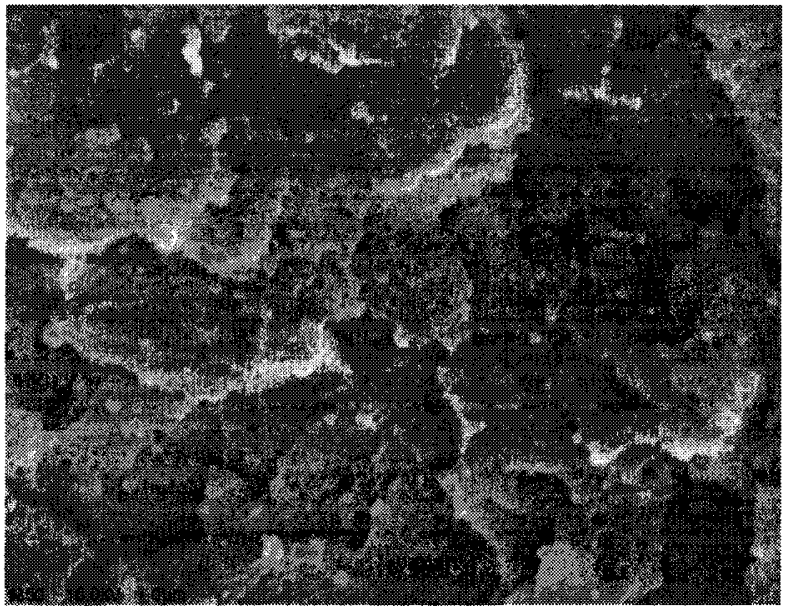

(G)

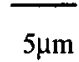

Figure 4-6 (continued): SEM micrographs of the fractured surfaces of $30 \mathrm{wt} \% \mathrm{LCP}$ blend extruded in twin screw extrusion at (E) $T_{\mathrm{pm}}=315^{\circ} \mathrm{C}$, (F) $T_{\mathrm{pm}}=325^{\circ} \mathrm{C}$, (G) $T_{\mathrm{pm}}=350^{\circ} \mathrm{C}$ (magnification $\times 2000)$. 
the droplet size (diameter) is expected to decrease with an increase in temperature. This point will be discussed again later in section 4.4.

Another direct analysis of the blend morphology is possible with polarized light microscopy (PLM). In order to study the melt phase behavior of the LCP/PC blend, \#2 specimens (Table 3-4) were microtomed in $5 \mu \mathrm{m}$ thickness by using different heating and cooling rates using the PLM hot-stage. Figure 4-7 shows PLM micrographs of these specimens. At room temperature, as Figure 4-7A and D show, LCP has very tiny droplets because $30 \mathrm{wt} \% \mathrm{LCP}$ is the minor phase in the blend. In addition, the droplets are fairly well distributed in the $\mathrm{PC}$ rich matrix phase. Figure 4-7B shows the morphology at $340^{\circ} \mathrm{C}$ (heating rate $2{ }^{\circ} \mathrm{C} / \mathrm{min}$ ), LCP droplets gradually disappeared. When it was heated to $347^{\circ} \mathrm{C}$ (see Figure 4-7C), LCP droplets disappeared completely and there was no change in morphology when cooled down to room temperature. Another sample was used (Figure 4-7D) to repeat the same experiment but the heating rate was changed to 5 ${ }^{\circ} \mathrm{C} / \mathrm{min}$. LCP droplets gradually disappeared at around $360^{\circ} \mathrm{C}$ (Figure 4-7E), after that the droplets disappeared. It seems that LCP droplets will not appear again. In order to fully understand the phenomenon, a third experiment was run using $1{ }^{\circ} \mathrm{C} / \mathrm{min}$ heating and cooling rates. Figure 4-8 shows PLM micrographs of \#2 specimens (Table 3-4) microtomed in $5 \mu \mathrm{m}$ thickness. Initially, the specimen (Figure 4-8A) was heated to $300^{\circ} \mathrm{C}$ as fast as possible (around $130{ }^{\circ} \mathrm{C} / \mathrm{min}$ ) and held for $2 \mathrm{~min}$ at $300^{\circ} \mathrm{C}$. When the temperature reached $180^{\circ} \mathrm{C}$, the sample began to melt (Figure 4-8B). From $300^{\circ} \mathrm{C}$ to $350^{\circ} \mathrm{C}$, the sample was heated using $1{ }^{\circ} \mathrm{C} / \mathrm{min}$ heating rate, the droplets disappeared completely at $333^{\circ} \mathrm{C}$ (Figure $4-8 \mathrm{C}$ ). Then the sample was cooled down from $350^{\circ} \mathrm{C}$ (Figure 4-8D) to ambient temperature at $1{ }^{\circ} \mathrm{C} / \mathrm{min}$, but the LCP droplets did not appear again.

From Figures 4-7 and 4-8, it seems that the results of PLM contradict the DSC and SEM results. There is a major reason for this apparent behavior. The resolution of $\operatorname{SEM}(10 \mathrm{~nm})$ is much higher than that of PLM $(0.2 \mu \mathrm{m})$ [3], which is merely sufficient to study very immiscible blend phase systems. This means that the PLM could not show the droplet as the blend was heated. 


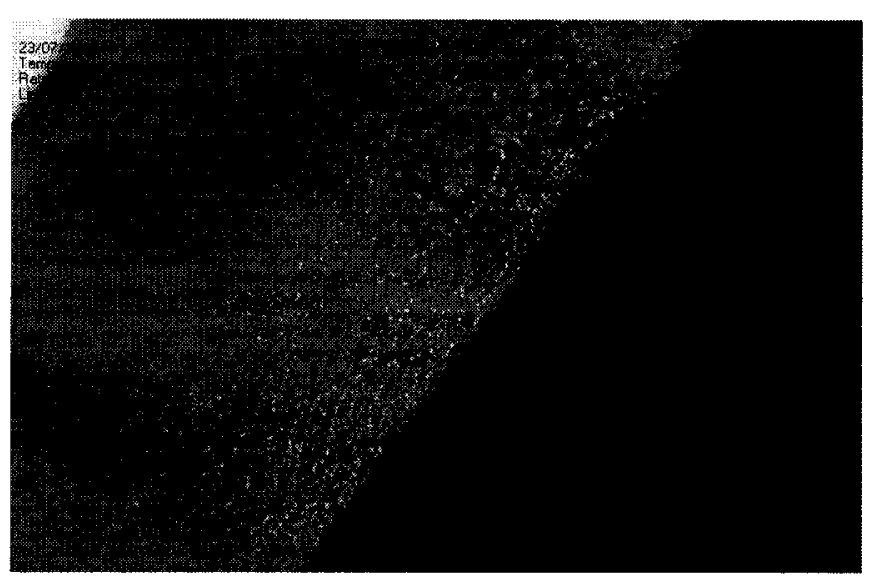

(A)

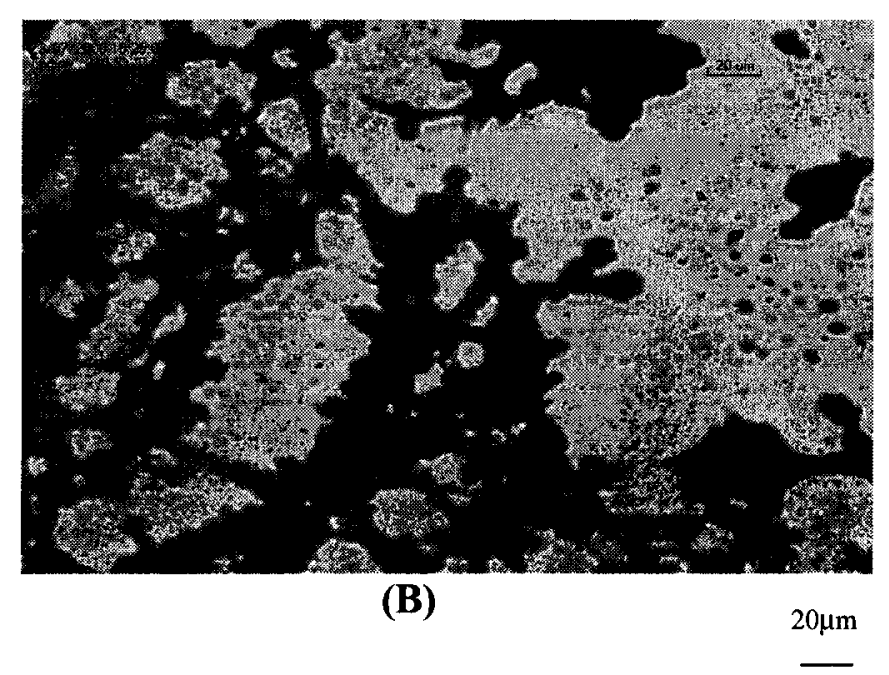

Figure 4-7: PLM micrographs of the $30 \mathrm{wt} \% \mathrm{LCP} / \mathrm{PC}$ blend in $5 \mu \mathrm{m}$ thickness at: (A) room temperature, (B) $340^{\circ} \mathrm{C}$ (heating rate $2{ }^{\circ} \mathrm{C} / \mathrm{min}$ ) (magnification: $\times 20$ ). 


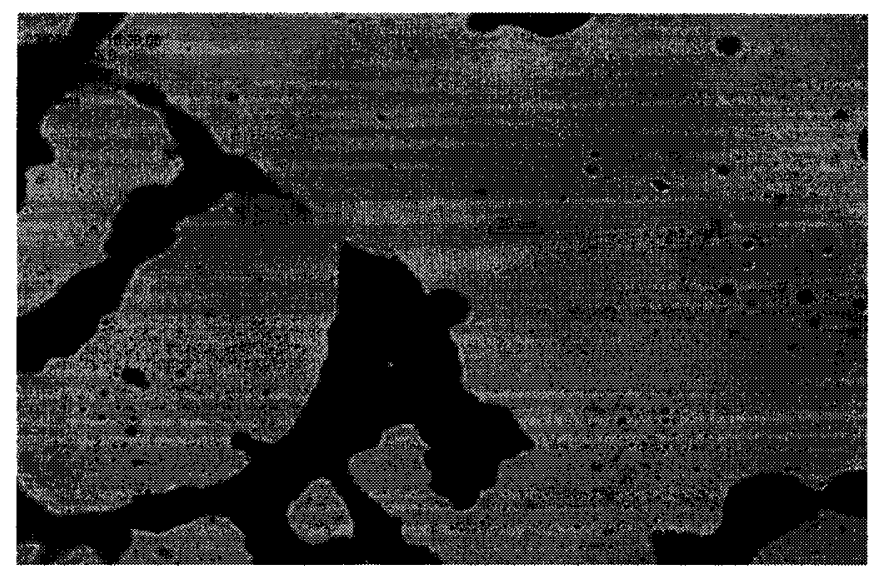

(C)

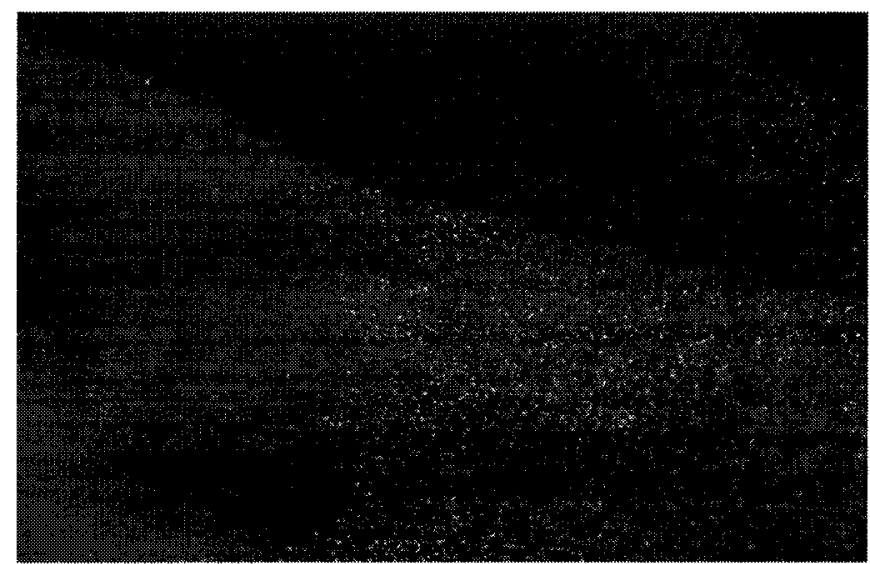

(D)

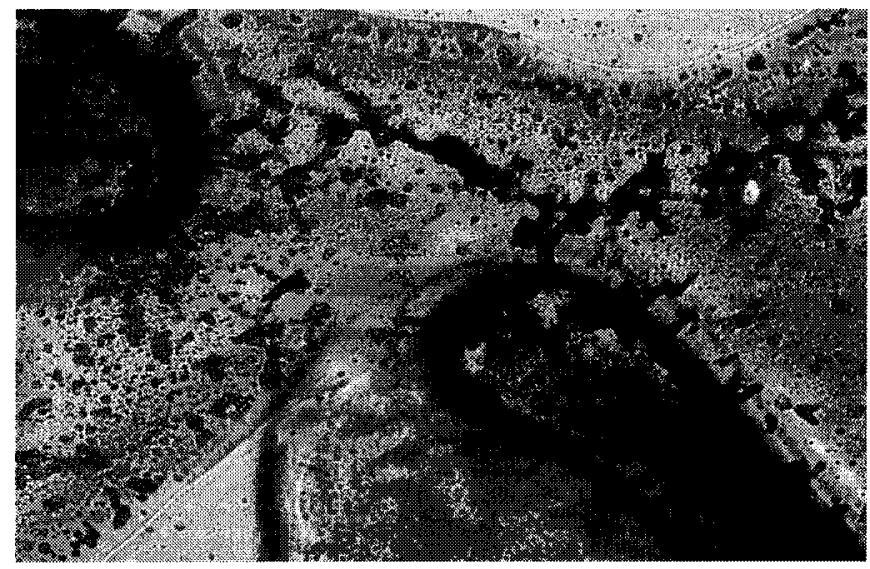

(E)

$20 \mu \mathrm{m}$

Figure 4-7: (continued) PLM micrographs of the $30 \mathrm{wt} \% \mathrm{LCP} / \mathrm{PC}$ blend in $5 \mu \mathrm{m}$ thickness at: (C) $347^{\circ} \mathrm{C}$ (heating rate $2{ }^{\circ} \mathrm{C} / \mathrm{min}$ ), (D) room temperature, and (E) $360^{\circ} \mathrm{C}$ (heating rate $5^{\circ} \mathrm{C} / \mathrm{min}$ ) (magnification: $\times 20$ ). 


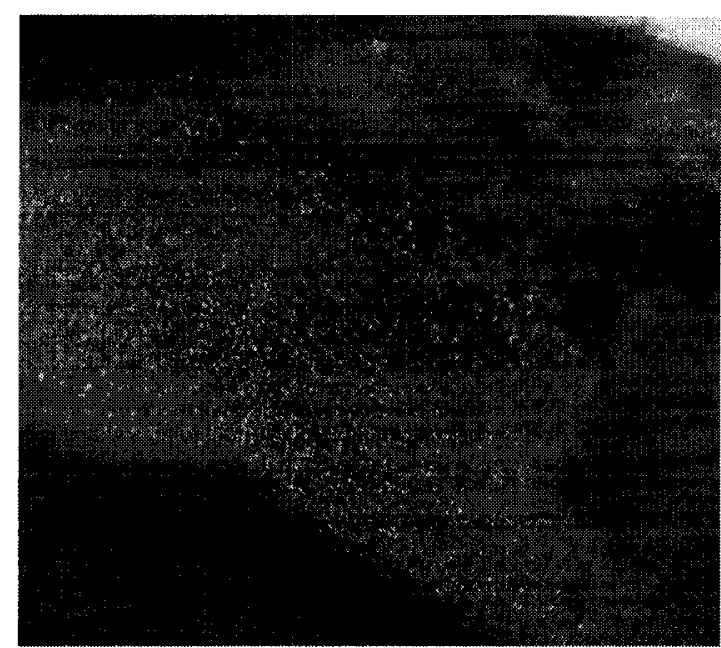

(A)

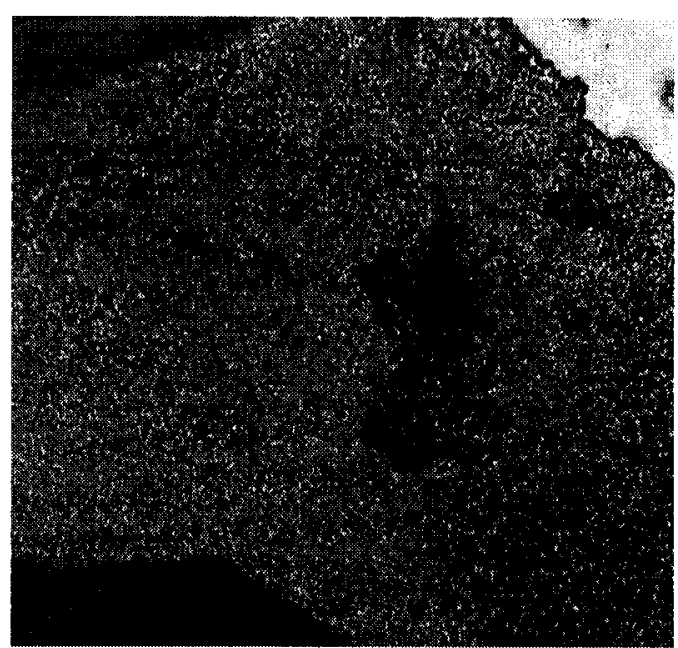

(B)

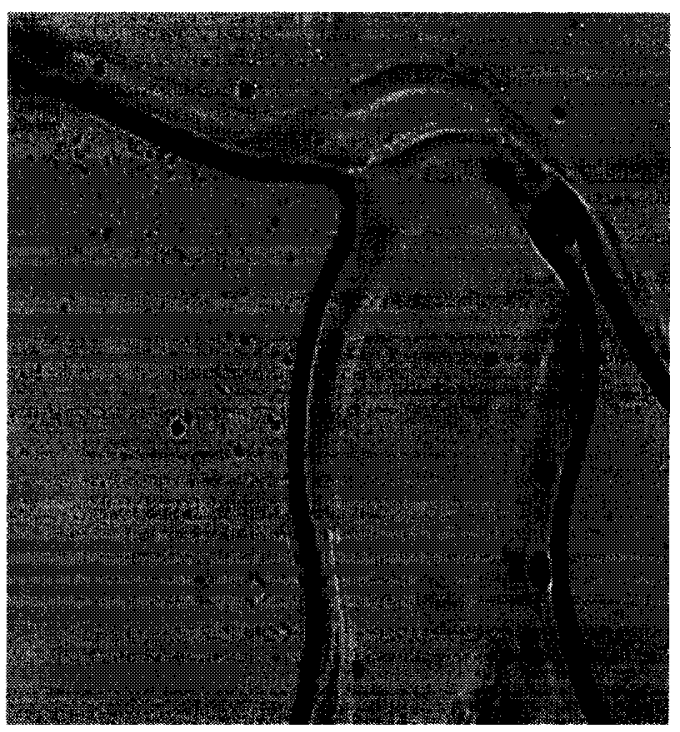

(C)

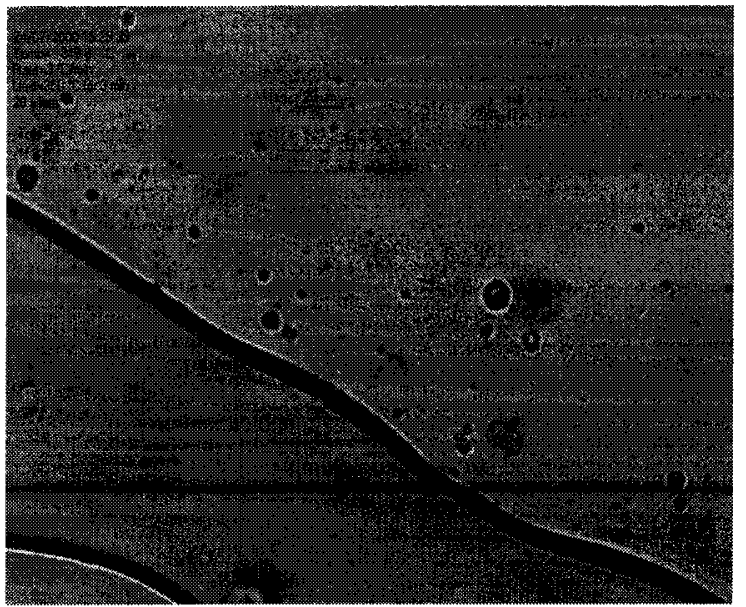

(D)

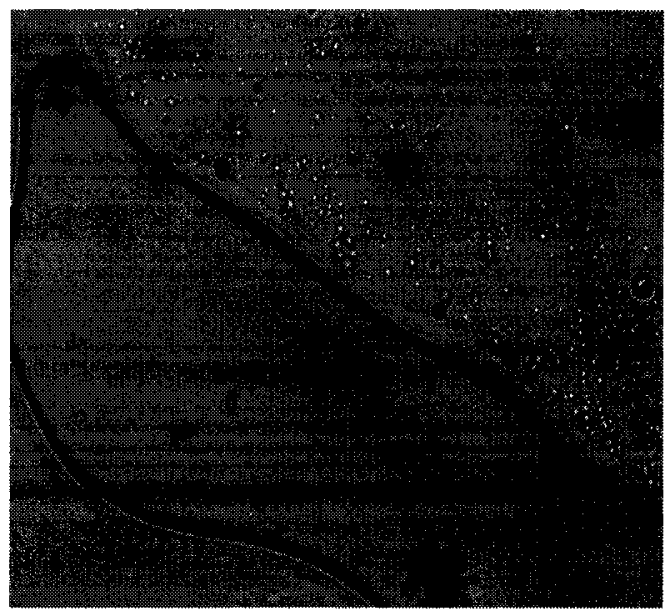

(E)

Figure 4-8: PLM micrographs of $30 \mathrm{wt} \% \mathrm{LCP} / \mathrm{PC}$ blend in $5 \mu \mathrm{m}$ specimen thickness with $1{ }^{\circ} \mathrm{C} /$ min heating and cooling rate at: (A) room temperature, (B) $180^{\circ} \mathrm{C}$, (C) $333^{\circ} \mathrm{C}$, (D) $350^{\circ} \mathrm{C}$, (E) $147^{\circ} \mathrm{C}$ (magnification: $\times 20$ ). 


\subsubsection{Influence of Shear Rate on Phase Morphology}

In explaining the morphology observed for the LCP/PC blend extruded by twinscrew extrusion, recall that phase separation via spinodal decomposition (SD) may be induced by shear, stress or pressure. In the present work, we assume that there is very little pressure change in the twin-screw extruder, so pressure effects were ignored. Figures 4-9 and 4-10 show fractured surfaces of $30 \mathrm{wt} \% \mathrm{LCP}$ blend extruded at $T_{\mathrm{pm}}=$ $300^{\circ} \mathrm{C}$ and $50 \mathrm{wt} \%$ LCP extruded at $T_{\mathrm{pm}}=310^{\circ} \mathrm{C}$ with different screw speeds. As can be seen, the morphologies are almost the same. Thus, it appears that the shear rate does not influence phase separation at these two concentrations. 


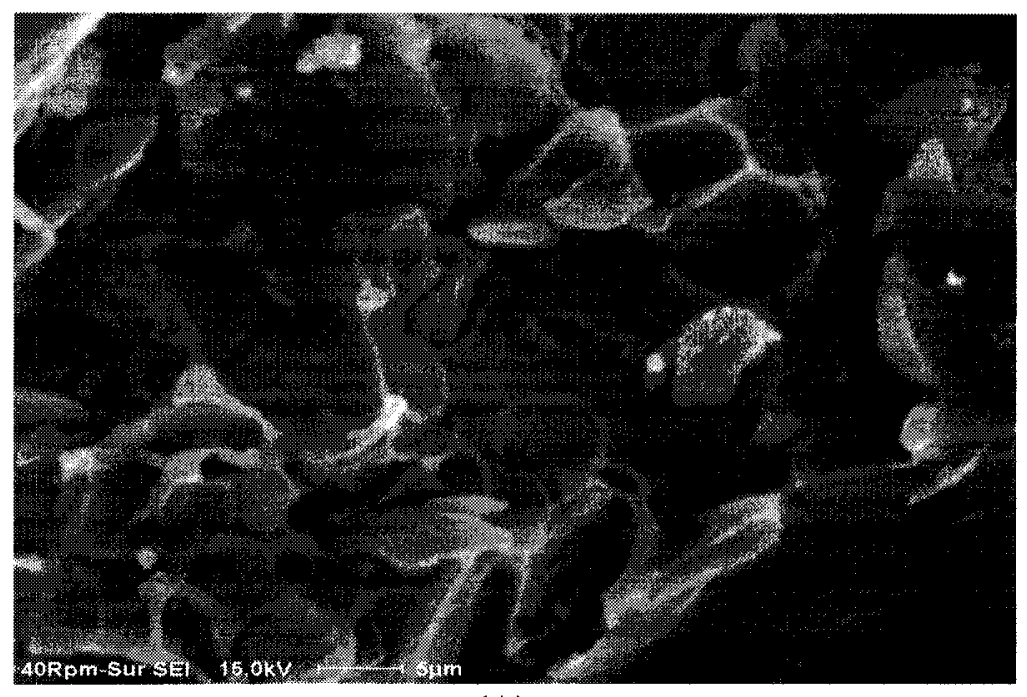

(A)

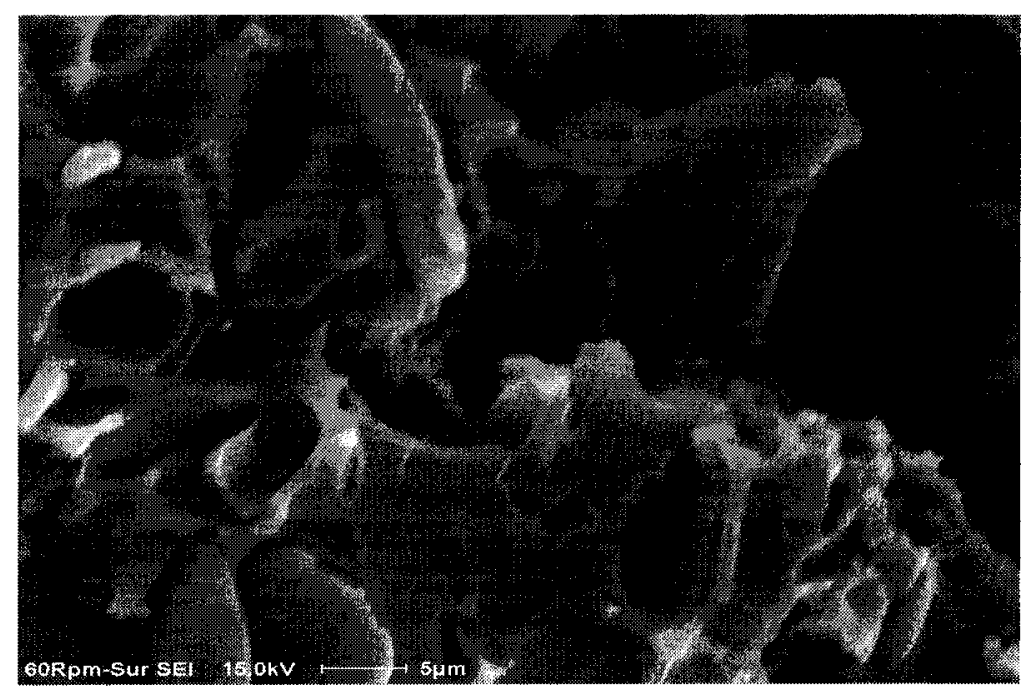

(B)

Figure 4-9: SEM micrograph of fractured surfaces of $30 \mathrm{wt} \% \mathrm{LCP}$ blend extruded at $T_{\mathrm{pm}}$ $=300^{\circ} \mathrm{C}$ with different screw speed, (A) $40 \mathrm{rpm}$, (B) $60 \mathrm{rpm}$ (magnification $\times 2000$ ). 


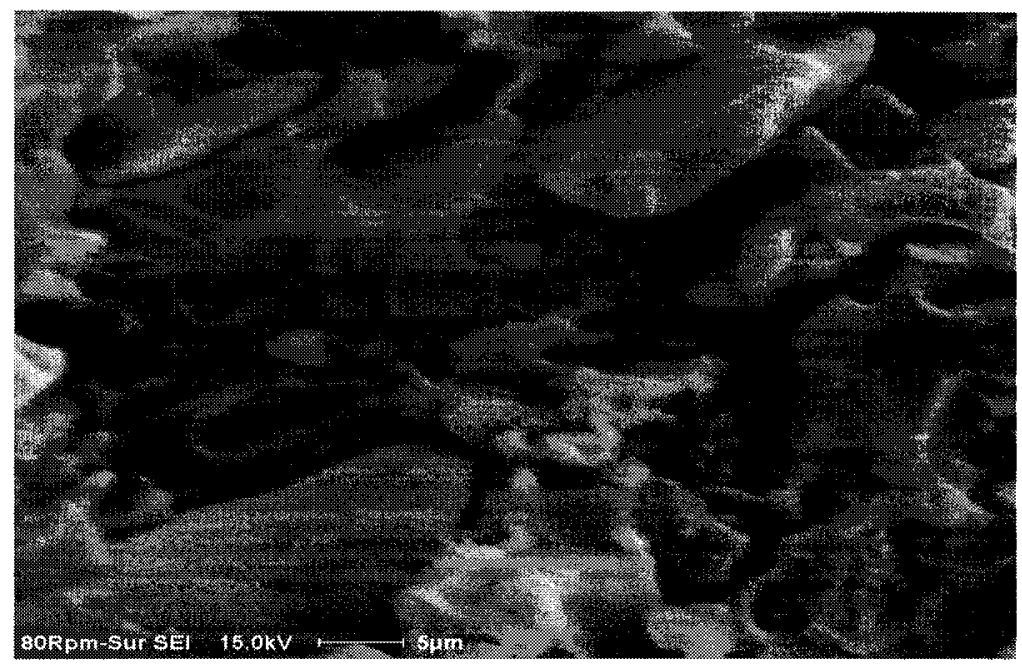

(C)

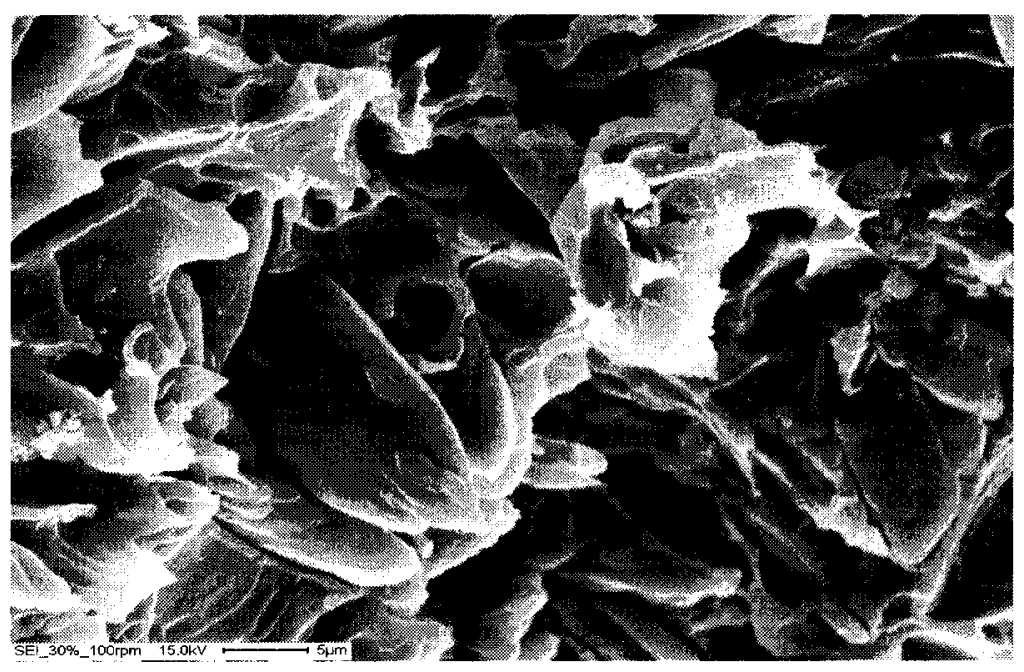

(D)

Figure 4-9: (continued) SEM micrograph of fractured surfaces of $30 \mathrm{wt} \%$ LCP blend extruded at $\mathrm{T}_{\mathrm{pm}}=300^{\circ} \mathrm{C}$ with different screw speed, (C) $80 \mathrm{rpm}$, (D) $100 \mathrm{rpm}$ (magnification $\times 2000$ ). 


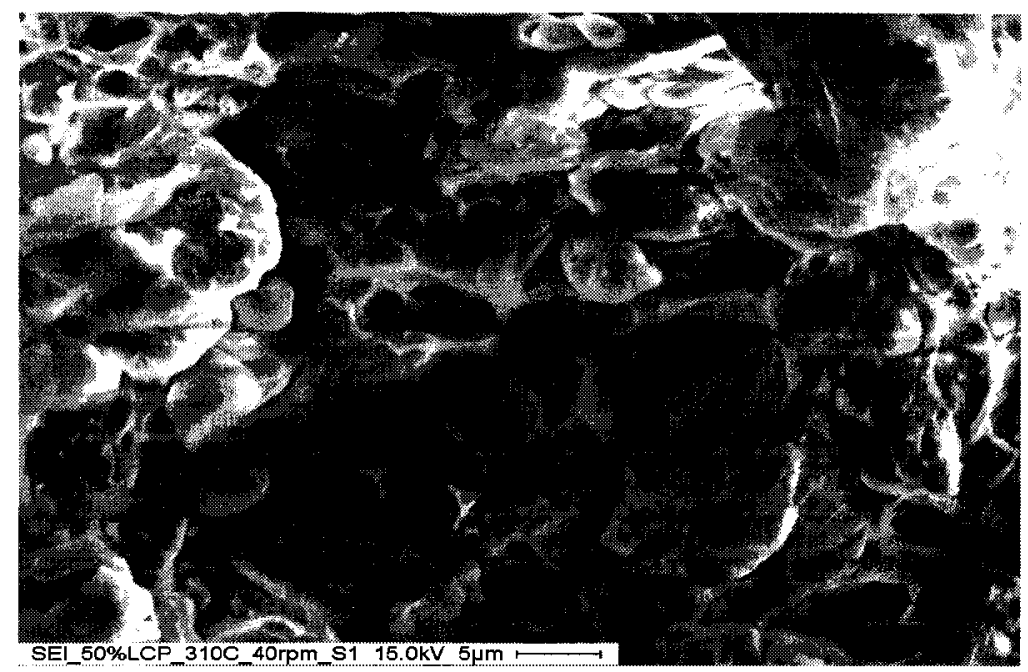

(A)

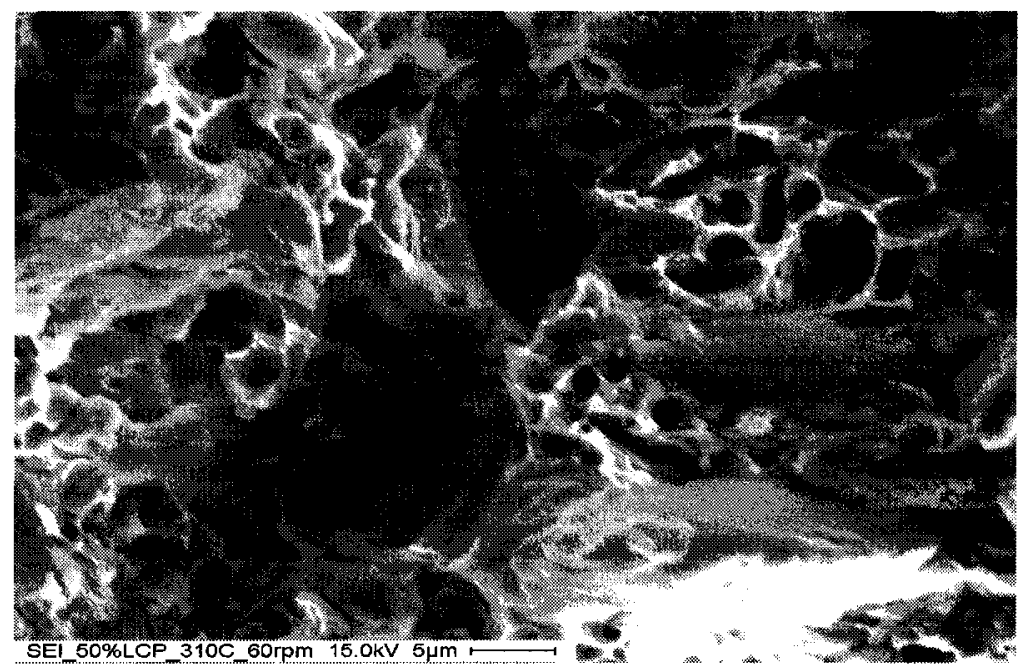

(B)

Figure 4-10: SEM micrograph of fractured surfaces of $50 \mathrm{wt} \% \mathrm{LCP}$ blend extruded at $\mathrm{T}_{\mathrm{pm}}=310^{\circ} \mathrm{C}$ with different screw speed, (A) $40 \mathrm{rpm}$, (B) $60 \mathrm{rpm}$ (magnification $\times 2000$ ). 


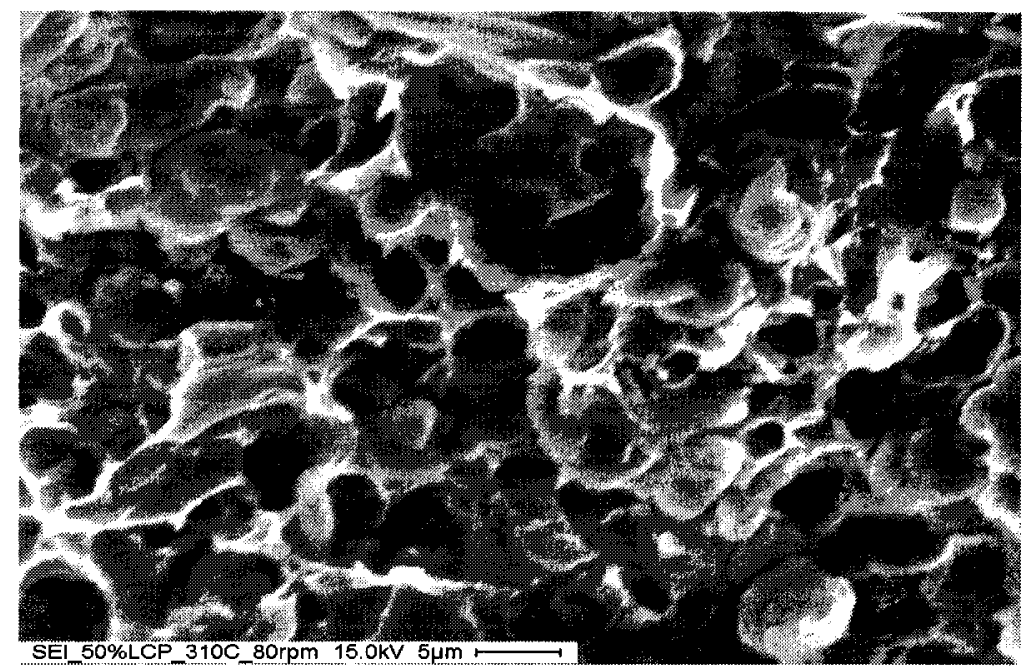

(C)

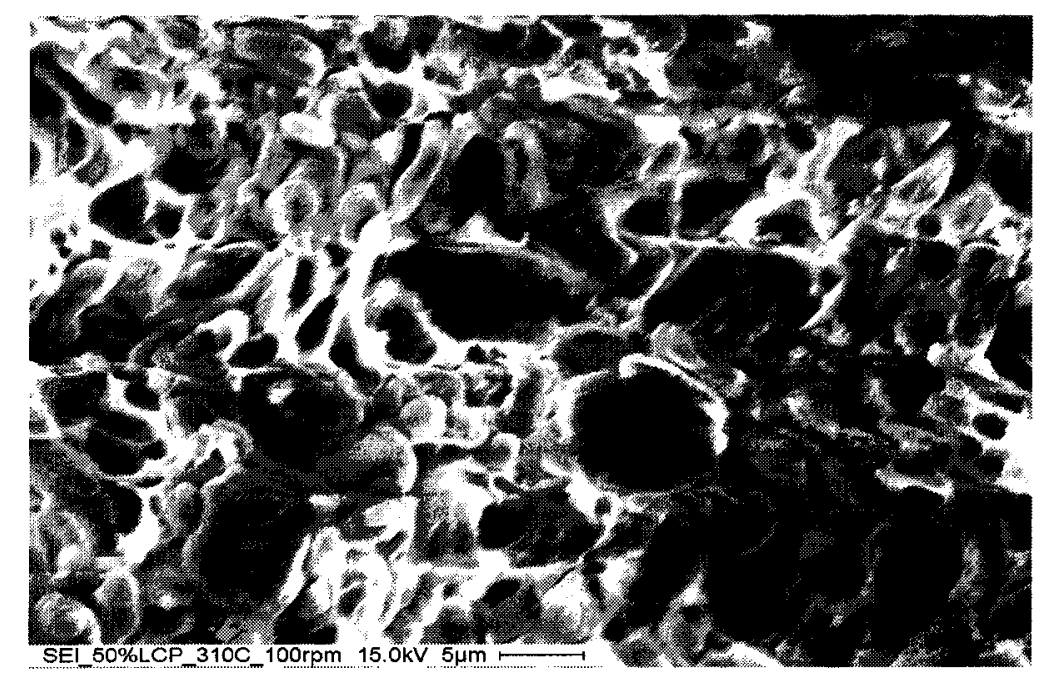

(D)

Figure 4-10: (continued) SEM micrograph of fractured surfaces of $50 \mathrm{wt} \%$ LCP blend extruded at $\mathrm{T}_{\mathrm{pm}}=310^{\circ} \mathrm{C}$ with different screw speed, (C) $80 \mathrm{rpm}$, (D) $100 \mathrm{rpm}$ (magnification $\times 2000$ ). 


\subsubsection{Error Estimation for the Phase Diagram}

As shown in Figure 4-5, many experiments were repeated. All experimental data are plotted in this figure. Some LCP concentrations show small deviations, which others show higher deviation. The largest discrepancy occurred in the $27.1 \mathrm{vol} \%$ LCP

concentration. There are three major reasons causing errors in determining the phase diagram.

1. It is difficult to precisely control the processing melt temperature in the twin screw extruder, the melt temperature recorded was not the real value near the exit of the die. Usually there is around $\pm 5^{\circ} \mathrm{C}$ difference. This factor causes temperature error ( $\mathrm{Y}$-axis error bar) in the phase diagram.

2. The calibration curve for the twin screw extruder feeders is not constant. Therefore, the blend weight ratio (LCP/PC) could vary from the estimated value. This may cause LCP volume fraction error (X-axis error bar) in the phase diagram.

3. The final results (phase diagram) involve many experimental steps, such as sample preparation and thermal analysis. Significant cumulation errors could result in the final phase diagram.

The phase diagram with error bars is shown in Figure 4-11. The dots represent the average value at each concentration. A quadratic curve was fitted to these points. 


\section{Phase Diagram for LCP/PC Blend}

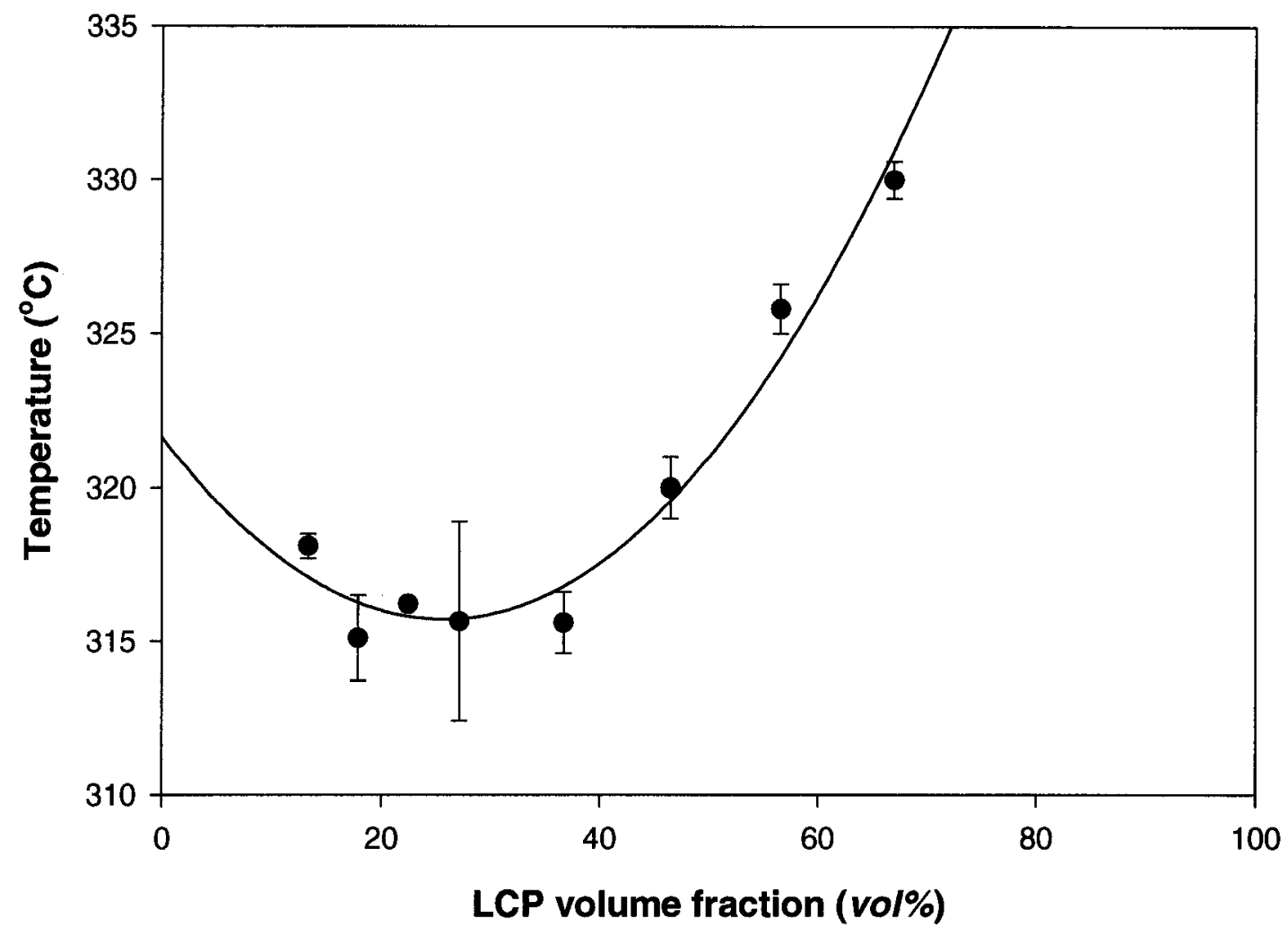

Figure 4-11: Phase diagram for LCP/PC blend prepared by twin screw extrusion, determined by DSC thermal analysis and calculation. The solid line is a quadratic fitting curve for the experimental data. The dots are the experimental data with error bars.

\subsection{Flory-Huggins Theory Phase Diagram for LCP/PC Blend}

As mentioned in Section 2.4.2, the Flory-Huggins $(\mathrm{F}-\mathrm{H})$ free energy equation has been quite successful in phase equilibrium studies $[8,14]$. Based on the condition that the second derivative of Equation (2-13) with respect to volume fraction equals zero, the $\chi$ - $\phi$ relationship equation can be expressed as,

$$
\phi_{1}^{2}+\left(\frac{N_{1}-N_{2}}{2 N_{1} N_{2} \chi}-1\right) \phi_{1}+\frac{1}{2 N_{1} \chi}=0
$$


where $N_{1}, N_{2}$ are the degrees of polymerization of components 1 and 2 , respectively, $\phi_{1}$ is the volume fraction of component 1 and $\chi$ is the polymer-polymer interaction parameter. Equation (4-3) can be expressed in another form,

$$
\chi=\frac{1}{2 N_{1} \phi}+\frac{1}{2 N_{2}(1-\phi)}
$$

The degree of polymerization $N$ can be calculated by,

$$
N=M_{n} / M_{\text {o }}
$$

where $M_{\mathrm{n}}$ is the number average molar mass of the polymer and $M_{\mathrm{o}}$ is the corresponding structural unit molar mass of this polymer. In this work, LCP and PC are components 1 and 2, respectively. In Table 3-1, $M_{\mathrm{n} 1}=10,365 \mathrm{~g} / \mathrm{mol}, M_{01}=182 \mathrm{~g} / \mathrm{mol}, N_{1}=M_{\mathrm{n} 1} / M_{01}=$ $57 ; M_{\mathrm{n} 2}=24,500 \mathrm{~g} / \mathrm{mol}$ (average value), $M_{0}=254 \mathrm{~g} / \mathrm{mol}, N_{2}=96$.

The experimental $\chi$ values can be obtained by substituting the experimental volume fraction of Table 4-3 into Equation (4-4). These $\chi$ values, with their corresponding processing melt temperature $T_{\mathrm{pm}}$, are given in Table 4-4,

Table 4-4: Summary of Experimental $\chi$ Values

\begin{tabular}{|c|c|c|c|c|c|c|c|c|}
\hline $\begin{array}{c}\text { Vol\% } \\
\text { LCP }\end{array}$ & $\mathbf{1 3 . 3}$ & $\mathbf{1 7 . 9}$ & $\mathbf{2 2 . 5}$ & $\mathbf{2 7 . 1}$ & $\mathbf{3 6 . 7}$ & $\mathbf{4 6 . 5}$ & $\mathbf{5 6 . 6}$ & $\mathbf{6 7 . 0}$ \\
\hline$\chi$ & 0.0720 & 0.0553 & 0.0457 & 0.0395 & 0.0321 & 0.0286 & 0.0275 & 0.0289 \\
\hline $\mathrm{T}_{\mathrm{pm}}$ & 317.7 & 316.5 & 316.23 & 317.7 & 314.6 & 319.0 & 325.0 & 329.4 \\
$\left({ }^{\circ} \mathrm{C}\right)$ & 318.5 & 313.7 & 316.19 & 318.9 & 316.6 & 321.0 & 326.6 & 330.6 \\
& & & & 312.4 & & & & \\
\hline
\end{tabular}

As discussed in Section 2.4.2, the temperature dependence of $\mathcal{X}$ relation is given by (Equation 2-12):

$$
\chi(T)=a+\frac{b}{T}
$$


The experimental $\mathcal{X}$ values are plotted as a function of reciprocal $T_{\mathrm{pm}}$ shown in Figure 4-12. The best linear fit for Equation (2-12) was used. This fitting also needs to have a good agreement with the phase diagram given by Equation (4-3). However, because of the wide scatter of these data, it is not possible at this time to confirm the general validity. Consequently, the fitting equation is not a perfect one and is given by:

$$
\chi(T)=1.025-\frac{583}{T}
$$

At the critical point, the volume fraction $\phi_{c}$ and interaction parameter $\chi_{c}$ are calculated by Equations (2-14 and 2-15),

$$
\phi_{c}=0.566 ; \chi_{\mathrm{c}}=0.0275 \text {. }
$$

From Equation (4-6), the $\chi$ values were recalculated by scanning the temperatures from $584 \mathrm{~K}$ to $608 \mathrm{~K}\left(311^{\circ} \mathrm{C}-335^{\circ} \mathrm{C}\right)$ with a step $0.05 \mathrm{~K}$. Then these $\chi$ values were substituted into Equation (4-3) to calculate the volume fractions $\phi$ of component 1 . In order to compare the theoretical and experimental phase diagrams, these calculated volume fractions were plotted in a $T-\phi$ phase diagram as shown in Figure 4-13. The curve appears concave with a minimum at $56.6 \mathrm{vol} \% \mathrm{LCP}$ concentration at $311.4^{\circ} \mathrm{C}$, while the experimental curve (Figure 4-11) has a minimum at the $27.1 \mathrm{vol} \%$ LCP concentration at $312.4^{\circ} \mathrm{C}$. The two curves have almost the same critical temperature but different critical concentrations $\phi_{c}$. The simulated curve is shifted to the right. As mentioned in section 4.2.2, when $N_{1}<N_{2}$, the curve will shift to the right of the diagram. It also should be noted that the simulated curve has a steep slope at lower LCP concentrations $(<10 \mathrm{vol} \%$ LCP). This situation brings about practical difficulties in either finding a transition temperature or controlling the errors at low LCP volume fraction ( $<10 \mathrm{vol} \% \mathrm{LCP})$. 


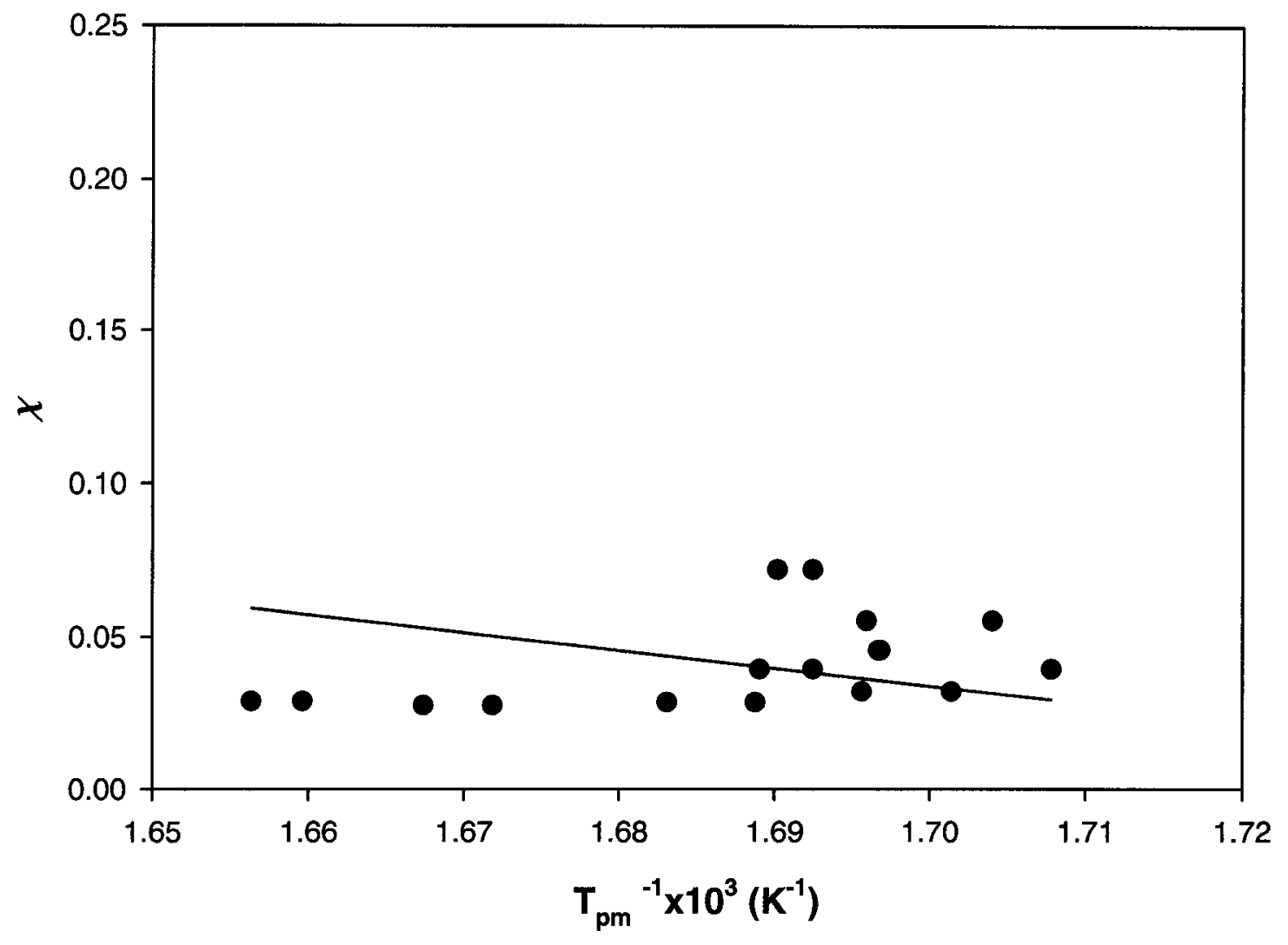

Figure 4-12: Curve fitting for experimental $\chi$ values. The solid line is given by Equation (4-6). The dots are the experimental data. 


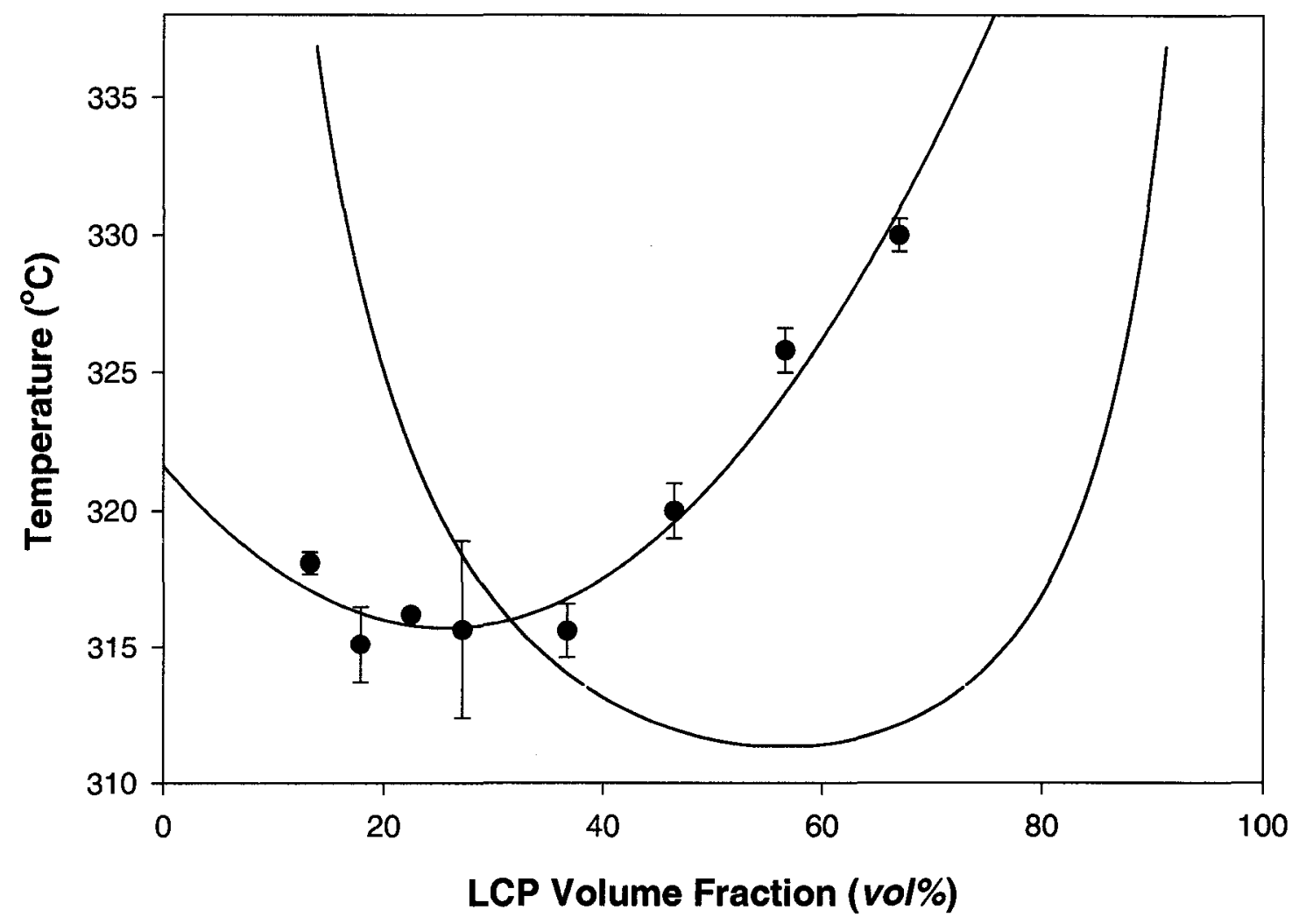

Figure 4-13: Phase diagram for LCP/PC blends. Left: the experimental phase diagram with error bars, right: simulated phase diagram derived from Flory-Huggins theory. 


\subsection{Droplet Size Distribution for LCP/PC Blend}

As discussed in section 2.4.1, the Cahn-Hilliard Equation (2-9) can be used to calculate the wavelength at an initial concentration $\phi_{0}$. Based on Equations (2-9) and (213), we can obtain the $T-\lambda_{m}$ relationship as follow,

$$
\lambda_{m}=2 \sqrt{2} \pi\left(\frac{k_{B}}{\kappa v}\right)^{-\frac{1}{2}}\left\{-\frac{T}{2}\left[\frac{1}{N_{1} \phi_{0}}+\frac{1}{N_{2}\left(1-\phi_{0}\right)}-2 \chi\right]\right\}^{-\frac{1}{2}}
$$

where $k_{B}$ is Boltzmann's constant, $v$ is the volume of a cell or segment, $\kappa$ is the gradient energy parameter, $\phi_{o}$ is the initial average concentration, $N_{1}$ and $N_{2}$ are the degree of polymerization of components 1 and 2, respectively, $\chi$ is the Flory-Huggins interaction parameter, $T$ is temperature and $\lambda_{m}$ is the wavelength.

It has been assumed that $\left(\frac{k_{B}}{\kappa \nu}\right)^{-\frac{1}{2}}$ is constant at an initial concentration $\phi_{0}$ and temperature. The dimensionless wavelength is given as:

$$
\lambda_{m}^{*}=\lambda_{m} /\left(\frac{k_{B}}{\kappa v}\right)^{-\frac{1}{2}}
$$

We selected some data in section 4.3 for calculation, $N_{1}=57, N_{2}=96, \chi \chi=1.025$ $583 / \mathrm{T}$ (Equation 4-6). In the case of $30 \mathrm{wt} \%$ LCP $\left(27.1 \mathrm{vol} \%\right.$ LCP $\left.\phi_{0}=0.271\right)$, the calculation results of $\lambda_{m}^{*}$ are given in Table 4-5.

Table 4-5: Summary of Calculated Dimensionless Wavelength for 30\% LCP Blend

\begin{tabular}{|c|c|c|c|c|}
\hline $\begin{array}{c}\text { Processing Melt } \\
\text { Temperature } \mathbf{T}_{\mathbf{p m}}\left({ }^{\circ} \mathbf{C}\right)\end{array}$ & 325 & 330 & 340 & 350 \\
\hline \hline$\lambda_{m}^{*}$ & $3.678^{*}$ & $2.697^{*}$ & $1.944^{*}$ & $1.598^{*}$ \\
\hline
\end{tabular}

In this table, the dimensionless wavelength decreases when the processing melt temperature increases. It means that at higher processing melt temperature $T_{\mathrm{pm}}$, smaller droplet size obtained. Figure 4-14 shows the SEM micrographs of 30wt\% LCP blend at 


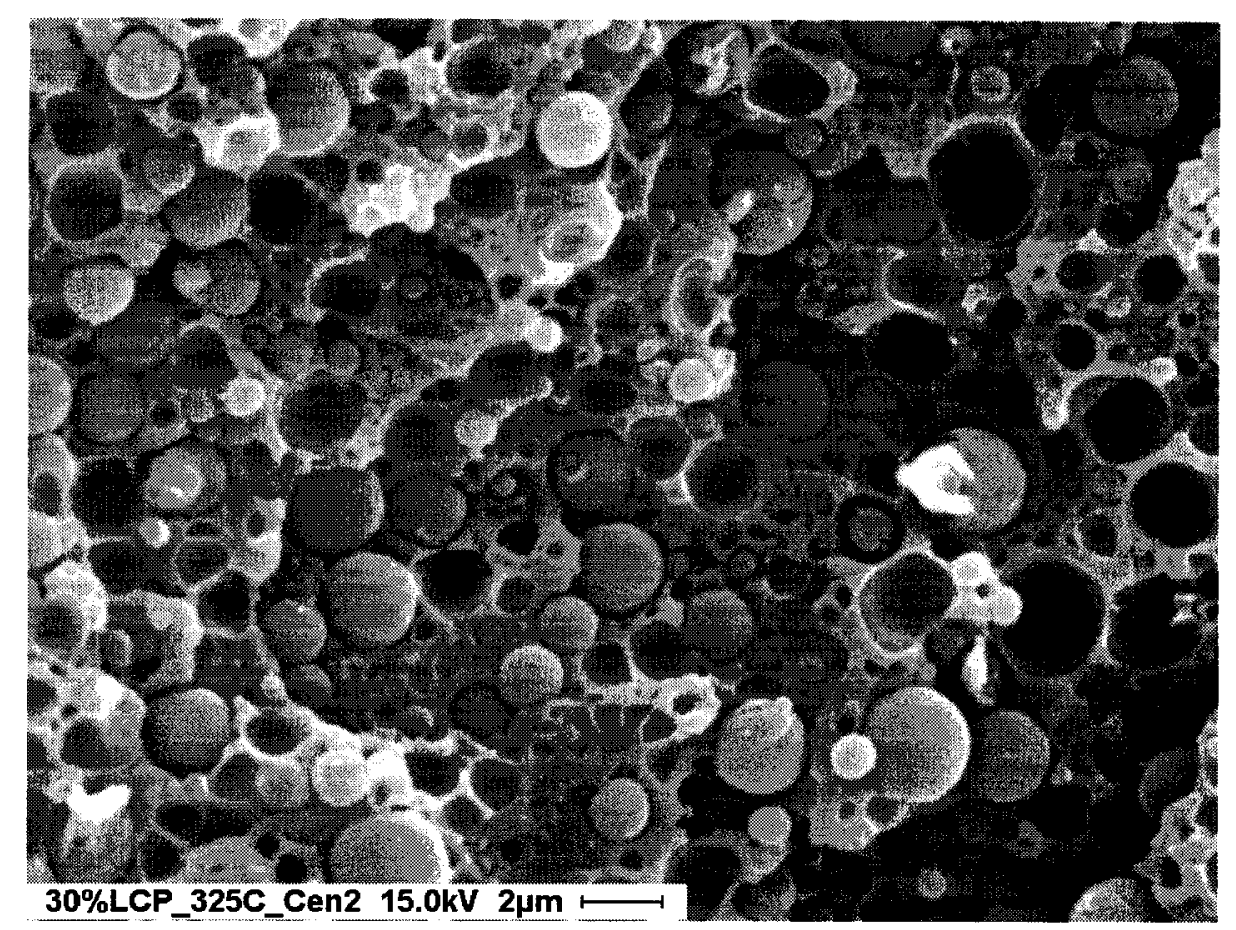

(A)

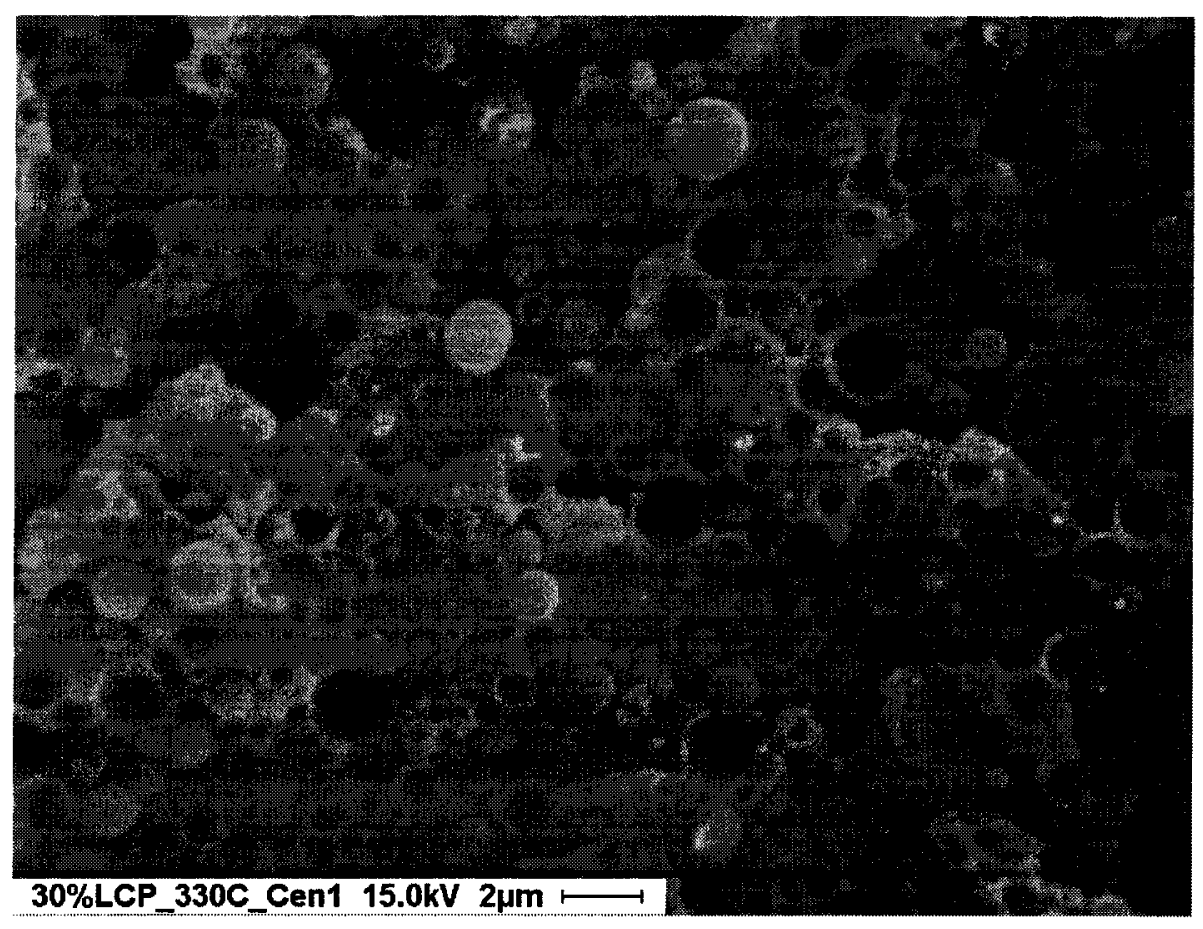

(B)

Figure 4-14: SEM micrographs of $30 \mathrm{wt} \% \mathrm{LCP}$ blend at different processing melt temperature (A) $T_{\mathrm{pm}}=325^{\circ} \mathrm{C}$, (B) $T_{\mathrm{pm}}=330^{\circ} \mathrm{C}$ (magnification $\times 4000$ ). 


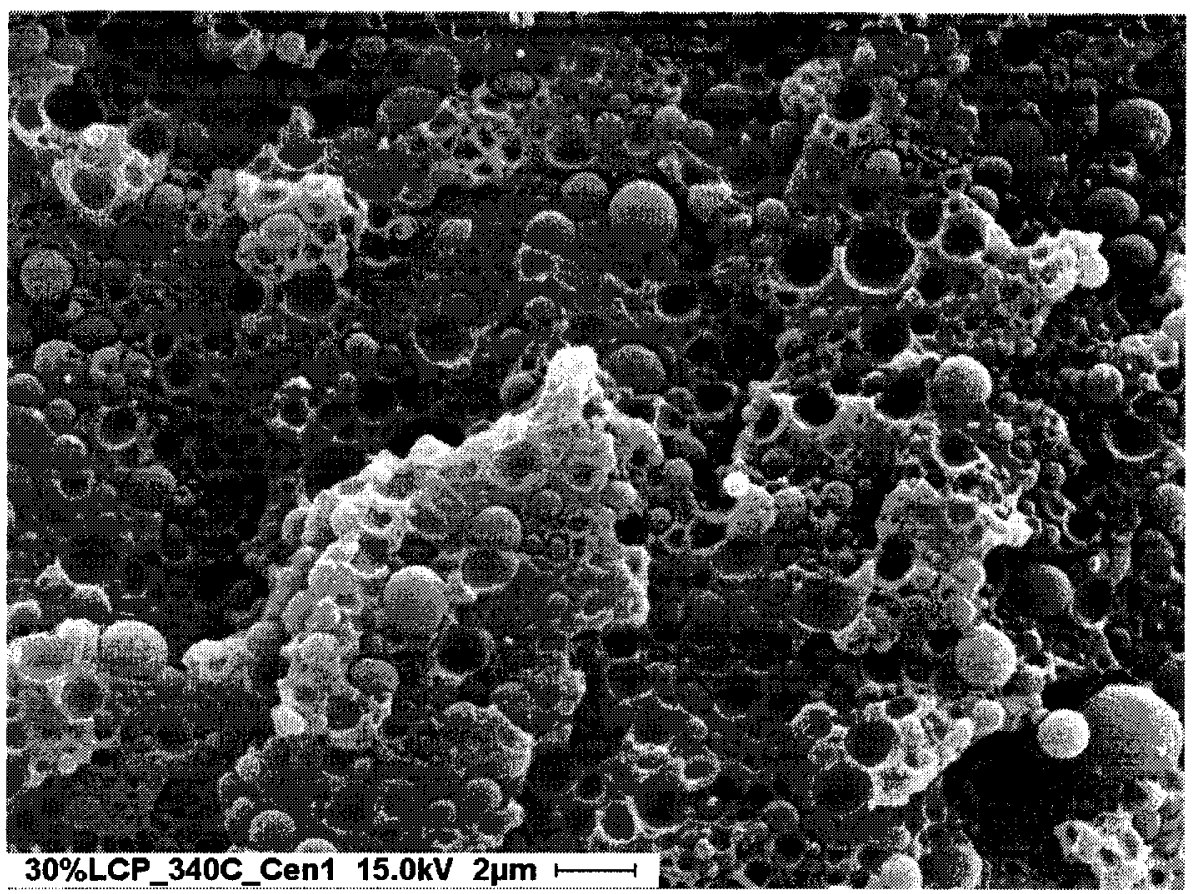

(C)

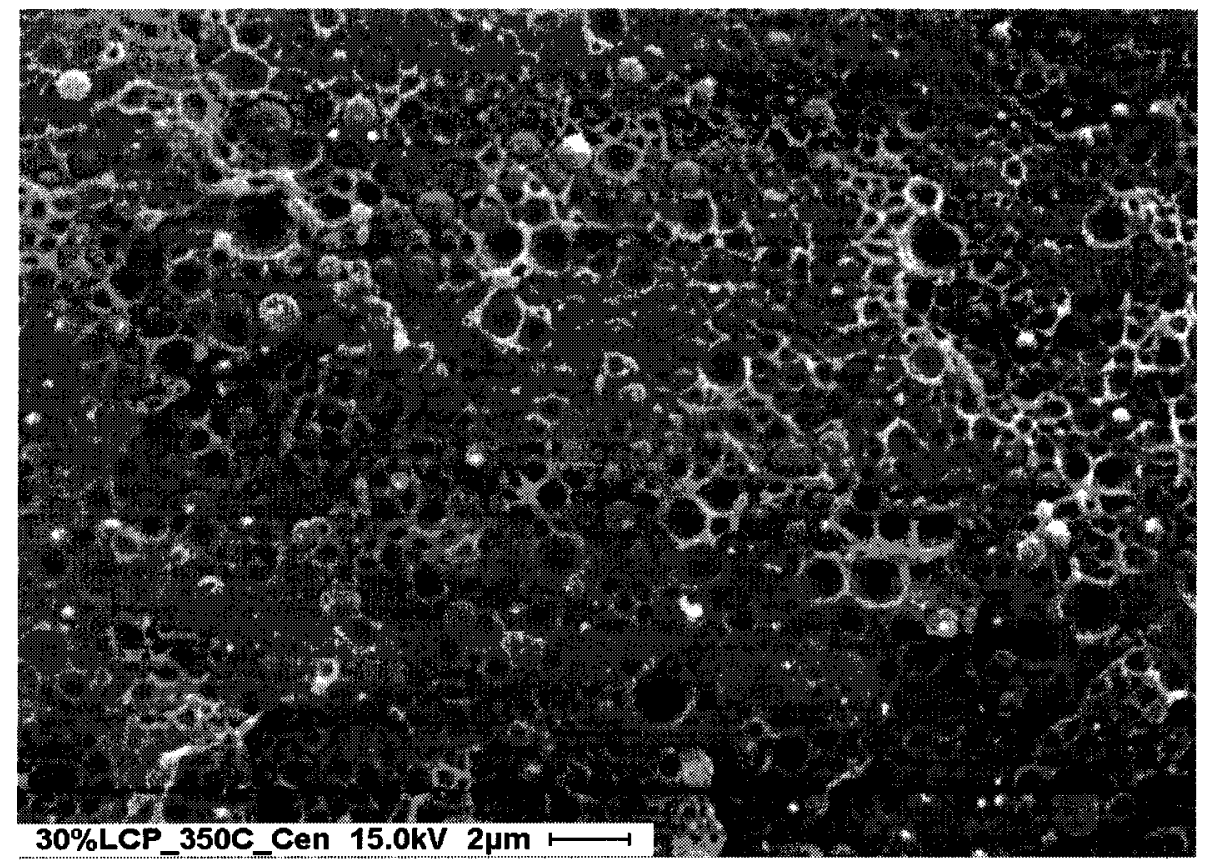

(D)

Figure 4-14 (continued): SEM micrographs of $30 \mathrm{wt} \%$ LCP blend at different processing melt temperature (C) $T_{\mathrm{pm}}=340^{\circ} \mathrm{C}$, (D) $T_{\mathrm{pm}}=350^{\circ} \mathrm{C}$ (magnification $\times 4000$ ). 
different $T_{\mathrm{pm}}$. The droplet size becomes smaller with the increase of processing melt temperature $T_{\mathrm{pm}}$, as indicated by the above analysis.

In order to quantify the above observations, the droplet size distribution of the blend was determined. The distributions can be described by a variety of averages, such as number-average and weight-average. The number-average droplet size $\langle D\rangle_{n}$ is defined by:

$$
<D>_{n}=\frac{\sum N_{i} D_{i}}{\sum N_{i}}
$$

where $N_{i}$ is the number of $i$ th particles with droplet diameter $D_{i}$. The brackets $<>$ indicate that it is an average value. The weight-average droplet size $\langle D\rangle_{w}$ is obtained by,

$$
<D>_{w}=\frac{\sum N_{i} D_{i}^{2}}{\sum N_{i} D_{i}}
$$

The breadth of the distribution can be gauged by establishing the particle distribution or polydispersity index $P D$, which can be defined as,

$$
P D=\frac{\langle D\rangle_{w}}{\langle D\rangle_{n}}
$$

As mentioned in section 3.3.2.4, the images (Figure 4-14) were analyzed manually. Figure 4-15 shows the plot of droplet size distribution of these images (Figure 4-14). A summary calculation of $\langle D\rangle_{n},\langle D\rangle_{w}$ and $P D$ for this blend is given in Table 4-6.

In Figure 4-15 A, the blend has the largest number of the smallest droplets $(\leqslant 0.27$ $\mu \mathrm{m})$ at $350^{\circ} \mathrm{C}$. However, the blend has the largest droplets $(\geqslant 3.33 \mu \mathrm{m})$ at $325^{\circ} \mathrm{C}$. Figure 4-15B is a scatter plot of droplet size distribution. The peak of each curve decreases with a decrease of temperature. This confirms that the higher temperature, the smaller droplet size.

In Table 4-6, the $P D$ values are almost the same. This suggests that there is no major difference in the breadth of the distribution. The $\langle D\rangle_{n}$ and $\langle D\rangle_{w}$ decrease when the processing melt temperatures increase. 


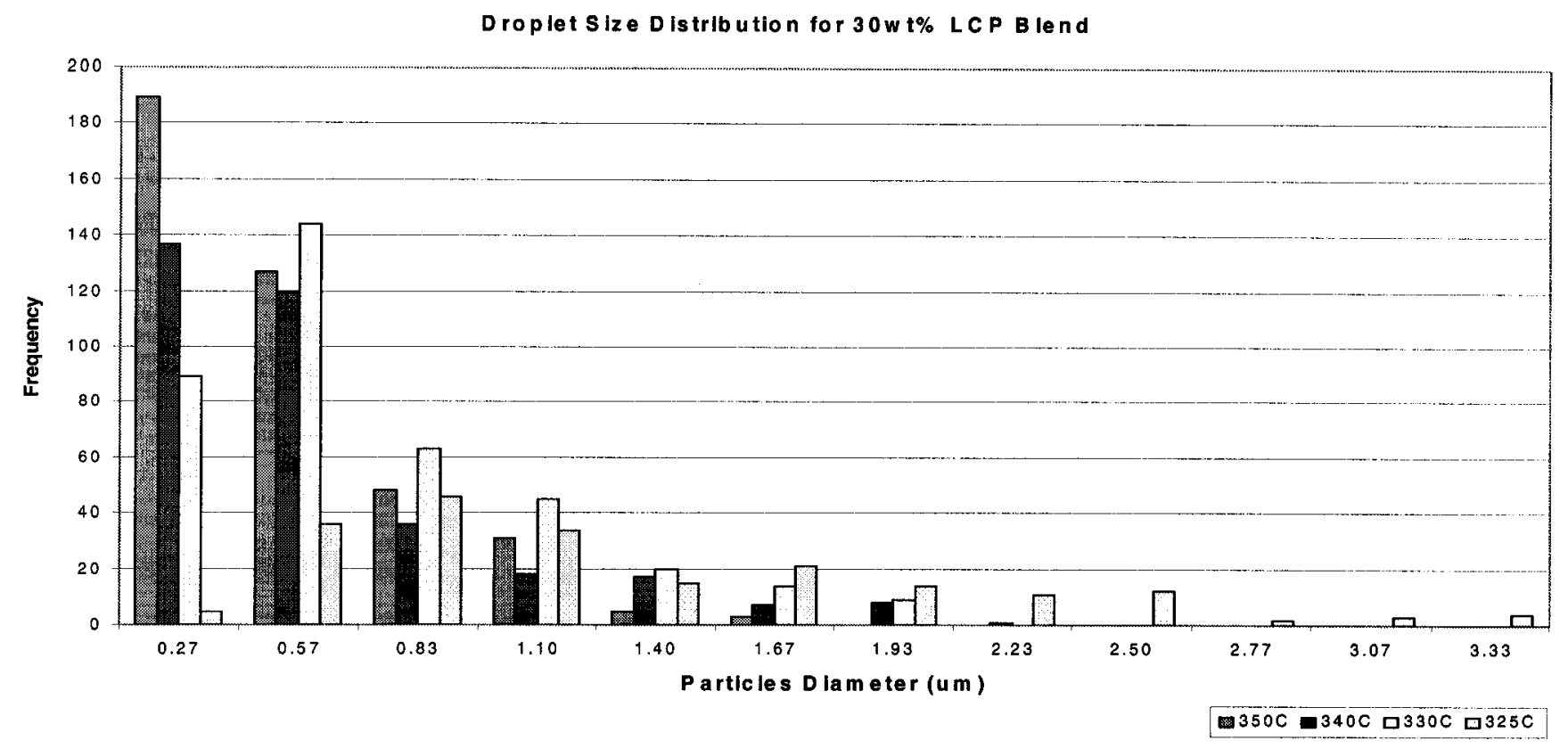

(A)

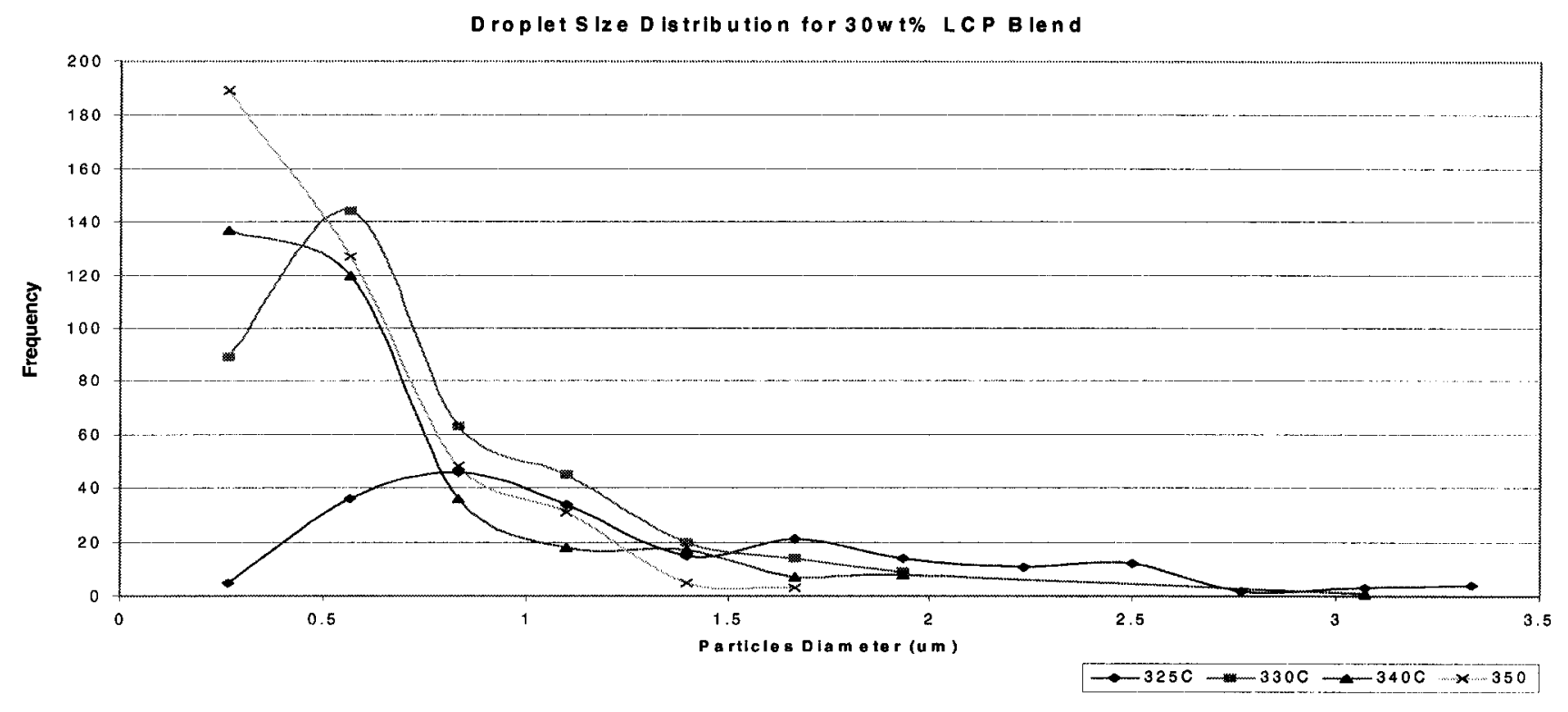

(B)

Figure 4-15: Droplet size distribution for 30wt\% LCP/PC blend (A) bar chart of particle number vs. diameter, (B) Scatter curve of particle number vs. diameter. 
Table 4-6: Summary of Calculated $\langle D\rangle_{n},\langle D\rangle_{w}$ and $P D$ for $30 \%$ LCP Blend

\begin{tabular}{|c|c|c|c|}
\hline Temperature $\left.{ }^{\circ} \mathrm{C}\right)$ & $\langle D\rangle_{n}$ & $\left\langle D>_{w}\right.$ & $P D$ \\
\hline 325 & 1.30 & 1.68 & 1.30 \\
\hline 330 & 0.719 & 0.951 & 1.32 \\
\hline 340 & 0.603 & 0.881 & 1.46 \\
\hline 350 & 0.517 & 0.687 & 1.33 \\
\hline
\end{tabular}




\section{Chapter 5}

\section{Conclusions and Recommendations}

The experimental results indicate that the techniques developed are successful for the purpose of obtaining the phase diagram for LCP/PC blends, which is known to undergo thermally induced phase separation via spinodal decomposition $[18,19]$. The DSC results and the fitting equation developed appear to provide a reliable method for determining the thermodynamic binary phase diagram. Furthermore, the SEM results support and confirm the DSC results and provide reliable phase morphology evidence. Thus, the results suggest that the proposed novel technique, involving twin screw extrusion coupled with DSC and SEM characterization, is suitable to generate blend behavior information about the thermally induced phase separation via spinodal decomposition.

The experimental techniques produced results which appear to be in agreement with those predicted by theory and generally, with experimental results reported by other researchers [16-29]. Some of the more pertinent conclusions that have been derived from these results are as follows:

1. Polycarbonate (PC) and liquid crystalline polymer (LCP) can form either miscible or immiscible blends under different processing conditions in twin screw extrusion.

2. The influence of blending process melt temperature $T_{\mathrm{pm}}$ in twin screw extrusion on the glass transition temperatures $\left(T_{\mathrm{g}} \mathrm{s}\right)$ of the blends was investigated. The blends show variable $T_{\mathrm{g}} \mathrm{s}$, depending on the processing melt temperatures. This 
observation has led to the development of a novel method to determine the thermodynamic phase diagram for the polymer blend system under consideration.

3. The LCP/PC blend is unstable and undergoes thermally induced phase separation via spinodal decomposition with a characteristic lower critical solution temperature (LCST).

4. As evidenced by DSC and SEM measurements, the processing melt temperature $T_{\mathrm{pm}}$ in twin screw extrusion appears to have a significant influence on phase morphology of the blends, while the screw speed (shear rate) does not.

5. At a given LCP concentration, higher processing melt temperature $\left(T_{\mathrm{pm}}\right)$ produce smaller droplet sizes.

Finally, knowledge of the temperature and concentration dependencies $(T-\phi)$ in the phase diagram provides important information which can be used to manipulate the properties of the polymer blend system. Phase morphology of the blend and its corresponding mechanical properties can be manipulated by using this $T$ - $\phi$ phase diagram. It is suggested that a relationship between the morphology and the mechanical properties can be further investigated using different polymer processing methods, such as injection molding. Finally, the behavior of the blend at the lower and higher LCP concentration ranges, below $15 \mathrm{wt} \%$ and above $70 \mathrm{wt} \%$, should be investigated. 


\section{References}

1. L. H. Sperling, Polymeric Multicomponent Materials: An Introduction, John Wiley \& Sons, New York (1997).

2. L. A. Utracki, Polymer Alloys and Blends: Thermodynamics and Rheology, Hanser Publishers, New York (1989).

3. M. J. Folkes and P. S. Hope, (ed.), Polymer Blends and Alloys, Blackie Academic \& Professional, London (1993).

4. W. Brostow, (ed.), Mechanical and Thermophysical Properties of Polymer Liquid Crystals, Chapman and Hall, London (1998).

5. J. F. Masson, Cellulose/Synthetic-polymer Blends, Ph.D. Thesis, McGill University (1990).

6. E. Kiran, NATO ASI Series E Applied Sciences - Advanced Study Institute, 366, 167 (2000).

7. M. A. Van Dijk and A. Wakker, Concepts of Polymer Thermodynamics, Technomic Publishing Co., Lancaster, PA (1997).

8. J. M. G. Cowie, Polymers: Chemistry and Physics of Modern Materials, Chapman and Hall, New York (1991).

9. O. Olabisi, L. M. Robeson and M. T. Shaw, Polymer-Polymer miscibility, Academic Press, New York (1979).

10. J. W. Cahn, J. Chem. Phys., 42, 93 (1965).

11. J. W. Cahn and J. E. Hilliard, J. Chem. Phys., 28, 258 (1958).

12. P.J. Flory, J. Chem. Phys., 10, 51 (1942).

13. M. L. Huggins, Ann. NY Acad. Sci., 43, 1 (1942).

14. P. J. Flory, Principles of Polymer Chemistry, Cornell University, Ithaca (1953).

15. K. Binder, in Materials Science and Technology, edited by R. W. Cahn, P. Haasen and E. J. Kramer, Volume 5, Chapter 7, VCH, New York (1991).

16. M. Kimura and R. S. Porter, J. Polym. Sci., Polym. Phys. Ed., 22, 1697 (1984).

17. P. Zhuang, T. Kyu, and J. L. White, SPE ANTEC Tech. Papers, 34, 1237 (1988).

18. A. Nakai, T. Shiwaku, H. Hasegawa, and T. Hashimoto, Macromolecules, 19, 3008 (1986). 
19. T. Kyu and P. Zhuang, Polym. Commun., 29, 4, 99 (1988).

20. M. J. Seurin, J. M. Gill, A. T. Bosch, and P. Sixou, Polymer, 25, 1073 (1984).

21. K. Friedlich, M. Hess, and R. Kosfield, Makromol. Chem., Macromol. Symp., 16, 251 (1988).

22. R. Kosfield, K. Friedlich, and M. Hess, $18^{\text {th }}$ Euro-physics Conference on Macromolecular Physics, 11c, 81 (1987).

23. M. Hess, K. Friedlich, and R. Kosfield, Int Conf. Liq. Cryst. Polym., Bordeaux, France, Paper 7P8 (July 1987).

24. S. Huang, A. C. Griffin, and R. S. Porter, Polym. Eng. Sci., 29, 55 (1989).

25. T. T. Hsieh, C. Tiu, K. H. Hsieh, and G. P. Simon, J. Appl. Polym. Sci., 77, 2319 (2000).

26. T. M. Malik, P. J. Carreau and N. Chapleau, Polym. Eng. Sci., 29, 600 (1988).

27. D. E. Turek, G. P. Simon, and C. Tiu, Polym. Eng. Sci., 35, 52 (1995).

28. K. Engberg, O. Stromberg, J. Martinsson, and U. W. Gedde, Polym. Eng. Sci., 34, 1336 (1994).

29. H. S. Lee, W. H. Jung and W. N. Kim, Polymer Bulletin, 37, 4, 503 (1996).

30. Instructions Manual berstorff ZE-25, twin screw extruder, Charlotte, N.C. (1991).

31. Instructions Manual BX50, System Microscope, Olympus (1999).

32. J. F. Rabek, Experimental Methods in Polymer Chemistry, John Wiley \& Sons (1980).

33. E. A. Turi, (edi.), Thermal Characterization of Polymeric Materials, Academic Press (1997).

34. D. R. Paul and S. Newman, Polymer Blends, Academic, New York (1978).

35. D. Patterson and A. Robard, Macromolecules, 11, 690 (1978).

36. L. P. McMaster, Macromolecules, 6, 760 (1973). 


\section{Screw Arrangement of Twin Screw Extruder}

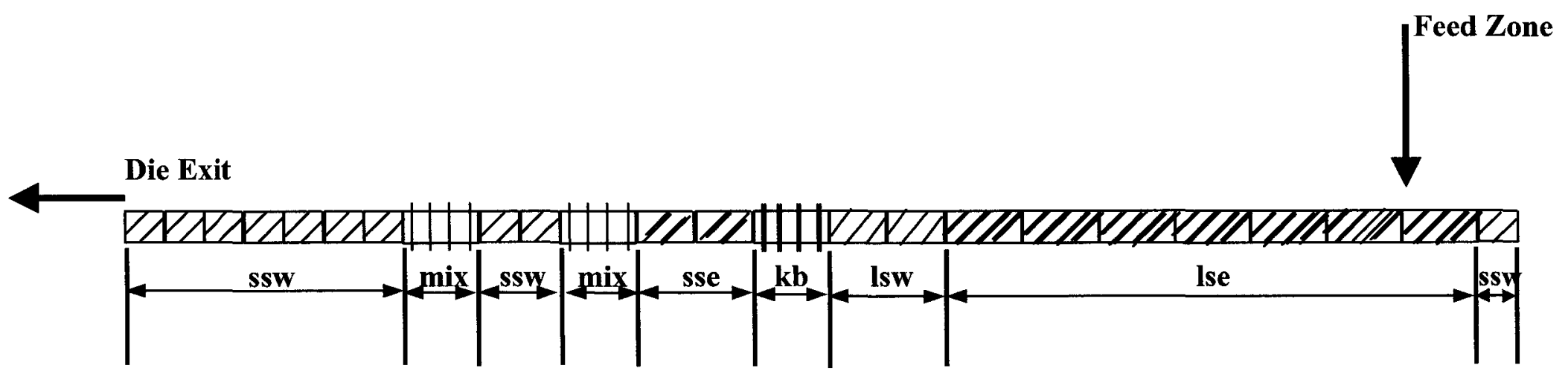

Figure A-1: Schematic design of the screw arrangement for twin screw extrusion. The initial words represent: ssw- short self-wiping, mix- toothed block mixing element, sse- short standard element, kb- $90^{\circ}$ double threaded kneading block, lsw- long self-wiping, and lse- long standard element. ssw, sse, lsw, and lse are double-threaded conveying elements. 